\title{
Genetic Polymorphisms and Molecular Mechanisms Mediating Oncolytic Potency of Reovirus Strains
}

Adil Mohamed ${ }^{1}$, Derek R. Clements ${ }^{2}$, Prathyusha Konda ${ }^{2}$, Shashi A. Gujar ${ }^{2,3}$, Patrick W. Lee ${ }^{2}$, James R. Smiley ${ }^{1}$,

Maya Shmulevitz ${ }^{1^{*}}$

$6 \quad{ }^{1}$ Department of Medical Microbiology and Immunology, Li Ka Shing Institute of Virology, University of Alberta,

7 Edmonton, Alberta, Canada.

$8 \quad{ }^{2}$ Department of Pathology and Department of Microbiology and Immunology, Dalhousie University, Halifax,

9 Nova Scotia, Canada.

$10{ }^{3}$ Centre for Innovative and Collaborative Health Systems Research, IWK Health Centre, Halifax, Nova Scotia, 11 Canada.

12

13 Running Head: Reovirus Strain Specific Oncolysis

14

15 *Correspondence: shmulevi@ualberta.ca

16 


\section{ABSTRACT}

The Dearing strain of Mammalian orthoreovirus (T3D) is undergoing clinical trials as an oncolytic virotherapeutic agent. In this study, a comprehensive phenotypic and genetic comparison of T3D virus stocks

21 from various laboratories and commercial sources revealed that T3D laboratory strains differ substantially in their

22 oncolytic activities in vitro and in vivo. Superior replication of the most-oncolytic T3D lab strain was attributed to

23 several mechanistic advantages: virus-cell binding, viral RNA transcriptase activity, viral inclusion morphology,

24 and differential activation of RIG-I versus NFkB-dependent signalling pathways. Viral S4, M1 and L3 gene

25 segments were each independently associated with a distinct mechanistic advantage. Furthermore, the specific

26 missense polymorphisms that governed replication potency were identified, and utilized to generate a hybrid of

27 T3D laboratory strains with further-augmented replication in tumor cells. Together, the results depict an elaborate

28 balance between reovirus replication and host-cell signaling to achieve optimal oncolytic reovirus efficacy. 


\section{INTRODUCTION}

Cancer is a global health concern and the necessity for novel cancer therapies is well appreciated. Viruses that specifically target tumor cells offer distinct benefits over conventional drug-based therapies. First, their amenability to engineering permits addition of multiple layers of specificity and tumoricidal activities, leading to low toxicity at high doses (Russell and Peng, 2018). Second, since viruses inherently replicate, their doses increase in tumors unlike conventional therapies. Third is that in addition to killing tumor cells directly, viruses induce secretion of cytokines and recruitment of immune cells to tumors, leading to promotion of anti-tumor immunity. These features of viruses that make them good potential therapies for cancer also come with a caveat; the immune system can clear viruses. Therefore, it is essential for an oncolytic virus to be so efficient that it can exert tumoricidal and immune-stimulating effects before clearance.

Three oncolytic viruses currently progressing through human phase III clinical trials include reovirus $\left(\right.$ REOLYSIN $\left.^{\circledR}\right)$, vaccinia virus $\left(\right.$ Pexa-Vec $\left.^{\circledR}\right)$ and herpes simplex virus (T-VEC/IMLYGIC ${ }^{\circledR}$ ) (Amgen Inc, 2018; Oncolytics Biotech Inc, 2018; SillaJen Inc, 2018). T-VEC (Imlygic ${ }^{\mathrm{TM}}$ ) received FDA approval for "use in melanoma with injectable but non-resectable lesions in the skin and lymph nodes" (Pol et al., 2016). HSV and vaccinia are both large DNA viruses, and their tumor specificity was conferred by deleting viral genes, for example genes critical for replication that can be uniquely supplied by tumor cells but not normal cells, and/or genes that normally regulate innate and adaptive immune responses (Potts et al., 2017). In contrast, reovirus is a smaller segmented double-stranded RNA (dsRNA) virus that naturally replicates preferentially in tumor cells (Coffey et al., 1998; Hirasawa et al., 2002; Norman et al., 2002b; Wilcox et al., 2001). In other words, the unmodified reovirus promotes tumor clearance without causing toxicity to healthy tissues. Previous studies demonstrated that replication of reovirus in non-transformed cells is restricted through 4 mechanisms: (1) poor uncoating of outer capsid proteins, (2) production of progeny virions with reduced specific infectivity, (3) reduced cell death and virus release, and (4) high interferon antiviral responses (Marcato et al., 2007; Shmulevitz et al., 2005, 2010a; Shmulevitz et al., 2010b). The existence of multiple barriers in non-transformed cells ensures that reovirus replication is tumor-specific.

Although generally referred to as 'reovirus', the specific reovirus undergoing clinical trials is the serotype 3 Dearing isolate of mammalian orthoreoviruses (T3D, tradename Reolysin $®$ ). In Phase I-III clinical trials, reovirus T3D is well tolerated and demonstrates some indications of efficacy (Carlson et al., 2005; Oncolytics Biotech Inc, 2018; Stoeckel and Hay, 2006). But despite promise, reovirus therapy produces incomplete response in the majority of immunocompetent tumor-bearing animals (Gujar et al., 2014; Rajani et al., 2016; Shmulevitz et al., 2012) and human patients. To enhance the oncolytic activity of reovirus, researchers and pharmaceutical companies are testing combination therapy, for example with chemotherapies or checkpoint blockade inhibitors. To complement these efforts, our laboratory strives to understand the impact of virus features, such as replication proficiency in tumors, on therapeutic efficacy. We predicted that maximum replication of reovirus in tumors would promote both direct killing and immunotherapeutic activities. Moreover, we predicted that features of the 
virus will impact the immune-stimulatory landscape (e.g. cytokines), by interacting with specific cellular signaling pathways. To test these predictions, we explored the relationships between oncolytic activity and virus genetic and phenotypic features, among various highly related laboratory strains of T3D.

In this study, we discovered that highly related laboratory strains of T3D exhibit significant differences in oncolytic potency in vitro and in vivo. These findings reinforce that virus genomic and phenotypic features have a strong impact on oncolytic proficiencies. Since the T3D strains were highly genetically related, they provided an opportunity to discover novel determinants of reovirus oncolysis. A comprehensive genetic and phenotypic comparison of T3D laboratory strains revealed that the most-oncolytic strain (obtained from the Patrick Lee laboratory, $\mathrm{T}^{\mathrm{PL}} \mathrm{P}^{\mathrm{L}}$ ) has 3 distinct and additive advantages over the less-oncolytic strains (obtained from the Terence Dermody and Kevin Coombs laboratories, $\mathrm{T}^{3} \mathrm{D}^{\mathrm{TD}}$ and $\mathrm{T}^{\mathrm{D}} \mathrm{\textrm {K }}^{\mathrm{KC}}$, respectively). Relative to $\mathrm{T} 3 \mathrm{D}^{\mathrm{TD}}$ and $\mathrm{T} \mathrm{D}^{\mathrm{KC}}, \mathrm{T} 3 \mathrm{D}^{\mathrm{PL}}$ exhibited superior replication in transformed cells in a single round of infection, and induced less IFN signaling which facilitated enhanced cell-cell spread. The genes that contribute to enhanced replication and spread of $\mathrm{T} 3 \mathrm{D}^{\mathrm{PL}}$ were then characterized, and found to be (1) the $\mathrm{T} 3 \mathrm{D}^{\mathrm{PL}} \mathrm{S} 1$-encoded $\sigma 1$, which increased the proportion of virions that harbour sufficient number of $\sigma 1$ trimers for binding to cells, (2) T3D ${ }^{\mathrm{PL}} \mathrm{S} 4$-encoded $\sigma 3$, which increased expression of NF- $\mathrm{BB}$ stimulated genes, (3) the M1-encoded $\mu 2$, which increased virus transcription and filamentous factories, and (4) the L3-encoded $\lambda 1$, which increased virus factory size. When evaluating which specific polymorphisms in S4, M1, and L3 contribute to oncolysis, surprisingly specific amino acid differences between $\mathrm{T} 3 \mathrm{D}^{\mathrm{PL}}$ versus $\mathrm{T} 3 \mathrm{D}^{\mathrm{TD}}$ had both positive and negative contributions, and ultimately a hybrid between $\mathrm{T}_{3} \mathrm{D}^{\mathrm{PL}}$ and $\mathrm{T} 3 \mathrm{D}^{\mathrm{TD}}$ exhibited superior oncolytic activity even relative to $\mathrm{T} 3 \mathrm{D}^{\mathrm{PL}}$. This finding suggests that the T3D oncolytic vector may benefit from continued genetic development to fully thrive in tumors. Finally, important to the current excitement surrounding the immunotherapeutic value of oncolytic viruses, was our discovery that T3D laboratory strains induced expression of different cytokines by infected tumor cells.

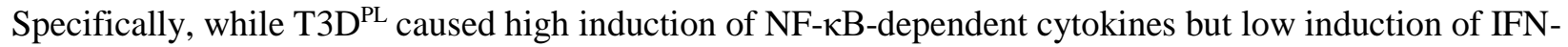
dependent cytokines, the reciprocal was true for T3D ${ }^{\mathrm{TD}}$. Altogether the study reveals novel strategies of improving specific steps of virus replication, as well as cytokine response, to augment oncolytic potency.

\section{RESULTS}

\section{Laboratory strains of reovirus exhibit distinct oncolytic activity in vitro and in vivo.}

As described above, REOLYSIN ${ }^{\circledR}$ is a promising oncolytic agent that is undergoing numerous clinical trials. REOLYSIN ${ }^{\circledR}$ was derived from a stock of T3D obtained from the laboratory of Patrick Lee (T3D ${ }^{\mathrm{PL}}$ ). T3D strains from different laboratories were previously shown to differ in several properties including factory morphology and in vivo respiratory pathogenesis, but $\mathrm{T}^{2} \mathrm{D}^{\mathrm{PL}}$ (or Reolysin ${ }^{\circledR}$ ) were not included in these studies, nor was replication efficiency in transformed cells suggested to be different (Nygaard et al., 2013; Parker et al., 2002; Yin et al., 2004). The use of distinct laboratory origins by laboratories across the world for studies on reovirus 
oncolysis made it imperative to determine if all strains of T3D share similar oncolytic properties. Accordingly, we compared the in vitro and in vivo oncolytic properties of $\mathrm{T} 3 \mathrm{D}^{\mathrm{PL}}$ to those of $\mathrm{T} 3 \mathrm{D}$ obtained from Kevin Coombs $\left(\mathrm{T}_{3} \mathrm{D}^{\mathrm{KC}}\right)$, Terence Dermody $\left(\mathrm{T} 3 \mathrm{D}^{\mathrm{TD}}\right)$, and the American Type Culture Collection $\left(\mathrm{T}_{3} \mathrm{D}^{\mathrm{ATCC}}\right)$.

In vitro oncolysis by a virus is defined by its ability to infect, disseminate, and ultimately cause 'destruction or dissolution' (oncolysis) of tumorigenic cells. As an initial strategy to explore in vitro oncolysis, we compared the plaque size of the various T3D laboratory strains on L929 tumorigenic mouse fibroblasts. Plaque size provides a measure of overall efficiency of virus replication and cell-to-cell spread over several rounds of infection. CsClpurified virus preparations were subjected to plaque titration and visualized by crystal violet staining (Figure 1A). Plaque size was quantified by densitometry and reported as units of pixels. When compared at 7 days postinfection (dpi), T3D ${ }^{\mathrm{PL}}$ had the largest average plaque size of 1644 pixels. $\mathrm{T}^{\mathrm{K}} \mathrm{KC}^{\mathrm{KC}}$ and $\mathrm{T} 3 \mathrm{D}^{\mathrm{TD}}$ had the smallest average plaque sizes of 42 pixels and 32 pixels, respectively. T3D ${ }^{\text {ATCC }}$ had an intermediate average plaque size of 225 pixels. To our knowledge, this is the first report of differential virus replication and in vitro oncolysis among T3D laboratory strains.

T3D ${ }^{\mathrm{PL}}$ can be traced back to the Joklik, W.K. laboratory (Duke University). Both T3D ${ }^{\mathrm{KC}}$ and T3D ${ }^{\mathrm{TD}}$ laboratory strains originated from the Fields, B.N. laboratory (Harvard Medical School), which was initially obtained from the Joklik laboratory but was proposed to have diverged from other T3D strains by the mid-1970s (Cross and Fields, 1972; Fields, 1971). The depositor of T3D ${ }^{\text {ATCC }}$, W. Adrian Chappell, was affiliated with the Centre for Disease Control (Atlanta), but could not be linked to any reovirus laboratories or publications. Due to the uncertain origin of $\mathrm{T}^{3} \mathrm{D}^{\mathrm{ATCC}}$, we omitted this strain from our subsequent experiments. However, laboratories using T3D ${ }^{\text {ATCC }}$ should note that replication kinetics are distinct from those of other T3D laboratory strains.

To determine if differential in vitro oncolysis by T3D strains extend to other cancer cells, we compared plaque sizes on a panel of mouse (ID8 ovarian cancer and B16-F10 melanoma) and human (Huh7.5 hepatocellular carcinoma and H1299 non-small cell lung carcinoma) tumorigenic cell lines (Figure 1B and 1C).

Immunocytochemical staining with polyclonal anti-reovirus antibodies was used to monitor reovirus-infected plaques, as not all cells produce monolayers sufficiently dense for crystal violet staining. In all cell lines assessed, $\mathrm{T} 3 \mathrm{D}^{\mathrm{PL}}$ formed visibly larger plaques compared to $\mathrm{T} 3 \mathrm{D}^{\mathrm{KC}}$ and $\mathrm{T} 3 \mathrm{D}^{\mathrm{TD}}$. Additionally, clearing of cells in the center of reovirus-infected plaques, indicative of cell death, was more apparent for $\mathrm{T}^{\mathrm{D}} \mathrm{D}^{\mathrm{PL}}$ relative to $\mathrm{T} 3 \mathrm{D}^{\mathrm{KC}}$ and $\mathrm{T} 3 \mathrm{D}^{\mathrm{TD}}$. Therefore, relative to $\mathrm{T} 3 \mathrm{D}^{\mathrm{KC}}$ and $\mathrm{T} 3 \mathrm{D}^{\mathrm{TD}}$, $\mathrm{T} 3 \mathrm{D}^{\mathrm{PL}}$ displayed greater in vitro oncolytic potency on an assortment of cancer cells.

Few studies have directly assessed whether in vitro oncolysis by viruses correlates with in vivo oncolytic activity, and hence it was critical to determine whether differences in in vitro replication potency corresponded with differential oncolytic efficacies in-vivo. $\mathrm{T}^{\mathrm{PL}} \mathrm{D}^{\mathrm{PL}}$ was previously characterized to reduce tumor burden in the aggressive B16-F10 syngeneic melanoma mouse model (Shmulevitz et al., 2012) and therefore this model was chosen to compare the in-vivo oncolytic efficacy of $\mathrm{T}^{3} \mathrm{D}^{\mathrm{PL}}$ versus $\mathrm{T} 3 \mathrm{D}^{\mathrm{TD}}$. B16-F10 cells were implanted 
subcutaneously into the hind flank of six-week old female C57BL/6 mice (Figure 1D). When tumors were palpable, equivalent doses $\left(5 \times 10^{8} \mathrm{pfu} / \mathrm{dose}\right)$ of $\mathrm{T} 3 \mathrm{D}^{\mathrm{PL}}$ and $\mathrm{T} 3 \mathrm{D}^{\mathrm{TD}}$ were injected intra-tumorally at 2-day intervals, for a total of 3 doses. PBS was injected as a negative control. Tumor volumes were monitored every 2 days postinoculation. Compared to the PBS control group, both $\mathrm{T}^{\mathrm{P}} \mathrm{D}^{\mathrm{PL}}$ and $\mathrm{T} 3 \mathrm{D}^{\mathrm{TD}}$ caused delayed tumor growth (Figure 1E). However, $\mathrm{T} 3 \mathrm{D}^{\mathrm{TD}}$ only marginally controlled tumor growth while $\mathrm{T} 3 \mathrm{D}^{\mathrm{PL}}$ controlled tumor growth in all mice. Specifically, at 13 days post inoculation when all mice were alive, $\mathrm{T}^{2} \mathrm{D}^{\mathrm{PL}}$-treated animals had significantly smaller tumors $(\mathrm{P}=0.0024, \mathrm{n}=5)$ than $\mathrm{T}_{3} \mathrm{D}^{\mathrm{TD}}$-treated mice (Figure $\left.1 \mathrm{~F}\right)$. Animal survival could not be compared because, as per the strict animal ethics protocol, mice had to be sacrificed when tumors became too large $\left(\sim 600 \mathrm{~mm}^{3}\right)$, or showed signs of necrosis or ulceration. While $3 / 5 \mathrm{~T} 3 \mathrm{D}^{\mathrm{TD}}$-treated mice were sacrificed due to large tumor volumes, two T3D $\mathrm{D}^{\mathrm{PL}}$-treated mice were sacrificed due to tumor scabbing despite small tumor volume and likely a positive indication of oncolytic activity. Thus, survival curves were uninformative with respect to reovirus mediated tumor regression. Importantly, no signs of virus pathogenesis in normal tissues were observed; specifically, reovirus can cause black tail and ears, cardiotoxicity and neurotoxicity in immunodeficient mice due to replication at sites other than tumors (Kim et al., 2011; Loken et al., 2004), but no such symptoms were observed in our immunocompetent mice. These results demonstrate that for reovirus, robust virus infection in vitro correlates with efficient in vivo oncolysis. These findings are important because a recent focus on the immunostimulatory aspect of oncolytic viruses has put into question the importance of virus replication proficiency in tumors as a determinant of oncolytic potency; our results demonstrating a strong relationship between virus replication in vitro and oncolysis in vivo for reovirus.

\section{Genetic variations between the differentially-oncolytic T3D laboratory strains.}

The differences in oncolytic potency among T3D lab strains warranted a close analysis of genetic divergence between T3D stocks passaged in independent laboratories. First, resolution of reovirus genomic dsRNA segments using SDS-PAGE was used to determine if gross changes could be observed among the 10 reovirus genome segments. Reovirus serotypes 1, 2, and 3 produce unique electrophenotype (Coombs, 2011; Shatkin et al., 1968), but even independent isolates of reovirus from the same serotype commonly show mobility differences (Hrdy et al., 1979). T3D ${ }^{\mathrm{PL}}, \mathrm{T}^{\mathrm{K}} \mathrm{D}^{\mathrm{KC}}$ and $\mathrm{T} 3 \mathrm{D}^{\mathrm{TD}}$ electrophenotypes were indistinguishable, although very distinct from serotype 1 Lang (T1L) and serotype 2 Jones (T2J) prototypes (Figure 1G), suggesting close ancestry.

Extensive genetic and phenotypic characterization of reovirus has been performed by comparing prototypic reovirus serotypes, commonly T1L versus T3D, but an in-depth analysis of whole genome sequences of T3D laboratory strains has yet to be performed. We collected and assembled complete reovirus nucleotide and amino acid sequences available on the NCBI database. T3D ${ }^{\text {BioProject }}$ represents the earliest published complete T3D sequences, which were obtained as a collaborative initiative as per NCBI BioProject PRJNA14861. As 
mentioned, REOLYSIN® is the proprietary reovirus strain under clinical investigation for cancer therapy, with

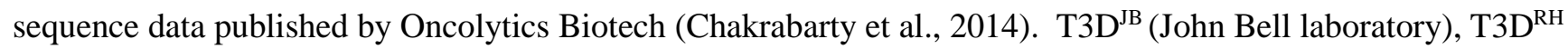
(Rob Hoeben laboratory), serotype 3 Abney (T3A), T1L, and T2J sequences from NCBI database were also included. The complete sequences for $\mathrm{T} 3 \mathrm{D}^{\mathrm{TD}}$ were obtained from Terence Dermody but also confirmed in-house to ensure absence of divergence in our hands. Finally, our laboratory strain T3D $\mathrm{D}^{\mathrm{MS}}$ obtained from $\mathrm{T} 3 \mathrm{D}^{\mathrm{PL}}$ over 15 years ago, $\mathrm{T} 3 \mathrm{D}^{\mathrm{TD}}, \mathrm{T} 3 \mathrm{D}^{\mathrm{PL}}$ and $\mathrm{T} 3 \mathrm{D}^{\mathrm{KC}}$ were also sequenced in-house.

For an overall reovirus lineage assessment, we used concatenated sequences of 11 reovirus proteins $(\sigma 1$, $\sigma 1 \mathrm{~s}, \sigma 2, \sigma \mathrm{NS}, \sigma 3, \mu 2, \mu 1, \mu \mathrm{NS}, \lambda 3, \lambda 2, \lambda 1)$ from each reovirus strain to generate a phylogenetic tree using the Jukes-Cantor model and Neighbour-Joining method (Geneious $\left.{ }^{\circledR}\right)$. All T3D strains branched together independent of the other reovirus serotypes T1L, T2J and T3A (Figure 1H, top). T3D ${ }^{\mathrm{PL}}$ and REOLYSIN® had 6 nucleotide differences but identical amino acid sequences, confirming homogeneity of the laboratory strain originating from Patrick Lee. T3D ${ }^{\mathrm{PL}}$ and REOLYSIN $®$ branched separately from T3D ${ }^{\mathrm{TD}}$ and $\mathrm{T}^{\mathrm{D}} \mathrm{D}^{\mathrm{KC}}$ (Figure $1 \mathrm{H}$, bottom). Other laboratory strain sequences such as $\mathrm{T}_{3} \mathrm{D}^{\mathrm{JB}}$, $\mathrm{T} 3 \mathrm{D}^{\mathrm{RH}}$, and $\mathrm{T} 3 \mathrm{D}^{\mathrm{SB}}$ clustered more-closely to $\mathrm{T} 3 \mathrm{D}^{\mathrm{TD}}$ and $\mathrm{T} 3 \mathrm{D}^{\mathrm{KC}}$ than to $\mathrm{T} 3 \mathrm{D}^{\mathrm{PL}}$.

To define the specific differences among T3D laboratory strains, we aligned the individual protein sequences (Figure 1I). T3D ${ }^{\mathrm{PL}}$ and REOLYSIN® were the most similar strains to T3D ${ }^{\text {BioProject }}$ in $\sigma 1, \sigma 1 \mathrm{~s}, \mu 2, \mu \mathrm{NS}$ and $\lambda 2$ proteins. $\mathrm{T}^{2} \mathrm{D}^{\mathrm{TD}}$ and $\mathrm{T} 3 \mathrm{D}^{\mathrm{KC}}$ were most similar to $\mathrm{T} 3 \mathrm{D}^{\text {BioProject }}$ in $\mu 1, \lambda 1$ and $\lambda 3$ proteins. All T3D strains had identical $\sigma 2$ and $\sigma$ NS proteins. Interestingly, the BioProject collaboration had $\sigma 1, \sigma 1 \mathrm{~s}, \mu 2, \mu \mathrm{NS}$ and $\lambda 2$ sequences obtained from the Wolfgang Joklik-affiliated laboratories, while $\mu 1, \lambda 1$ and $\lambda 3$ protein sequences were obtained from the Bernard Fields-affiliated laboratories. Accordingly, we predict the major distinction between laboratory strains of T3D dates as far back as the conception of the Bioproject. Altogether there were 43 and 45 nucleotide differences between $\mathrm{T}_{3} \mathrm{D}^{\mathrm{PL}}$ versus $\mathrm{T} 3 \mathrm{D}^{\mathrm{TD}}$ or $\mathrm{T} 3 \mathrm{D}^{\mathrm{KC}}$, respectively, of which 21 and 22 resulted in amino acid changes. The amino acid differences were dispersed among 8 of the 10 virus genome segments.

\section{The S4, M1 and L3 genes are determinants of enhanced T3D ${ }^{\mathrm{PL}}$ oncolysis.}

The distinct oncolytic potencies of $\mathrm{T}_{3} \mathrm{D}^{\mathrm{PL}}$ versus $\mathrm{T} 3 \mathrm{D}^{\mathrm{TD}}$ despite only 21 amino acid differences provided a unique opportunity to decipher the genetic and phenotypic basis for robust oncolysis. As the first step, a classical genome segment reassortment analysis was conducted in search of reovirus genes that contribute to the enhanced plaque size of $\mathrm{T}^{\mathrm{PL}} \mathrm{D}^{\mathrm{PL}}$. $\mathrm{L} 929$ cells were co-infected with $\mathrm{T} 3 \mathrm{D}^{\mathrm{PL}}$ and $\mathrm{T} 3 \mathrm{D}^{\mathrm{TD}}$ at a ratio of 1:10 to favor reassortment of $\mathrm{T}^{\mathrm{PL}}$ genes in a primarily $\mathrm{T} 3 \mathrm{D}^{\mathrm{TD}}$ background (Figure $2 \mathrm{~A}$ ). The co-infection lysates were plaque titrated and 20 large plaques were twice plaque purified and sequenced. Of the 20 large plaques, 8 were of composed entirely of $\mathrm{T}^{\mathrm{PL}} \mathrm{PL}^{\mathrm{PL}}$ genes (Figure $2 \mathrm{~B}$ ). The remaining 14 large plaques were reassortants that contain between $2-7 \mathrm{~T}^{\mathrm{PL}}$ genome segments. The $\mathrm{T}_{3} \mathrm{D}^{\mathrm{PL}}$-derived $\mathrm{M} 1$ gene was present in all (12/12) reassortants, and was therefore very 
likely a determinant of the larger plaque size of $\mathrm{T} 3 \mathrm{D}^{\mathrm{PL}}$. Other $\mathrm{T} 3 \mathrm{D}^{\mathrm{PL}}$ genome segments found in $\geq 50 \%$ of the large-plaque reassortants were S4 (9/12) and L3 (6/12).

To further discriminate genes that contribute to the large plaque phenotype of $\mathrm{T}^{\mathrm{P}} \mathrm{D}^{\mathrm{PL}}$, we generated monoreassortants between $\mathrm{T} 3 \mathrm{D}^{\mathrm{PL}}$ and $\mathrm{T} 3 \mathrm{D}^{\mathrm{TD}}$ using reverse genetics $(\mathrm{RG})$ (Figure $2 \mathrm{C}$ ). The 10 reovirus genome segments from $\mathrm{T} 3 \mathrm{D}^{\mathrm{PL}}$ and $\mathrm{T} 3 \mathrm{D}^{\mathrm{TD}}$ were cloned in-house into the $\mathrm{T} 7$ RNA polymerase-driven reverse genetics plasmid backbone. Parental viruses generated using the $\mathrm{RG}$ system $\left(\mathrm{PL}^{\mathrm{RG}}\right.$ and $\mathrm{TD}^{\mathrm{RG}}$ ) produced plaques of similar size to $\mathrm{T} 3 \mathrm{D}^{\mathrm{PL}}$ and $\mathrm{T} 3 \mathrm{D}^{\mathrm{TD}}$, respectively, confirming genetic authenticity of reverse genetics-derived viruses (Figure $2 \mathrm{D}$ and $2 \mathrm{E}$ ). Mono-reassortants in a $\mathrm{TD}^{\mathrm{RG}}$ backbone revealed that $\mathrm{T}^{\mathrm{P}} \mathrm{D}^{\mathrm{PL}}$-derived $\mathrm{M} 1, \mathrm{~S} 4$ and $\mathrm{L} 3$ significantly increased plaque size compared to $\mathrm{TD}^{\mathrm{RG}}$ (Figure 2D). Importantly, none of the PL genes individually restored plaque size to the parental $\mathrm{PL}^{\mathrm{RG}}$. In the reciprocal assessment, where $\mathrm{T}_{3} \mathrm{D}^{\mathrm{TD}}$-derived genes were mono-reassorted into a PL ${ }^{\mathrm{RG}}$ background, M1, S4 and L3 also individually reduced plaque size relative to parental PL ${ }^{\mathrm{RG}}$ (Figure 2E). Given that these three genes were incapable of fully restoring the large plaque size of PL-derived T3D strain, we tested the genes in combinations of 2 or 3 . The M1 gene had the greatest impact on plaque size, any combination of M1, S4, and L3 provided additive enhancement of plaque size relative to independent genes. Ultimately, the combination of all three genes could restore the parental phenotype. Our genetic evaluation therefore implicated S4, M1 and L3 genes as having a pronounced impact on replication of T3D ${ }^{\mathrm{PL}}$ versus $\mathrm{T}^{\mathrm{T}} \mathrm{D}^{\mathrm{TD}}$.

Reovirus particles are composed of two concentric proteinaceous capsid layers (Figure 3A). The inner capsid (core) consists of proteins $\sigma 2, \lambda 1$, and $\lambda 2$, while the outer capsid, which is removed during entry, consists of $\mu 1 \mathrm{C}$, $\sigma 3$, and $\sigma 1$. The S4, M1, and L3 genome segments encode viral proteins $\sigma 3, \mu 2$, and $\lambda 1$ proteins, respectively. More comprehensive descriptions of these genes will follow during discovery of their specific contribution to oncolytic differences among T3D lab strains. As a general description, $\sigma 3$ fulfills several known functions; it is the outermost capsid protein, contributes to stability of reovirus particles (Wetzel et al., 1997; Wilson et al., 2002), and must be removed by proteolysis during reovirus entry to reveal the transcriptionally-active core particles that establish infection (Acs et al., 1971; Chang and Zweerink, 1971; Skehel and Joklik, 1969). In addition, $\sigma 3$ binds and sequesters dsRNA from cellular sensors of pathogen associated molecular patters (PAMPS) (Huismans and Joklik, 1976; Imani and Jacobs, 1988; Lloyd and Shatkin, 1992). Reovirus $\mu 2$ serves at least two functions known functions; within the virion core, it provides NTPase activity and serves as a co-factor for the viral RNA-dependent RNA polymerase $\lambda 3$ (Kim et al., 2004; Noble and Nibert, 1997b). In addition, $\mu 2$ bridges viral proteins to tubulin to promote formation of localized sites of virus replication called factories. Specifically $\mu 2$ links tubulin to the viral non-structural protein $\mu \mathrm{NS}$, which then associates with viral structural proteins and the ssRNA-binding $\sigma$ NS (Broering et al., 2004; Broering et al., 2002; Parker et al., 2002). The primary role of $\lambda 1$ is to form the inner core of reovirus particles, though additional functions have been suggested (Bisaillon et al., 1997; Lemay and Danis, 1994; Noble and Nibert, 1997a). The multi-functionality of viral proteins makes it challenging to infer precise mechanisms for amino acid variations, and therefore an in-depth 
comparison of $\mathrm{T} 3 \mathrm{D}^{\mathrm{PL}}, \mathrm{T} 3 \mathrm{D}^{\mathrm{KC}}$, and $\mathrm{T} 3 \mathrm{D}^{\mathrm{TD}}$ in terms of virus particle composition and efficiency of completing the various steps of the viral replication cycle was necessary.

\section{Enhanced attachment of $\mathrm{T}_{3} \mathrm{D}^{\mathrm{PL}}$ virions to cells due to increased numbers of $\sigma 1$ trimers.}

Previous studies demonstrated that modifications to outer capsid proteins such as $\sigma 1, \sigma 3$ and $\mu 1 \mathrm{C}$ can impact reovirus infectivity (Mohamed et al., 2015; Shmulevitz et al., 2012). For example, levels of the $\sigma 1$ cell attachment proteins were previously found to affect cell binding (Larson et al., 1994; Mohamed et al., 2015), while mutations in $\sigma 3$ and $\mu 1$ could affect the efficiency of virus uncoating (Danthi et al., 2008; Doyle et al., 2012). To determine if T3D laboratory strains exhibit distinct protein compositions, $\mathrm{CsCl}$ gradient-purified $\mathrm{T} 3 \mathrm{D}^{\mathrm{PL}}, \mathrm{T}^{\mathrm{T}} \mathrm{D}^{\mathrm{KC}}$ and $\mathrm{T} 3 \mathrm{D}^{\mathrm{TD}}$ virus particles were subjected to denaturing gel electrophoresis and proteins visualized by Imperial ${ }^{\mathrm{TM}}$ total protein staining (Figure 3B top) and Western blot analysis using reovirus protein specific antibodies (Figure 3B bottom). The ratio of capsid proteins $\lambda 1 / 2, \mu 1 \mathrm{C}, \sigma 2$ and $\sigma 3$ were similar between $\mathrm{T} 3 \mathrm{D}^{\mathrm{PL}}, \mathrm{T} 3 \mathrm{D}^{\mathrm{KC}}$ and $\mathrm{T} 3 \mathrm{D}^{\mathrm{TD}}$. However, for equivalent capsid protein $(\sigma 3), \mathrm{T}_{3} \mathrm{D}^{\mathrm{KC}}$ and $\mathrm{T} 3 \mathrm{D}^{\mathrm{TD}}$ had lower average levels of $\sigma 1$ compared to $\mathrm{T}^{\mathrm{P}} \mathrm{D}^{\mathrm{PL}}$ (Figure $3 \mathrm{~B}$ bottom, 3C left).

The $\sigma 1$ protein is a trimer that extends from channels generated by pentameric $\lambda 2$ proteins at vertices of reovirus particles, and functions as the cell-attachment protein. Not all reovirus virion vertices need to be occupied by $\sigma 1$; in fact, reovirus particles can have 0-to- $12 \sigma 1$ trimers depending on the sequence of $\sigma 1$ or $\lambda 2$ (Mohamed et al., 2015; Shmulevitz et al., 2012). We and others previously observed that 3 or more $\sigma 1$ trimersper-virion are necessary and sufficient for virion binding to cells (Larson et al., 1994; Mohamed et al., 2015). Given the importance of having $\geq 3 \sigma 1$ trimers for attachment, we characterized the number of $\sigma 1$ trimers-pervirion for each T3D reovirus laboratory strain. Since Western blot analysis provides only an average level of virion $\sigma 1$, agarose gel separation of full virions was applied as a method to distinguish virions based on $\sigma 1$-pervirion levels (Figure $3 \mathrm{C}$ right). More than $80 \%$ of $\mathrm{T}^{\mathrm{P}} \mathrm{D}^{\mathrm{PL}}$ particles possessed a range of $7-12 \sigma 1$ trimers-per-virion. Contrastingly, only $28 \%$ and $6 \%$ of $\mathrm{T}_{3} \mathrm{D}^{\mathrm{KC}}$ and $\mathrm{T} 3 \mathrm{D}^{\mathrm{TD}}$ particles, respectively, had 7-12 $\sigma 1$ trimers-per-virion. Close to $50 \%$ of $\mathrm{T}_{3} \mathrm{D}^{\mathrm{KC}}$ and $\mathrm{T} 3 \mathrm{D}^{\mathrm{TD}}$ virions had a range of 3-6 $\sigma 1$ trimers/virion. $\mathrm{T}^{\mathrm{D}} \mathrm{D}^{\mathrm{KC}}$ and $\mathrm{T} 3 \mathrm{D}^{\mathrm{TD}}$ had $24 \%$ and $48 \%$ of virions with $0-2 \sigma 1$-per-virion, respectively. Most-importantly, $24 \%$ and $48 \%$ of $\mathrm{T}^{3} \mathrm{D}^{\mathrm{KC}}$ and $\mathrm{T} 3 \mathrm{D}^{\mathrm{TD}}$ particles (respectively), but only $2 \%$ of $\mathrm{T}^{3} \mathrm{D}^{\mathrm{PL}}$ particles, had fewer than $3 \sigma 1$ trimers-per-virion.

Since a greater proportion of $\mathrm{T}_{3} \mathrm{D}^{\mathrm{PL}}$ particles had more than $3 \sigma 1$ trimers-per-virion, we predicted that a greater proportion of $\mathrm{T}_{3} \mathrm{D}^{\mathrm{PL}}$ particles would successfully attach to cells. To compare cell attachment efficiency among the three laboratory strains, L929 cells were exposed to equivalent particle numbers of each laboratory strain at $4^{\circ} \mathrm{C}$ for 1 hour to permit virus binding without entry, then washed extensively. Flow cytometric analysis was used to measure bound virions per cell, reflected by the mean-fluorescence intensity (Figure 3D). Flow cytometry provides a highly linear assessment of reovirus binding over a wide range (81- fold) of virus dilutions 
(Supplementary Figure 1). T3D $\mathrm{D}^{\mathrm{KC}}$ and $\mathrm{T} 3 \mathrm{D}^{\mathrm{TD}}$ bound cells at $60 \%$ and $40 \%$ efficiency of $\mathrm{T}^{\mathrm{D}} \mathrm{D}^{\mathrm{PL}}$, respectively, which correlated closely to the percentage of particles with fewer than $3 \sigma 1$ trimers-per-virion. Together our analysis indicates that oncolytic potency of the most-oncolytic laboratory strain $\mathrm{T}_{3} \mathrm{D}^{\mathrm{PL}}$ correlates with enhanced attachment to tumor cells and higher proportion of virus particles with $\geq 3 \sigma 1$ trimers-per-virion. Accordingly, assessment of $\sigma 1$ levels-per-virion could be used as one of the measures of good binding and oncolysis.

The $\sigma 1$ proteins of $\mathrm{T} 3 \mathrm{D}^{\mathrm{TD}}$ and $\mathrm{T} 3 \mathrm{D}^{\mathrm{KC}}$ differ from $\mathrm{T} 3 \mathrm{D}^{\mathrm{PL}}$ at 2 positions (Figure $\left.1 \mathrm{I}\right)$. We consider it likely that the alanine-to-valine change at position 22 is responsible for decreased levels of $\sigma 1$ on $\mathrm{T}^{2} \mathrm{D}^{\mathrm{TD}}$ and $\mathrm{T} 3 \mathrm{D}^{\mathrm{KC}}$ virions, as we and others previously found that mutations in the $\sigma 1$ anchor domain (amino acids 1-27) affect incorporation of $\sigma 1$ trimers into the $\lambda 2$ vertex (Bokiej et al., 2012; Mohamed et al., 2015; Nygaard et al., 2013). The sequence difference at residue 408 is located in the $\sigma 1$ head domain (amino acids 311-455), which interacts with cell surface JAM-A (Barton et al., 2001; Campbell et al., 2005). This difference could contribute to the differential virion cell binding levels; though we think this unlikely because the change is not located at the JAMA binding interface and because binding deficiency of $\mathrm{T} 3 \mathrm{D}^{\mathrm{KC}}$ and $\mathrm{T} 3 \mathrm{D}^{\mathrm{TD}}$ very closely correlated with having virions with less than $3 \sigma 1$ trimers (Figure 3C versus 3D).

Importantly, the $\mathrm{S} 1$ genome segment that encodes $\sigma 1$ did not strongly segregate with the large plaque phenotype in our reassortant studies (Figure 2B, 2D, 2E), likely because differences in cell binding are only $~ 2-$ fold, and therefore less impactful than contributions by M1, S4, and L3. The remainder of our studies therefore focused on understanding the mechanisms by which the M1, S4, and L3 genome segments contribute dominantly towards oncolytic activity of $\mathrm{T} 3 \mathrm{D}^{\mathrm{PL}}$.

\section{$\mathrm{T}^{\mathrm{PL}} \mathrm{PL}^{\mathrm{PL}}$ replicates more rapidly and to higher burst size in a single round of infection.}

The larger plaques produced by $\mathrm{T} 3 \mathrm{D}^{\mathrm{PL}}$ could stem from more rapid rates of virus replication, increased burst size, enhanced cell lysis and virus release, or increased cell-to-cell spread. To determine if $\mathrm{T}^{\mathrm{PL}}{ }^{\mathrm{PL}}$ replicates more rapidly and/or to higher burst size than $\mathrm{T} 3 \mathrm{D}^{\mathrm{TD}}$ in a single round of infection, single-step virus growth analyses were performed at a multiplicity of infection (MOI) of 3 (Figure 3E top). L929 cells were exposed to $\mathrm{T}_{3} \mathrm{D}^{\mathrm{PL}}$ and $\mathrm{T} 3 \mathrm{D}^{\mathrm{TD}}$ at $4{ }^{\circ} \mathrm{C}$ for 1 hour to synchronize infection, then incubated at $37^{\circ} \mathrm{C}$ for various time-points. Reovirus titres at 1 hour post infection (hpi) were similar between $\mathrm{T}_{3} \mathrm{D}^{\mathrm{PL}}$ and $\mathrm{T} 3 \mathrm{D}^{\mathrm{TD}}$, indicating equal input virion titers. Following entry, reovirions uncoat to cores and become non-infectious, leading to a drop in titers at 3 and 6hpi for both $\mathrm{T}_{3} \mathrm{D}^{\mathrm{PL}}$ and $\mathrm{T} 3 \mathrm{D}^{\mathrm{TD}}$. Between 8-12hpi, 1000 -fold new infectious progeny were produced per input of $\mathrm{T} 3 \mathrm{D}^{\mathrm{PL}}$. In contrast, titers increased by only $\sim 50$-fold for $\mathrm{T}^{\mathrm{T}} \mathrm{D}^{\mathrm{TD}}$. $\mathrm{T} 3 \mathrm{D}^{\mathrm{PL}}$ reached maximum saturation titers at 18hpi, while T3D ${ }^{\mathrm{TD}}$ titers saturated at $24 \mathrm{hpi}$. Furthermore, saturation titers for $\mathrm{T}^{\mathrm{D}} \mathrm{PL}^{\mathrm{PL}}$ were $\sim 9$-fold higher than $\mathrm{T} 3 \mathrm{D}^{\mathrm{TD}}$. The one-step growth curves therefore indicated that new progeny production for $\mathrm{T} 3 \mathrm{D}^{\mathrm{PL}}$ occurs faster, and produces higher virus burst size, relative to $\mathrm{T} 3 \mathrm{D}^{\mathrm{TD}}$. Importantly, these findings suggest that oncolytic potential 
correlates with proficiency of virus replication in a single round of replication. When multi-step virus growth curves were performed at an MOI of 0.01, the cumulative advantage of improved replication over several rounds of infection was striking; T3D ${ }^{\mathrm{PL}}$ accumulated $\sim 4000$-fold higher virus titers relative to T3D ${ }^{\mathrm{TD}}$ by $48 \mathrm{hpi}$ (Figure $3 \mathrm{E}$ bottom).

Increased virus replication could result from higher efficiency of virus entry, or post-entry steps of virus replication and assembly. Following attachment to cells, reovirus undergoes endocytosis and trafficking to endolysosomes where cathepsins L and B mediate virus uncoating (Ebert et al., 2002; Johnson et al., 2009). Here, the outermost $\sigma 3$ protein is degraded and $\mu 1 \mathrm{C}$ is cleaved to the membrane-destabilizing products $\delta, \mu 1 \mathrm{~N}$ and $\varphi$ (Odegard et al., 2004; Zhang et al., 2006). The resulting intermediate subviral particles (ISVPs) are capable of penetrating membranes and delivering reovirus core particles to the cytoplasm. Given that efficient reovirus uncoating is a crucial step for successful infection, we compared uncoating among T3D laboratory strains. Note that in all subsequent studies, to overcome differences in cell binding, virus doses were adjusted to give equivalent cell-bound virus particles. To monitor uncoating, cleavage of $\sigma 3$ and $\mu 1 \mathrm{C}$ was followed by Western blot analysis at various times post-infection (Figure 3F). Complete cleavage of $\sigma 3$ was observed by 3 hpi and coincided with initiation of $\mu 1 \mathrm{C}$ to $\delta$ cleavage. The rate of $\mu 1 \mathrm{C}$ cleavage to $\delta$ was quantified as a percentage of $\delta$ to $\delta+\mu 1 \mathrm{C}$, and standardized to $\beta$ actin housekeeping protein. All T3D strains displayed similar uncoating rates and almost complete uncoating was attained by 5 hpi. Unlike $\mathrm{T}^{\mathrm{K}} \mathrm{D}^{\mathrm{KC}}$ and $\mathrm{T}^{2} \mathrm{D}^{\mathrm{TD}}$, de-novo synthesized $\mu 1$ (precursor to $\mu 1 \mathrm{C}$ ) and $\sigma 3$ was observed at $5 \mathrm{hpi}$ in $\mathrm{T}^{\mathrm{D}} \mathrm{D}^{\mathrm{PL}}$, suggesting that a post-uncoating step was enhanced during $\mathrm{T} 3 \mathrm{D}^{\mathrm{PL}}$ infection.

Following uncoating of the outer capsid, reovirus cores that enter the cytoplasm become transcriptionally active. Positive-sense mRNAs are transcribed within reovirus cores and released into the cytoplasm for translation by host protein synthesis machinery (Acs et al., 1971; Chang and Zweerink, 1971; Skehel and Joklik, 1969). To assess core transcriptase activity and overall accumulation of viral RNA, we used quantitative RT-PCR for viral RNAs over the course of infection (Figure 3G). S4 and M2 viral RNAs were used as representative viral genes, while GAPDH was used for standardization between samples. Over 12hpi, viral transcripts accumulated at a significantly faster rate for $\mathrm{T} 3 \mathrm{D}^{\mathrm{PL}}$ than $\mathrm{T} 3 \mathrm{D}^{\mathrm{KC}} / \mathrm{T} 3 \mathrm{D}^{\mathrm{TD}}$. Specifically, prior to viral RNA saturation at $8 \mathrm{hpi}, \mathrm{T} 3 \mathrm{D}^{\mathrm{PL}}$ exhibited 77- and 85-fold higher levels of S4 viral RNA compared to T3D ${ }^{\mathrm{KC}}$ and T3D ${ }^{\mathrm{TD}}$, respectively (Figure 3G left). Differences in viral M2 RNA were even greater, with T3D ${ }^{\mathrm{PL}}$ having 92- and 133-fold higher levels than $\mathrm{T} 3 \mathrm{D}^{\mathrm{KC}}$ and $\mathrm{T} 3 \mathrm{D}^{\mathrm{TD}}$, respectively (Figure $3 \mathrm{G}$ right). As anticipated, viral protein levels closely reflected virus transcript levels; Western blot analysis with polyclonal anti-reovirus antibody showed substantially higher accumulation of $\mathrm{T} 3 \mathrm{D}^{\mathrm{PL}}$ viral proteins compared to $\mathrm{T}^{\mathrm{D}} \mathrm{D}^{\mathrm{KC}}$ and $\mathrm{T} 3 \mathrm{D}^{\mathrm{TD}}$ at every timepoint from $6 \mathrm{hpi}$ onwards (Figure 3H). Not surprisingly given the large increase in kinetics and total level of viral RNA and proteins for $\mathrm{T}^{\mathrm{D}} \mathrm{D}^{\mathrm{PL}}$, cell death measured by flow cytometry with Annexin V (measures early apoptosis) or 7Aminoactinomycin (measures cell death) was higher for $\mathrm{T}^{\mathrm{PL}}{ }^{\mathrm{PL}}$ relative to $\mathrm{T} 3 \mathrm{D}^{\mathrm{TD}}$; for example $\sim 85 \%$ versus $19 \%$ at MOI of 3 for these strains respectively (Figure 3I). To monitor cell-cell spread, we use immunofluorescence 
staining of reovirus-antigen-positive L929 cells (Figure 3J). In order to decipher the extent of cell-cell spread versus initially-infected cells, staining was compared in the absence or presence of reovirus neutralizing antibodies added at $3 \mathrm{hpi}$ to prevent cell-cell spread. Cells became positive for $\mathrm{T}^{3} \mathrm{D}^{\mathrm{PL}}$ staining more rapidly than $\mathrm{T}^{\mathrm{T}} \mathrm{D}^{\mathrm{TD}}$ (i.e. compare viruses at $12 \mathrm{hpi}$ ) and equalized at $\sim 24 \mathrm{hpi}$, reflecting the enhanced kinetics of RNA and protein synthesis during $\mathrm{T} 3 \mathrm{D}^{\mathrm{PL}}$ infection. By $48 \mathrm{hpi}$, $\mathrm{T} 3 \mathrm{D}^{\mathrm{PL}}$ very effectively spread to neighbouring cells (i.e. compare 48hpi No Ab to anti-reovirus Ab), while limited cell-cell spread was observed for T3D ${ }^{\mathrm{TD}}$. By $120 \mathrm{hpi}$, very few cells remained alive following $\mathrm{T} 3 \mathrm{D}^{\mathrm{PL}}$ infection, indicated by a lack of Hoechst nuclear staining. In comparison, T3D ${ }^{\mathrm{TD}}$ successfully underwent cell-cell spread by $120 \mathrm{hpi}$ but cells remained relatively intact (Figure 3J). Altogether, the analysis indicates that kinetics of reovirus macromolecule synthesis, cell death, and cell-cell spread are drastically faster for $\mathrm{T} 3 \mathrm{D}^{\mathrm{PL}}$ relative to $\mathrm{T} 3 \mathrm{D}^{\mathrm{TD}}$.

$\mathrm{M} 1, \mathrm{~S} 4$, and $\mathrm{L} 3$ reovirus genes were associated with increased plaque size of $\mathrm{T} 3 \mathrm{D}^{\mathrm{PL}}$ (Figure 2), so we determined if these three genes also affect the levels of viral RNA and protein in the first round of infection. RNA and protein analysis were chosen over later steps in virus replication, in order to capture the earliest difference between T3D laboratory strains. Quantitative RT-PCR (Figure 3K) and Western blot analysis (Figure 3L) was repeated for single mono-reassortants at $12 \mathrm{hpi}$. M1, S4, and L3 genes from $\mathrm{T}^{\mathrm{D}} \mathrm{D}^{\mathrm{PL}}$ increased reovirus RNAs in an otherwise $\mathrm{TD}^{\mathrm{RG}}$ background, relative to $\mathrm{T} 3 \mathrm{D}^{\mathrm{TD}}$, while $\mathrm{M} 1, \mathrm{~S} 4$, and $\mathrm{L} 3$ genes from $\mathrm{T} 3 \mathrm{D}^{\mathrm{TD}}$ decreased reovirus RNAs in an otherwise PL background relative to T3D ${ }^{\mathrm{PL}}$. In a T3D ${ }^{\mathrm{TD}}$ background, it was evident that M1, S4, and L3 genes from $\mathrm{T}^{\mathrm{P}} \mathrm{D}^{\mathrm{PL}}$ could increase virus protein $(\mu 1 \mathrm{C})$ levels. Importantly, when introduced independently, each gene only conferred intermediate levels of RNA and protein relative to the parental strains, indicating that each gene only confers a portion of the replication advantage that $\mathrm{T}_{3} \mathrm{D}^{\mathrm{PL}}$ exhibits over $\mathrm{T} 3 \mathrm{D}^{\mathrm{TD}}$. The data therefore indicated that S4, M1 and L3 each contribute to the higher accumulation of virus macromolecules for the mostoncolytic $\mathrm{T} 3 \mathrm{D}^{\mathrm{PL}}$ strain relative to the less-oncolytic $\mathrm{T} 3 \mathrm{D}^{\mathrm{TD}}$ strain.

\section{M1-encoded $\mu 2$ confers accelerated core transcription.}

The observation that virus transcripts accumulate at a faster rate for $\mathrm{T}_{3} \mathrm{D}^{\mathrm{PL}}$ does not directly indicate whether $\mathrm{T} 3 \mathrm{D}^{\mathrm{PL}}$ cores transcribe more efficiently, since reovirus RNAs are packaged into new progeny cores that amplify RNA and protein synthesis. In other words, increased transcription or translation would produce more cores and therefore more RNA and protein in subsequent rounds of amplification; therefore making it difficult to distinguish which process is directly enhanced. To directly assess transcription activities of T3D laboratory strains, we therefore performed in-vitro transcription assays (Figure 4A). Reovirus particles become transcriptionally active once the outer capsid proteins are uncoated to generate virus cores with only the innercapsids intact (Acs et al., 1971; Chang and Zweerink, 1971). As is a routine approach to generate cores in-vitro, $\mathrm{T} 3 \mathrm{D}^{\mathrm{PL}}, \mathrm{T} 3 \mathrm{D}^{\mathrm{KC}}$ and $\mathrm{T} 3 \mathrm{D}^{\mathrm{TD}}$ particles were treated with chymotrypsin $(\mathrm{CHT})$ and purified by high speed centrifugation. The purity of viral cores was confirmed by Coomassie staining and Western blot analysis (Figure 
4B); cores had the characteristic loss of outer capsid proteins $(\sigma 1, \sigma 3$ and $\mu 1)$ but fully retained core inner-capsid proteins $(\sigma 2, \lambda 1, \lambda 2)$. Cores were then subjected to transcription reactions for various time intervals, and levels of S4 and M2 viral RNAs measured by qRT-PCR (Figure 4C). Each sample was spiked with in-vitro synthesized mouse GAPDH RNA prior to RNA extraction to control for sample-to-sample processing variations. Negative control reactions lacking rATP produced no increases in RNA levels, confirming that RNA measured in the presence of all four rNTPs accurately reflected de-novo core transcription (Figure 4D). Furthermore, in-vitro core transcription rates were linear, unlike the exponential rates observed during intracellular infection, reflecting the absence of secondary rounds of amplification that occur during reovirus infection but not in vitro. Importantly, the rates of both $\mathrm{S} 4$ and $\mathrm{M} 2$ viral RNA transcription were significantly higher for $\mathrm{T}_{3} \mathrm{D}^{\mathrm{PL}}$ compared to $\mathrm{T} 3 \mathrm{D}^{\mathrm{KC}}$ and $\mathrm{T}^{2} \mathrm{D}^{\mathrm{TD}}$. For example $\mathrm{S} 4$ transcripts increased for $\mathrm{T} 3 \mathrm{D}^{\mathrm{PL}}$ at $16.8 \pm 0.9 /$ minute while at $3.6 \pm 0.3$ and $2.5 \pm 0.3 /$ minute for $\mathrm{T}_{3} \mathrm{D}^{\mathrm{KC}}$ and $\mathrm{T}_{3} \mathrm{D}^{\mathrm{TD}}$ respectively. For $\mathrm{M} 2$, rates were $7.3 \pm 0.5,1.1 \pm 0.2$, and $0.9 \pm 0.1$ transcripts/minute for $\mathrm{T} 3 \mathrm{D}^{\mathrm{PL}}, \mathrm{T} 3 \mathrm{D}^{\mathrm{KC}}$ and $\mathrm{T} 3 \mathrm{D}^{\mathrm{TD}}$ respectively. Therefore, $\mathrm{T} 3 \mathrm{D}^{\mathrm{PL}}$ has an inherent transcriptase advantage within the viral cores.

Having identified core transcription as a key mechanism for the superior replication $\mathrm{T} 3 \mathrm{D}^{\mathrm{PL}}$, we then asked if any of the 3 genes that segregated with large-plaque phenotype of $\mathrm{T}^{\mathrm{P}} \mathrm{D}^{\mathrm{PL}}$ (Figure 3E-G) account for the inherent core transcription advantage. The M1-encoded $\mu 2$ protein seemed a likely candidate, as one of the $\mu 2$ functions is to hydrolyze NTPs (NTPase) and act as a co-factor to the RNA-dependent RNA polymerase $\lambda 3$ (Kim et al., 2004; Noble and Nibert, 1997b). The inner-capsid $\lambda 1$ protein encoded by L3 could indirectly impact the structure and activity of cores, while the $\sigma 3$ viral protein encoded by the S4 gene is completely removed from cores and therefore was not anticipated to affect core transcription in vitro. Using parental and mono-reassortant viruses generated in Figure 2, we assessed the effects of M1, S4, and L3 genes on core transcription. All viruses were successfully uncoated to cores with chymotrypsin digestion (Figure 4E) and subjected to in vitro transcription reactions (Figure 4F). To facilitate more-rapid comparison among many samples, we developed an assay that measures RNA levels in real-time throughout the reaction, using RNA-binding SYBR II. It should be noted that the SYBR II method has notably lower detection sensitivity than qRT-PCR (i.e. compare readouts for Figure 4F versus 4D), but nevertheless consistently recapitulated the enhanced transcriptional rates of $\mathrm{T}^{\mathrm{P}} \mathrm{D}^{\mathrm{PL}}$ relative to T3D ${ }^{\mathrm{TD}}$, and was chosen over qRT-PCR because it eliminated the cumbersome steps of spike-in controls, RNA purification and qRT-PCR for every time point. As expected, no RNA was produced in the absence of rATP (negative control). When the $\mathrm{T}^{2} \mathrm{D}^{\mathrm{PL}}$-derived $\mathrm{M} 1$ was introduced into an otherwise $\mathrm{T} 3 \mathrm{D}^{\mathrm{TD}}$ background, it was sufficient to restore core transcription to rates similar to $\mathrm{T} 3 \mathrm{D}^{\mathrm{PL}}$ (Figure $4 \mathrm{~F}$ right). Reciprocally, $\mathrm{T}^{\mathrm{D}}{ }^{\mathrm{TD}}$-derived $\mathrm{M} 1$ decreased RNA synthesis rates when placed into an otherwise $\mathrm{T}^{2} \mathrm{D}^{\mathrm{PL}}$ background, relative to $\mathrm{T} 3 \mathrm{D}^{\mathrm{PL}}$ (Figure $4 \mathrm{~F}$ left). When slopes of transcription rates were graphed for three independent experiments (Figure 4G), it was evident that the M1 gene was necessary and sufficient to confer high transcription rates of $\mathrm{T}^{\mathrm{D}} \mathrm{D}^{\mathrm{PL}}$. These data clearly demonstrate that the M1-encoded $\mu 2$ protein contributes to improved transcription by $\mathrm{T} 3 \mathrm{D}^{\mathrm{PL}}$, contributing to the positive impact of $\mu 2$ on the oncolytic potency of $\mathrm{T}_{3} \mathrm{D}^{\mathrm{PL}}$. 
M1-encoded $\mu 2$ and L3-encoded $\lambda 1$ alter virus factory morphology and increase factory size respectively.

A second characterized function of M1-encoded $\mu 2$ is to help organize newly made viral proteins at localized sites of virus replication called "factories" (Broering et al., 2004; Broering et al., 2000a; Broering et al., 2002; Parker et al., 2002). Shortly after escape of the endosome into the cytoplasm, reovirus cores establish factories by localized production of viral RNAs and proteins, and an active strategy to recruit newly synthesized viral proteins (Broering et al., 2004; Broering et al., 2000a; Broering et al., 2002). Specifically, three reovirus proteins play an essential role in factory formation: the non-structural protein $\mu \mathrm{NS}$ recruits de-novo synthesized core proteins $(\lambda 1$, $\lambda 2, \lambda 3, \sigma 2, \mu 2$ ) (Becker et al., 2003; Broering et al., 2005; Broering et al., 2004; Broering et al., 2000b; Broering et al., 2002; Miller et al., 2007; Miller et al., 2010; Miller et al., 2003), $\sigma N S$ binds RNAs, and $\mu 2$ tethers this complex to the cytoskeleton (Broering et al., 2004; Broering et al., 2000a; Broering et al., 2002; Miller et al., 2003). Host protein translational machinery is also recruited to the periphery of factories through unknown mechanisms (Desmet et al., 2014). One of the amino acid differences in $\mu 2$ between $\mathrm{T}^{\mathrm{D}} \mathrm{D}^{\mathrm{PL}}$ and $\mathrm{T} 3 \mathrm{D}^{\mathrm{TD}}$ is at position 208, which was previously demonstrated to affect virus factory morphology by comparison of serotype 3 versus 1 reoviruses (Kobayashi et al., 2009; Yin et al., 2004). Specifically, a serine at position 208 in T3D ${ }^{\mathrm{TD}}$ was associated with a globular factory morphology, while a proline at the same position caused more tubulinassociated fibrous morphology (Kobayashi et al., 2009; Yin et al., 2004). Studies have yet to demonstrate a relationship between factory characteristics and effects on virus titers. Most-recently however, factory morphology was found to affect the encapsidation efficiency of genomic RNAs, as globular factories were associated with an increased fraction of genome-devoid (empty) virions (Shah et al., 2017).

To determine if T3D laboratory strains differed in factory morphology, immunofluorescence staining was conducted on $\mathrm{T} 3 \mathrm{D}^{\mathrm{PL}}$ and $\mathrm{T} 3 \mathrm{D}^{\mathrm{TD}}$ infected L929 cells. Reovirus factories were detectable by staining for factoryassociated proteins $\sigma \mathrm{NS}$ and $\mu 2$, and also the outercapsid protein $\sigma 3$ (Figure $4 \mathrm{H}$ ). Not surprisingly, the $\mathrm{T}_{3} \mathrm{D}^{\mathrm{PL}}$ which has a proline at position 208 of $\mu 2$ similar to T1L, showed fibrous morphology. As anticipated, substitution of the $\mathrm{T}_{3} \mathrm{D}^{\mathrm{PL}}$-encoded $\mathrm{M} 1$ into an otherwise $\mathrm{T} 3 \mathrm{D}^{\mathrm{TD}}$ genomic background, recapitulated the fibrous factory morphology of $\mathrm{T}^{\mathrm{P}} \mathrm{D}^{\mathrm{PL}}$. Our analysis therefore shows that the molecular basis for enhanced in vitro replication and oncolysis of $\mathrm{T}^{\mathrm{PL}} \mathrm{PL}^{\mathrm{PL}}$ includes an increase in transcription kinetics conferred by $\mu 2$ (Figure $4 \mathrm{~A}-\mathrm{G}$ ), but perhaps also relates to $\mu 2$-dependent establishment of tubulin-associated fibrous viral factories (Figure $4 \mathrm{H}$ ).

The most striking and unexpected result of immunofluorescence staining of reovirus factories was that L3encoded $\lambda 1$ was clearly associated with establishing factory size (Figure 4H, quantified in Figure 4I). As mentioned, the $\lambda 1$ protein is an essential component of the reovirus core, which is composed of $\lambda 1-\lambda 1$ homodimers and $\lambda 1-\sigma 2$ heterodimers. Amino acid differences between $\lambda 1 \mathrm{~T}^{\mathrm{PL}} \mathrm{PL}^{\mathrm{LL}} \mathrm{T} 3 \mathrm{D}^{\mathrm{TD}}$ laboratory strains are at $\lambda 1-\lambda 1$ and $\lambda 1-\sigma 2$ interfaces, as will be further depicted and described in the discussion. While the $\mathrm{T}_{3} \mathrm{D}^{\mathrm{PL}}$ derived $\mathrm{L} 3 / \lambda 1$ in an otherwise $\mathrm{T} 3 \mathrm{D}^{\mathrm{TD}}$ genomic background did not affect the morphology of factories (i.e. they 
remained globular), it starkly increased the size of the globular factories (Figure 4I). Keeping in mind that M1 and S4 monoreassortants had similar levels of viral RNA and protein as L3, yet did not increase factory size, the findings suggest a novel role for $\lambda 1$ in accumulation of viral macromolecules efficiently at virus factories. This is the first time, to our knowledge, that differences in factory size (rather than morphology) are described between reoviruses and correlated with improved virus amplification.

\section{$\mathrm{T}^{\mathrm{TD}} \mathrm{D}^{\mathrm{TD}}$ activates interferon signaling more than $\mathrm{T}^{\mathrm{P}} \mathrm{D}^{\mathrm{PL}}$, but IFN signaling does not impact the first round of} reovirus infection.

In addition to virus factors that impact virus replication, host interferon signaling can inhibit virus infection. Upon entry into host cells, RNA viruses activate pathogen associated molecular pattern (PAMP)-recognition receptors such as cytosolic retinoic acid-inducible gene I (RIG-I), melanoma differentiation-associated factor 5 (MDA5), laboratory of genetics and physiology 2 (LGP2)), protein kinase R (PKR) and endosomal toll-like receptor 3 (TLR3). Although reovirus dsRNA genomes are encased in core particles, it is proposed that reovirus PAMPs are generated from occasional unstable cores and/or viral mRNA secondary structures (Henderson and Joklik, 1978). Activation of PAMP receptors, through a cascade of adaptor proteins and signaling events, results in phosphorylation (activation) and nuclear translocation of IRF3/7 and NFאB transcription factors, which subsequently induce expression of interferons (IFNs), antiviral interferon stimulated genes (ISGs) and inflammatory cytokines (Figure 5A). Numerous studies have demonstrated the importance of the RIG-I/MDA5 signaling axis on reovirus mediated IFN production and subsequent paracrine suppression of reovirus spread to neighbouring cells (Goubau et al., 2014; Loo et al., 2008; Shmulevitz et al., 2010b). However, whether autocrine RIG-I/MDA5 and IFN signaling can reduce the initial round of reovirus infection is less clearly understood. Therefore an obvious question was whether $\mathrm{T}^{2} \mathrm{D}^{\mathrm{TD}}$ induces more robust IFN signalling, and if so, whether this contributes to the reduced replication of $\mathrm{T} 3 \mathrm{D}^{\mathrm{TD}}$ relative to $\mathrm{T} 3 \mathrm{D}^{\mathrm{PL}}$.

First we determined if there were differences in IFN signalling between T3D laboratory strains. L929 cells were infected with $\mathrm{T}_{3} \mathrm{D}^{\mathrm{TD}}$ or $\mathrm{T} 3 \mathrm{D}^{\mathrm{PL}}$ at a range of doses (MOI 1, 3, and 9), or mock infected. IFN signalling was then assessed at $12 \mathrm{hpi}$, an intermediate timepoint of virus replication when the potentially confounding effects of cell-cell spread of virus are minimal. IRF3 phosphorylation (activation) was strongly induced by $\mathrm{T}^{\mathrm{D}} \mathrm{D}^{\mathrm{TD}}$ but not $\mathrm{T}_{3} \mathrm{D}^{\mathrm{PL}}$, despite a reciprocal trend for reovirus protein expression (Figure 5B). Moreover, while both T3D laboratory strains caused a dose-dependent increase in transcripts of IFN (Ifn $\alpha 4$, Ifn $\beta$ ) and IFN-inducible genes (Mxl, Rsad2), T3D ${ }^{\mathrm{TD}}$ induced higher expression relative to $\mathrm{T} 3 \mathrm{D}^{\mathrm{PL}}$, as assessed by qRT-PCR (Figure 5C). In other words, despite producing lower levels of viral proteins and transcripts, $\mathrm{T} 3 \mathrm{D}^{\mathrm{TD}}$ induced elevated levels of antiviral signaling compared to $\mathrm{T} 3 \mathrm{D}^{\mathrm{PL}}$. 
We considered two alternative explanations to account for increased IFN signalling by T3D ${ }^{\mathrm{TD}}$ : i) T3D ${ }^{\mathrm{TD}}$ might be a more potent inducer of antiviral signaling, or ii) $\mathrm{T}^{\mathrm{PL}}$ is a more potent inhibitor of antiviral signaling. To distinguish between these possibilities, L929 cells were co-infected with T3D ${ }^{\mathrm{PL}}$ and T3D ${ }^{\mathrm{TD}}$ at a high MOI of 9 (each) to ensure that most cells were infected with both viruses, and cell lysates were subjected to Western blot analysis for IRF3 phosphorylation. Phospho-IRF3 levels were similar between T3D ${ }^{\mathrm{TD}}$ and T3D $\mathrm{D}^{\mathrm{PL}} / \mathrm{T}^{\mathrm{TD}}$ coinfection (Figure 5D), suggesting that $\mathrm{T}^{\mathrm{T}} \mathrm{D}^{\mathrm{TD}}$-dependant activation of IRF3 could not be overcome by the presence of $\mathrm{T} 3 \mathrm{D}^{\mathrm{PL}}$. Therefore, $\mathrm{T} 3 \mathrm{D}^{\mathrm{TD}}$ is most likely a more potent activator of antiviral signaling than $\mathrm{T} 3 \mathrm{D}^{\mathrm{PL}}$. $\mathrm{In}$ other words, paradoxically, the less-prolific replicating variant is more dominant for IFN expression. Furthermore, the levels of reovirus proteins were either unchanged (Figure 5D, $\sigma 3$ ) or only marginally reduced (Figure 5D, $\mu 1 / \mu 1 C$ ) in $T 3 D^{\mathrm{PL}} / \mathrm{T} \mathrm{D}^{\mathrm{TD}}$ co-infection compared to $\mathrm{T}^{\mathrm{D}} \mathrm{D}^{\mathrm{PL}}$ despite high phospho-IRF3 levels, suggesting that IRF3 activation and downstream signaling may not play a major role in restricting the first round of reovirus replication.

Next, we determined if any of the 3 genes that segregated with the large plaque phenotype of $\mathrm{T}^{\mathrm{PL}} \mathrm{D}^{\mathrm{P}}$ (i.e. S4, M1, and L3) contributed to the differential activation of IFN signalling between the two virus strains, by analyzing mono-reassortants. As previously noted (Figure 3I and 3J), the mono-reassortants of S4, M1, and L3 produced intermediate viral RNA and protein levels compared to the $\mathrm{T}_{3} \mathrm{D}^{\mathrm{PL}}$ and $\mathrm{T} 3 \mathrm{D}^{\mathrm{TD}}$ parental strains, reflecting their intermediate levels of replication. As for IFNs and IFN-induced genes, mono-reassortants also gave intermediate IFN signalling and no mono-reassortant fully reversed the phenotype of IFN signalling (Figure 5E). For example, IFN $\beta$ was induced more by $\mathrm{T}^{2} \mathrm{D}^{\mathrm{TD}}$ than $\mathrm{T}^{2} \mathrm{D}^{\mathrm{PL}}$ parental strain, but individually adding $\mathrm{S} 4$, M1, or L3 from $\mathrm{T}^{\mathrm{D}} \mathrm{D}^{\mathrm{TD}}$ into an otherwise $\mathrm{T} 3 \mathrm{D}^{\mathrm{PL}}$ genomic background, did not increase IFN $\beta$ levels to those achieved by $\mathrm{T} \mathrm{D}^{\mathrm{TD}}$. One possible interpretation of this data is that $\mathrm{S} 4, \mathrm{M} 1$, and $\mathrm{L} 3$ each independently contribute 'somewhat' to IFN signalling, such that mono-reassortants are insufficient to confer the full parental phenotype. Previous studies have indeed implicated these genes (and other genes such as S1) in affecting IFN signalling (Beattie et al., 1995; Lanoie and Lemay, 2018; Zurney et al., 2009). Of these IFN modulating viral proteins, the S4-encoded $\sigma 3$ has been clearly demonstrated to sequester dsRNA, inhibit activation of PKR and rescue other viruses depleted of inhibitors of antiviral response (Beattie et al., 1995; Denzler and Jacobs, 1994; Yue and Shatkin, 1997). But it should be noted that most studies on reovirus genes that impact IFN signalling do not consider whether effects are direct (e.g. the gene or protein directly modulate IFN mediators), or whether instead the viral genes impact virus replication and thereby indirectly impact IFN induction. To consider the differences in virus replication kinetics between parental and mono-reassortant viruses, we determined the relationship between IFN signaling (IFN $\beta$ mRNA) and measures of virus replication (progeny titers) (Figure 5E right). A strong negative correlation $\left(\mathrm{R}^{2}=0.86\right)$ between virus replication proficiency and IFN signalling was found, suggesting that S4, M1, or L3 could contribute to differences in IFN signalling between $\mathrm{T} 3 \mathrm{D}^{\mathrm{TD}}$ and $\mathrm{T} 3 \mathrm{D}^{\mathrm{PL}}$ indirectly, by affecting the extent of virus replication. Specifically, we propose that incoming cores must establish viral RNA and protein expression, and factory formation around the core, with sufficient speed to prevent detection of foreign virus patterns by the 
host. Indeed, recent studies showed the ability of reovirus factories to selectively sort IFN signalling components (Stanifer et al., 2017). Our data is therefore consistent with a model where the extent of IFN signalling is inversely related to the efficiency of virus replication; this paradox will be further explored in the discussion.

Given that $\mathrm{T} 3 \mathrm{D}^{\mathrm{TD}}$ induced more IFN signalling than $\mathrm{T} 3 \mathrm{D}^{\mathrm{PL}}$, the pivotal question became whether IFN signalling contributed to reduced replication of $\mathrm{T} 3 \mathrm{D}^{\mathrm{TD}}$ relative to $\mathrm{T} 3 \mathrm{D}^{\mathrm{PL}}$. While it is well established that IFN signalling can prevent dissemination of reovirus to neighboring cells through paracrine signalling (Shmulevitz et al., 2010b), it is unknown whether IFN signalling can affect the initial infection of reovirus in an autocrine manner. To address this question, we made use of double knock-out (DKO) mouse embryo fibroblasts (MEFs) lacking both RIG-I and MDA5 (Errett et al., 2013; Loo et al., 2008). We reasoned that if IFN signalling can impact the first round of virus infection, then the DKO cells should demonstrate increased infection by reovirus at an intermediate timepoint of $12 \mathrm{hpi}$ where cell-cell spread is minimal. Wild-type (WT) and DKO MEFs were exposed to $\mathrm{T}^{\mathrm{PL}} \mathrm{D}^{\mathrm{PL}}$ or $\mathrm{T} 3 \mathrm{D}^{\mathrm{TD}}$ at MOIs of $0.7,2$, and 6 (based on WT MEF titers) and flow cytometric analysis was conducted to measure the number of cells positive for reovirus antigen expression (Figure 5F). At 12hpi, WT and DKO cells showed equivalent infection at matched MOIs, indicating that IFN signalling likely does not affect the first round of infection. As expected, at 24hpi when reovirus already spreads to new cells, the DKO cells showed enhanced infection relative to WT, supporting the paracrine contribution of IFNs to reducing virus dissemination. To confirm the absence of IFN signalling in DKO cells, qRT-PCR was conducted at 12hpi for IFNs (Ifnb1, Ifna4) and IFN-induced gene Rsad2; all demonstrated a strong inhibition (> 97\%) of IFN signaling relative to WT cells following infection by either $\mathrm{T} 3 \mathrm{D}^{\mathrm{PL}}$ or $\mathrm{T} 3 \mathrm{D}^{\mathrm{TD}}$ (Figure $5 \mathrm{G}$ ). Analysis of reovirus transcript levels by qRT-PCR confirmed that WT and DKO cells supported equal levels of virus replication during the initial round of infection.

While having minimal-to-no effect on the first round of T3D reovirus infection, IFN signalling did have the predicted activity on restricting cell-cell spread of reovirus. Specifically, when plaque assays were used to assess the overall replication and spread of $\mathrm{T}_{3} \mathrm{D}^{\mathrm{PL}}$ and $\mathrm{T} 3 \mathrm{D}^{\mathrm{TD}}$, both viruses produced the same number of reovirusinfected cell foci on DKO MEFs versus wildtype MEFs (Figure 5H), suggesting that the initial round of infection was independent of IFN signaling. Plaques for both $\mathrm{T}_{3} \mathrm{D}^{\mathrm{PL}}$ and $\mathrm{T} 3 \mathrm{D}^{\mathrm{TD}}$ were larger on DKO MEFs relative to wildtype MEFs, supporting the importance of IFN signalling during cell-cell spread. Importantly however, plaque size of $\mathrm{T} 3 \mathrm{D}^{\mathrm{TD}}$ remained much smaller than $\mathrm{T} 3 \mathrm{D}^{\mathrm{PL}}$ even on DKO MEFs; this supports the model that the oncolytic advantage of $\mathrm{T} 3 \mathrm{D}^{\mathrm{PL}}$ relative to $\mathrm{T} 3 \mathrm{D}^{\mathrm{TD}}$ is not dependent of IFN signalling, but rather dependent on differences in virus replication discovered in Figures 3 and 4. Similar results were obtained in the NIH/3T3 mouse fibroblast cell line in which RIG-I was knocked down using shRNA (Supplemental Figure 3). Altogether these results strongly suggest that RIG-I signaling does not affect the first round of reovirus replication for either T3D laboratory strain. However, the differences in IFN signalling appear to impact subsequent rounds of infection, permitting $\mathrm{T}_{3} \mathrm{D}^{\mathrm{PL}}$ to disseminate more efficiently. Furthermore as explored in the discussion, the finding that $\mathrm{T} 3 \mathrm{D}^{\mathrm{TD}}$ induces more IFN signalling than $\mathrm{T}_{3} \mathrm{D}^{\mathrm{PL}}$ is likely to also indirectly affect the landscape of anti-tumor and anti-viral immune cells and 
therefore is an impactful discovery for understanding the contribution of virus genetics on the immunotherapeutic aspect of virus oncolysis.

\section{T3D $^{\mathrm{PL}}$ S4-encoded $\sigma 3$ stimulates expression of NFKB-dependent but IFN-independent cytokines.}

Having eliminated IFN as being relevant in the first round of infection, we turned to other signalling pathways in the cell. The MAPK/ERK, p38 stress-activated kinase, and NF- $\kappa$ B pathways have all been implicated in replication of an assortment of viruses (Bonjardim, 2017; Lim et al., 2016; Mohamed and McFadden, 2009; Schmitz et al., 2014). As for reovirus specifically, ERK, p38, and NF-кB signalling were positively associated with reovirus oncolytic activities (Norman et al., 2004; Shmulevitz et al., 2010b; Thirukkumaran et al., 2017). Western blot analysis was therefore conducted to monitor total levels versus phosphorylation status of ERK p42

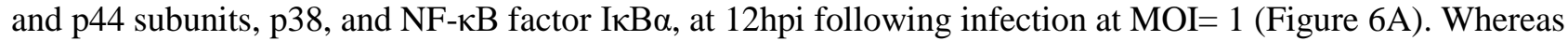
phosphorylation of p42/p44 and p38 are a direct indication of kinase activity, the phosphorylation of IkB $\alpha$ results

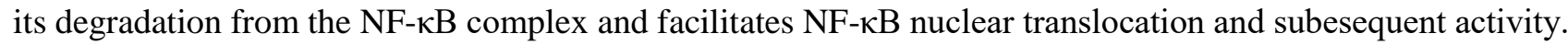
Densitometric analysis for three independent experiments showed that $\mathrm{T}^{\mathrm{D}} \mathrm{D}^{\mathrm{PL}}$ induced higher levels of phospho-

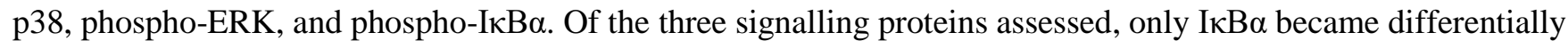
phosphorylated by T3D laboratory strains in a gene-dependent manner. Specifically, T3D ${ }^{\mathrm{PL}}$ induced accumulation of phosphorylated $\mathrm{I} \kappa \mathrm{B} \alpha$ while $\mathrm{T} 3 \mathrm{D}^{\mathrm{TD}}$ did not. Moreover, the phosphorylation of $\mathrm{I} \kappa \mathrm{B} \alpha$ corresponded with the $\mathrm{T}_{3} \mathrm{D}^{\mathrm{PL}}$-derived $\mathrm{S} 4 / \sigma 3$, since addition of this $\mathrm{T}_{3} \mathrm{D}^{\mathrm{PL}}$ gene into an otherwise $\mathrm{T} 3 \mathrm{D}^{\mathrm{TD}}$ background was sufficient for NF- $\mathrm{BB}$ activation. The $\sigma 3$ protein has two well characterized activities; it functions as an outer-capsid protein and it sequesters viral RNAs away from cellular dsRNA-detecting signalling molecules such as PKR and RIG-I (Denzler and Jacobs, 1994; Yue and Shatkin, 1997). Our data now suggested that $\sigma 3$ may contribute to NF- $\kappa B$ activation.

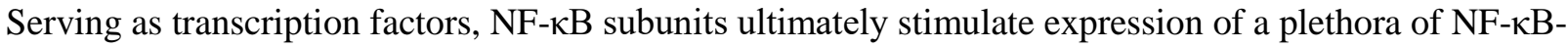
dependent genes. The discovery that $\mathrm{T}_{3} \mathrm{D}^{\mathrm{PL}}$ activated RIG-I, IRF3, and IFN-dependent genes less robustly than $\mathrm{T} 3 \mathrm{D}^{\mathrm{TD}}$ (Figure 5), but reciprocally may activate NF- $\mathrm{kB}$ more than $\mathrm{T}^{\mathrm{D}} \mathrm{D}^{\mathrm{TD}}$ (Figure 6), raised the possibility that

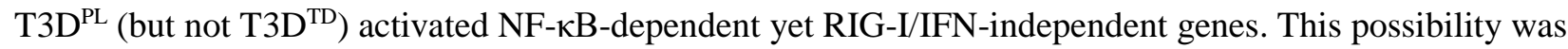
exciting because NF- $\kappa \mathrm{B}$ signaling is typically characterized as being downstream of RIG-I activation, whereas our data potentially introduces a RIG-I independent NF- $\mathrm{BB}$ signalling cascade that is differentially stimulated by strains of reovirus with distinct oncolytic potencies. To test this possibility, it was essential that the western blot data be corroborated by data indicating that NF-кB-dependent (and RIG-I independent) genes are indeed stimulated by $\mathrm{T} 3 \mathrm{D}^{\mathrm{PL}}$ but not $\mathrm{T} 3 \mathrm{D}^{\mathrm{TD}}$. Microarray and bioinformatics analysis was therefore conducted to identify $\mathrm{T}_{3} \mathrm{D}^{\mathrm{PL}}$ - and NF-kB-regulated genes that were RIG-I and IFN- independent. First, we conducted whole genome microarray analysis for NIH3T3 cells that were mock infected, or infected with T3D ${ }^{\mathrm{PL}}(\mathrm{MOI}=60)$, and focused on genes that were up-regulated by $\geq 2$-fold in $\mathrm{T} 3 \mathrm{D}^{\mathrm{PL}}$ infected cells relative to mock infection (Supplemental Figure 
4). Microarray analysis was also conducted for $\mathrm{T} 3 \mathrm{D}^{\mathrm{PL}}$-infected NIH3T3 cells stably transduced with shRIG-I, and genes upregulated by reovirus were further subdivided into those whose expression was suppressed by RIG-I knock-down (RIG-I-dependent, cluster 1) versus those that were independent of RIG-I status (RIG-I-independent, cluster 2). To then determine which genes in each cluster are NF- $\kappa \mathrm{B}$-dependent, we made use of a publically available microarray dataset where lipopolysaccharide (LPS) was used to induce both NF- $\kappa$ B and IFN pathways.

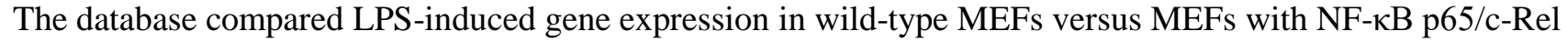
subunit knock-out or with IFN receptor (IFNAR) knock-out, to distinguish NF-кB-dependent versus IFNdependent genes ((Cheng et al., 2017), GEO:GSE35521). Using this public dataset, we further classified T3D ${ }^{\mathrm{PL}_{-}}$ upregulated genes into four groups: genes that are RIG-I-dependent, NF-kB-dependent, and IFNAR-dependent

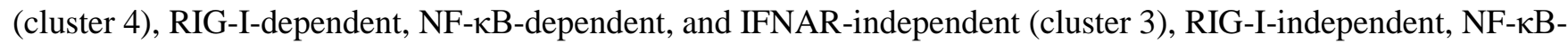
dependent, and IFNAR-dependent (cluster 5), and RIG-I-independent, NF-אB-dependent, and IFNARindependent (cluster 6). Cluster 6 represented T3 $\mathrm{D}^{\mathrm{PL}}$-upregulated genes predicted to be independent of both RIG-I and IFN signalling, but dependent on NF- $\mathrm{B}$ activation, and was therefore chosen for empirical analysis.

Included in cluster 6 were Cxcl1, Csf2, Cxcl2, and Fas. To confirm that these four genes were independent of IFN, L929 cells were treated with IFN $\alpha$ or IFN $\beta$ for 12 hours, and gene expression monitored by qRT-PCR (Supplemental Figure 5). As expected, IFN-dependent genes such as Mx1, Cxc110, Rsad2, Ccl4, Ifi44 and IL6 were upregulated by exposure to IFNs. Conversely, Cxc11, Csf2, Cxcl2, and Fas genes were not upregulated by IFN treatment, suggesting they are indeed IFN-independent genes as the bioinformatics analysis suggested. When levels of Cxcl1, Csf2, Cxcl2, and Fas were compared between L929 cells infected with T3D laboratory strains at MOIs of 1, 3, and 9 for $12 \mathrm{hpi}$, strong induction (up to 30-fold) was evident in a dosedependent manner during infection by $\mathrm{T}^{2} \mathrm{D}^{\mathrm{PL}}$ but not $\mathrm{T} 3 \mathrm{D}^{\mathrm{TD}}$ (Figure 6B). Cxcl1, Csf2, Cxcl2, and Fas induction was also RIG-I independent, since these genes were upregulated by $\mathrm{T}^{\mathrm{D}} \mathrm{D}^{\mathrm{PL}}$ to similar extent in NIH3T3 cells transduced with shSCR or shRIG-I (Figure 6C). Moreover, analysis of gene expression among S4, M1, and L3

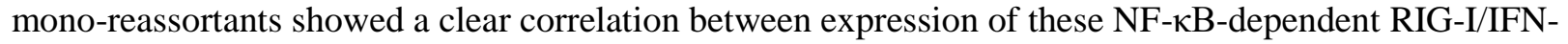
independent genes and presence of the $\mathrm{T}_{3} \mathrm{D}^{\mathrm{PL}}$-derived $\mathrm{S} 4 / \sigma 3$ (Figure 6D). Most surprising about the findings, is that NFKB and IRF3 signalling are inversely activated by T3D laboratory strains; $\mathrm{T}^{\mathrm{PL}}$ caused high expression of NFkB-dependent genes and low expression of RIG-I/IFN-dependent genes, but the reciprocal scenario occurred for $\mathrm{T}^{\mathrm{D}} \mathrm{D}^{\mathrm{TD}}$. These two signalling pathways are often linked, for example it was recently shown that serotype 3 (T3D) activates both NFאB and IRF3 more than serotype 1 (T1L) (Stuart et al., 2018). While many studies show NFkB and IRF3 downstream of cytosolic sensors like RIG-I, our data suggests an independent source of NFKB signalling that is modulated by $\sigma 3$. The inverse induction of NFkB - versus RIG-I/IFN-dependent genes by $\mathrm{T}^{\mathrm{P}} \mathrm{D}^{\mathrm{PL}}$ versus $\mathrm{T} 3 \mathrm{D}^{\mathrm{TD}}$ was recapitulated in all four cells lines that we evaluated, including NIH/3T3 $(n=2)$, L929 ( $n=3)$, B16-F10 ( $n=2)$, and ID8 ( $n=1)$, suggesting a widespread phenomenon (data not shown). As will be extrapolated in the discussion, that minor modifications to viral genomes can produce distinct cytokine 
expression landscapes could be relevant for optimizing virus-induced anti-tumor immunity and for understanding how closely-related viruses cause distinct pathogenic outcomes.

Finally, although NFKB signalling was previously found necessary for induction of cell death by $\mathrm{T} 3 \mathrm{D}^{\mathrm{PL}}$ (Pan et al., 2011), we determined the effects of modulating NFkB signalling on $\mathrm{T}^{\mathrm{P}} \mathrm{D}^{\mathrm{PL}}$ versus $\mathrm{T} 3 \mathrm{D}^{\mathrm{TD}}$ (Supplemental Figure 5B). While addition of InSolution ${ }^{\mathrm{TM}}$ NF-кB Activation Inhibitor decreased cell death following $\mathrm{T}_{3} \mathrm{D}^{\mathrm{PL}}$ infection in a dose-dependent manner, addition of TNF to induce NF- $\kappa \mathrm{B}$ activation reciprocally increased cell death following T3D ${ }^{\mathrm{TD}}$ infection. Moreover, InSolution ${ }^{\mathrm{TM}} \mathrm{NF}-\kappa \mathrm{B}$ Activation Inhibitor also decreased levels of reovirus proteins (Supplemental Figure 5C), suggesting a role in virus replication in addition to cell death induction. Furthermore, pre-incubation with InSolution ${ }^{\mathrm{TM}} \mathrm{NF}-\kappa \mathrm{B}$ Activation Inhibitor for 3 hours prior to infection reduced virus protein accumulation and cell death by either laboratory strain. Together, the data suggests that both $\mathrm{T}_{3} \mathrm{D}^{\mathrm{PL}}$ and $\mathrm{T} 3 \mathrm{D}^{\mathrm{TD}}$ benefit from basal activity of $\mathrm{NF} \kappa \mathrm{B}$, but that $\mathrm{T} 3 \mathrm{D}^{\mathrm{PL}}$ can further activate and therefore benefit from NFKB stimulation.

\section{Specific polymorphisms in $\mathrm{S4}, \mathrm{M1}$ and $\mathrm{L3}$ of $\mathrm{T}^{\mathrm{PL}}{ }^{\mathrm{PL}}$ relative to $\mathrm{T}^{\mathrm{TD}} \mathrm{D}^{\mathrm{TD}}$ have positive or negative effects on replication; and a hybrid between $\mathrm{T}^{\mathrm{PL}} \mathrm{P}^{\mathrm{PL}}$ and $\mathrm{T}^{\mathrm{TD}}$ has superior oncolytic activity over either T3D} laboratory strain.

Having identified the genetic and phenotypic contribution of S4, M1, and L3 genes for enhanced oncolysis by $\mathrm{T}_{3} \mathrm{D}^{\mathrm{PL}}$ relative to $\mathrm{T} 3 \mathrm{D}^{\mathrm{TD}}$, but given that each of these genome segments had 2-3 amino acid differences between the two laboratory strains, we sought to pinpoint the precise amino acids that define oncolytic potency of $\mathrm{T}_{3} \mathrm{D}^{\mathrm{PL}}$. For each polymorphism, the $\mathrm{T}_{3} \mathrm{D}^{\mathrm{PL}}$-derived amino acid was individually cloned into the otherwise $\mathrm{T} 3 \mathrm{D}^{\mathrm{TD}}$ genetic background. In our nomenclature, the $\mathrm{T} 3 \mathrm{D}^{\mathrm{TD}}$ amino acid is listed first, then the numerical location of the amino acid, followed by the amino acid identity introduced from T3D ${ }^{\mathrm{PL}}$ (e.g., W133R indicates that the T3D ${ }^{\mathrm{TD}}$ derived tryptophan was replaced by a $\mathrm{T}_{3} \mathrm{D}^{\mathrm{PL}}$-derived arginine into an otherwise $\mathrm{T} 3 \mathrm{D}^{\mathrm{TD}}$ genomic background). If the sequence difference indeed contributes to the enhanced oncolytic potency of $\mathrm{T} 3 \mathrm{D}^{\mathrm{PL}}$, then we expected that the substitution would increase plaque size relative to the $\mathrm{T}^{3} \mathrm{D}^{\mathrm{TD}}$ parental strain.

A surprising result came from segregating the 3 individual variations in the $S 4$-encoded $\sigma 3$ protein; some amino acid variations increased plaque size, while others decreased plaque size. Among the three amino acid differences at positions 133,198 , and 229, the W133R modification alone was sufficient to almost fully restore plaque size of $\mathrm{T}^{\mathrm{D}} \mathrm{D}^{\mathrm{TD}}$ to $\mathrm{T} 3 \mathrm{D}^{\mathrm{PL}}$ (Figure 7A). Surprisingly, G198K or E229D substitutions marginally reduced plaque size relative to $\mathrm{T} 3 \mathrm{D}^{\mathrm{TD}}$, and strongly reduced plaque size relative to $\mathrm{T} 3 \mathrm{D}^{\mathrm{TD}}$ containing the $\mathrm{W} 133 \mathrm{R}$ mutation. These experiments therefore indicated that the increased plaque size of $\mathrm{T}^{2} \mathrm{D}^{\mathrm{PL}}$ is attributable to the arginine at position 133 of $\sigma 3$, while the lysine and aspartic acid at positions 198 and 229 of $\mathrm{T}^{\mathrm{PL}}$ actually suppress plaque size potential. 
The M1-encoded $\mu 2$ contains four amino acid differences between T3D ${ }^{\mathrm{TD}}$ and T3D ${ }^{\mathrm{PL}}$; Q150R, S208P, R342Q, and A528S. The most prominent contributor to plaque size was the S208P polymorphism (Figure 7A). As mentioned, a serine-to-proline difference at position 208 of $\mu 2$ was previously described for T1L versus T3D ${ }^{\mathrm{TD}}$ and changed the morphology of virus factories (Parker et al., 2002). Q150R, R342Q, and A528S each had marginal contribution to plaque size on their own, but both R342Q, and A528S increased plaque size when combined with S208P relative to S208P alone. Our analysis therefore suggests that in addition to S208P, R342Q and $\mathrm{A} 528 \mathrm{~S}$ are key contributors to the large plaque phenotype of $\mathrm{T} 3 \mathrm{D}^{\mathrm{PL}}$ (Figure 7B). Unfortunately, the crystal structure of $\mu 2$ has not yet been solved, so it is not possible to map these polymorphisms in tertiary structure. However, both R342Q, and A528S lie near the regions proposed to be involved in NTPase activity and putative nucleotide binding (Eichwald et al., 2017; Kim et al., 2004; Noble and Nibert, 1997b), so these changes could help explain the strongly increased transcriptional activity imparted by the $\mathrm{T} 3 \mathrm{D}^{\mathrm{PL}} \mathrm{M} 1$ gene.

There are two amino acid differences between $\mathrm{T} 3 \mathrm{D}^{\mathrm{TD}}$ and $\mathrm{T} 3 \mathrm{D}^{\mathrm{PL}}$ in the L3-encoded $\lambda 1$ protein; I500S and Q852H. Only the I500S modification increased plaque size in an otherwise T3D ${ }^{\mathrm{TD}}$ genomic background, implicating $\lambda 1$ amino acid 500 as a determinant of enhanced $\mathrm{T}^{\mathrm{D}} \mathrm{D}^{\mathrm{PL}}$ replication relative to $\mathrm{T} 3 \mathrm{D}^{\mathrm{TD}}$ (Figure $7 \mathrm{C}$ ). On the crystal structure of reovirus core proteins, the I500S mutation maps to the interface between $\lambda 1$ and $\sigma 2$. The potential impact of the $\lambda 1-\sigma 2$ on core assembly and subsequent accumulation of reovirus macromolecules in viral factories, to produce larger factory size will be explored in the discussion.

Finally, our discovery that the $\sigma 3$ of $\mathrm{T} 3 \mathrm{D}^{\mathrm{PL}}$ had two variations that were actually restricting $\mathrm{T}^{\mathrm{D}} \mathrm{D}^{\mathrm{PL}}$ plaque size, suggested that it may be possible to further increase the oncolytic potency of $\mathrm{T}^{\mathrm{P}} \mathrm{D}^{\mathrm{PL}}$ by creating a hybrid sequence between the laboratory strains. Specifically, the data suggested that an arginine at position 133 of $\sigma 3$ is strongly favorable for in vitro oncolysis relative to a tryptophan, while residues 198 and 229 are most favorable as glycine and glutamic acid from the $\mathrm{T} 3 \mathrm{D}^{\mathrm{TD}}$ sequence, respectively. If this is true, then we predicted that introduction of glycine at position 198 and glutamic acid at position 229 should further increase plaque size of $\mathrm{T}^{\mathrm{PL}} \mathrm{P}^{\mathrm{PL}}$. Indeed, plaque size of $\mathrm{T}^{\mathrm{P}} \mathrm{D}^{\mathrm{PL}}$ was further increased by K198G and D229E mutations in $\sigma 3$ (Figure 7D). These findings suggest that this hybrid between $\mathrm{T}_{3} \mathrm{D}^{\mathrm{PL}}$ and $\mathrm{T} 3 \mathrm{D}^{\mathrm{TD}}\left(\mathrm{T}_{3} \mathrm{D}^{\mathrm{PL} / \sigma 3 \mathrm{~K} 198 \mathrm{G} / \sigma 3 \mathrm{D} 229 \mathrm{E}}\right)$ exhibits even higher in vitro oncolytic activity than either parental strain, and supports a potential for further improving the activity of $\mathrm{T}_{3} \mathrm{D}^{\mathrm{PL}}$ by genomic manipulation. Lastly, our exploration of $\sigma 1$ status (Figure $3 \mathrm{~B}-\mathrm{D}$ ) suggested that $\mathrm{T}^{\mathrm{D}} \mathrm{D}^{\mathrm{TD}}$ had $\sim 50 \%$ particles with insufficient $\sigma 1$ cell attachment proteins for efficient binding (i.e., $<3$ ), while $\mathrm{T}^{2} \mathrm{D}^{\mathrm{PL}}$ had a predominance of particles with 7-12 $\sigma 1$ trimers. Previous studies showed that having 3-7 $\sigma 1$ per reovirus was optimal for reovirus replication initiation in tumor cells, and could be achieved by a serine-to-isoleucine mutation at position 18 (S18I) of $\sigma 1$ optimal for efficient entry. The S18I mutation was therefore introduced into $\mathrm{T} 3 \mathrm{D}^{\mathrm{PL} / \sigma 3 \mathrm{~K} 198 \mathrm{G} / 63 \mathrm{D} 229 \mathrm{E}}$, as a strategy to maintain sufficient $\sigma 1$ for binding but not too many $\sigma 1$ for efficient entry. The product, T3D $\mathrm{D}^{\mathrm{PL} / \sigma 3 \mathrm{~K} 198 \mathrm{G} / \sigma 3 \mathrm{D} 229 \mathrm{E} / \sigma 1 \mathrm{D} 229 \mathrm{E}}$, exhibited further increase in plaque size (Figure 7D). Altogether our studies demonstrate the genomic and phenotypic contribution of S1, S4, M1, and L3 in reovirus oncolytic potency, and demonstrate that the ideal oncolytic vector may actually be a hybrid between laboratory strains. 


\section{DISCUSSION}

Our detailed analysis of reovirus laboratory strains showed that very closely related strains can differ substantially in in vitro and in vivo oncolytic potency, revealed the mechanisms for enhanced replication in cancer cells associated with superior-oncolytic strains, and discovered unanticipated differences in virus-induced cytokine profiles that could further contribute to the immunotherapeutic aspect of oncolytic reovirus treatment (Figure 7E). These findings provide a cautionary reminder that very small changes in viral proteins can have a very large impact. In recent years, the large market for cancer immunotherapies has provoked a focus on adding immune-stimulating genes to oncolytic viruses (e.g. tumor antigens or GM-CSF), or on combination therapy of oncolytic viruses with checkpoint blockade agents. Our study demonstrates the potential of single amino acid differences alter oncolytic potency, and even to change the cytokine landscape, both of which could affect immunotherapeutic activity. As oncolytic virus studies across the world use independently propagated virus stocks, our findings at minimum propose that the most-oncolytic strain of each virus should be identified and shared for research studies related to cancer therapy; in the case of reovirus, that $\mathrm{T} 3 \mathrm{D}^{\mathrm{PL}}$ be used as a comparative. Given the increasing ease of sequencing, careful documentation of virus genome sequences would be an important step forward.

Reovirus $\mathrm{T} 3 \mathrm{D}^{\mathrm{PL}}$ laboratory strain showed substantially better replication than $\mathrm{T} 3 \mathrm{D}^{\mathrm{TD}}$ on a panel of cancer cell lines that clearly correlated with in vivo control of aggressive melanoma (Figure 1A-F). If our goal is to develop the strongest virus oncolytic therapy, then ideally the reovirus $\mathrm{T} 3 \mathrm{D}^{\mathrm{PL}}$ base vector should continue to undergo development towards utmost oncolytic activity. With respect to improving the oncolytic potency of

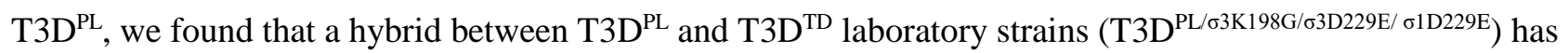
superior oncolytic activity in vitro (Figure 7E). For herpesvirus, it was suggested that "the in vitro cytolytic properties of OVs [oncolytic viruses] are poor prognostic indicators of in vivo antitumor activity" (Sobol et al., 2011); but it should not be assumed that all viruses are equally maximized. In fact, we previously demonstrated that single amino acid mutations in $\mathrm{T} 3 \mathrm{D}^{\mathrm{PL}}$, which promote capsid disassembly in tumor cells, can enhance reovirus oncolysis both in vitro and in vivo (Mohamed et al., 2015; Shmulevitz et al., 2012). Our current data further supports that the reovirus genome has not yet achieved maximal adaptation towards tumors. Keeping in mind that reovirus naturally evolved to be exquisitely well-adapted towards enteric infections, and that the ileum of a gut is quite distinct from a tumor, it seems unsurprising that modifications to reovirus genomes could enhance replication in tumors, dissemination to metastatic sites, and/or induction of anti-tumor immunity. It will be important to test the oncolytic activity of T3D $\mathrm{D}^{\mathrm{PL} / \sigma 3 \mathrm{~K} 198 \mathrm{G} / \sigma 3 \mathrm{D} 229 \mathrm{E} / \sigma 1 \mathrm{D} 229 \mathrm{E}}$ in several animal tumor models, and if it is superior to $\mathrm{T} 3 \mathrm{D}^{\mathrm{PL}}$ in vivo, this variant could function as the next reovirus base vector for further development.

In addition to differences in replication, reovirus laboratory strains induced distinct profiles of virusstimulated cellular immunomodulatory genes (IMGs). Remarkably, T3D ${ }^{\text {TD }}$ caused upregulation of IFN-induced 
IMGs such as CCL5, CCL4, and CXCL10 (Supplementary Figure 3D), while conversely T3D ${ }^{\mathrm{PL}}$ caused upregulation of IFN-independent but NF-אB-dependent IMGs such as CXCL2 and CSF2 (Figure 6B, 6C). Reovirus-mediated oncolysis is a combination of both direct virus-induced cytolysis (i.e. demonstrated by tumor clearance in many immunodeficient models (Alain et al., 2002; Hata et al., 2008; Norman et al., 2002a; Sei et al., 2009; Yang et al., 2004) and anti-tumor immune stimulation (Clements et al., 2015; Gujar et al., 2013; Gujar and Lee, 2014; Gujar et al., 2011; Prestwich et al., 2009; Steele et al., 2011). Given that cytokines, chemokines, and innate signalling molecules strongly influence anti-tumor immunity (Adler et al., 2017; Izzi et al., 2014; Romee et al., 2014; Showalter et al., 2017; Waldmann, 2017), we predict that they will impact anti-tumor immunity during reovirus oncolysis. Our data suggests a close investigation into the roles of IFN-dependent versus IFNindependent cytokines on reovirus-strain-specific anti-tumor activity. Based on the 5 cytokines we analyzed, it is impossible to predict the impact of the distinct cytokine profile induced by each strain. As an example, CXCL10 is proposed to have both pro- and anti-proliferative action on Breast cancer depending on the receptors it engages (Liu et al., 2011). Most importantly, many more IFN-dependent and -independent cytokines are likely upregulated differentially by reovirus strains that were not evaluated in this study. A systematic approach will be necessary to determine precisely the benefits or costs of using reovirus strains that induce IFN-dependent versus IFNindependent cytokines. Should both IFN-dependent and -independent IMGs prove important during oncolytic virus treatment, then combination therapy with both $\mathrm{T} 3 \mathrm{D}^{\mathbf{P L}}$ and $\mathrm{T} 3 \mathrm{D}^{\mathrm{TD}}$ reovirus strains (or a hybrid variant that induces both types of signalling) warrants consideration. One must also consider that such cytokines would contribute to heightened clearance of the virus, and therefore to achieve a balance between strong virus replication and strong anti-tumor activity, immunologically distinct oncolytic viruses may need to be sequentially used. Overall, our findings suggest that apart from adding genes to oncolytic viruses to stimulate immunity, small genomic differences among virus strains could impact the immunotherapeutic potential of an oncolytic virus.

Understanding the mechanisms of IFN signalling induction by viruses is important for both virus oncolysis and virus pathogenesis. With respect to IFN-dependent genes, countless examples show that many viruses express viral genes that counteract cellular signalling. Indeed even for reovirus, previous reassortants analysis between reovirus serotypes (T1L) and 3 (T3D) suggested that S2, S4, M1 and L2 reovirus genes function to regulate IFN signalling (Beattie et al., 1995; Bergeron et al., 1998; Sandekian and Lemay, 2015; Sherry, 2009; Sherry et al., 1998; Zurney et al., 2009). But our studies suggest an alternative mechanism affects activation of IFN-dependent IMGs; replication of mono-reassortant and parental viruses was inversely correlated with IFN induction (Figure $5 \mathrm{E}$ ). We therefore propose an alternative model: $\mathrm{T}^{3} \mathrm{D}^{\mathrm{TD}}$, via delayed onset of replication kinetics, lead to accumulation of viral PAMPs and therefore detection by cellular genes such as RIG-I and MDA5 that activate IFNs, prior to achieving sufficient localized expression of virus proteins that conceal de-novo PAMPS (such as $\sigma 3$ which binds dsRNA portions of RNAs) or usurp host IRFs. In other words, if incoming reovirus cores fail to establish a virus factory around them quickly, there is less protection from cellular proteins. 
In this model, virus replication would inversely correlate with IFN induction. Our findings are very timely, as there is growing interest in the concept that defective virions in a virus quasispecies contribute to innate detection of viruses, since such defective virions are debilitated in their ability to dampen the immune response (reviewed in (Lopez, 2014, 2019)). If our model is correct, then similar to T3D ${ }^{\mathrm{TD}}$, other virus variants in a quasispecies with slow kinetics of establishing infection may be inherently more vulnerable to innate detection, which could help protect from rapid-replicating variants in the quasispecies, but may also increase immune-associated pathogenesis; for example in Ebola and Zika, for which pathogenesis correlates with heighted innate signalling response (Ebihara et al., 2006; Tripathi et al., 2017).

With respect to IFN induction, it seemed also paradoxical that co-infections with $\mathrm{T}^{\mathrm{D}} \mathrm{DL}^{\mathrm{PL}}$ and $\mathrm{T} 3 \mathrm{D}^{\mathrm{TD}}$ still produced high IFN signalling (i.e. phenocopy of $\mathrm{T} 3 \mathrm{D}^{\mathrm{TD}}$ with respect to IFN activation), yet high replication of virus (i.e. phenocopy of $\mathrm{T} 3 \mathrm{D}^{\mathrm{PL}}$ with respect to virus macromolecular synthesis), suggesting it unlikely that $\mathrm{T} 3 \mathrm{D}^{\mathrm{PL}}$ globally counteracts the IFN signalling. Reovirus incoming cores were previously demonstrated to establish virus factories around them (Broering et al., 2004; Broering et al., 2000a), so during co-infections, we predict that incoming $\mathrm{T}_{3} \mathrm{D}^{\mathrm{PL}}$ and $\mathrm{T} 3 \mathrm{D}^{\mathrm{TD}}$ cores each establish their own factories. In this scenario, the slow-replicating $\mathrm{T} 3 \mathrm{D}^{\mathrm{TD}}$ virus would still cause induction of the IFN signalling pathway. But since IFN signalling does not affect the first round of reovirus replication (Figure 5F-H, Supplementary Figure 3B-D), induction of IFN by T3D ${ }^{\mathrm{TD}}$ would not impact the replication of $\mathrm{T}_{3} \mathrm{D}^{\mathrm{PL}}$, thus explaining the continued high levels of viral proteins during $\mathrm{T} 3 \mathrm{D}^{\mathrm{PL}} / \mathrm{T} 3 \mathrm{D}^{\mathrm{TD}}$ co-infections. T3D ${ }^{\mathrm{TD}}$-mediated IFN induction would presumably affect cell-cell spread of either $\mathrm{T}^{\mathrm{D}} \mathrm{D}^{\mathrm{PL}}$ or $\mathrm{T} 3 \mathrm{D}^{\mathrm{TD}}$, since IFN was inhibitory to both strains through paracrine fashion (Figure 5H). The results beckon a better understanding of how incoming cores establish factories, and whether individual incoming variants have distinct consequences in a co-infected cell.

Our phenotypic comparison of the highly oncolytic $\mathrm{T}^{2} \mathrm{D}^{\mathrm{PL}}$ to the less-oncolytic $\mathrm{T} 3 \mathrm{D}^{\mathrm{TD}}$ also revealed four virus attributes that yield a strong oncolytic reovirus base vector (Figure 7E). First, T3D ${ }^{\mathrm{PL}}$ exhibited higher binding to tumorigenic cells than $\mathrm{T}^{\mathrm{T}} \mathrm{D}^{\mathrm{TD}}$ (Figure 3D). Cell attachment is mediated by reovirus outer capsid $\sigma 1$ protein (Lee et al., 1981). We and others previously demonstrated that reovirus particles can house from 0 to 12 $\sigma 1$ molecules, and that 3 or more $\sigma 1$ molecules are sufficient for binding to cells (Larson et al., 1994; Mohamed et al., 2015). We now show that $\mathrm{T} 3 \mathrm{D}^{\mathrm{TD}}$ has higher proportion of particles with two or less $\sigma 1$ molecules, which explains the reduced cell binding capacity of this strain. The difference in binding between the two strains was reproducible but small, and therefore not surprisingly the genes previously shown to affect $\sigma 1$ level (i.e. $\sigma 1$ or $\lambda 2$ proteins that anchor $\sigma 1$ ) did not robustly assort with high oncolytic activity (Figure 2B, 2D, 2E). Second, and most strikingly, $\mathrm{T}^{2} \mathrm{D}^{\mathrm{PL}}$ established rapid onset of viral RNA and protein synthesis, leading to more rapid kinetics of progeny virus production and a larger virus burst size (Figure 3E-H, Supplementary Figure 2). This points to the importance of rapid onset of infection for oncolysis. Thirdly, $\mathrm{T}^{\mathrm{PL}}{ }^{\mathrm{PL}}$ also establishes globular factories, and while the importance of globular over filamentous factories remains to be fully characterized, it was clear that variations in L3-encoded $\lambda 1$ increase the size of globular factories likely reflecting more-efficient virus 
amplification (Figure 4H). Fourthly, T3D $\mathrm{D}^{\mathrm{PL}}$ more-rapidly caused cell death and efficiently disseminated (Figure 3E, 3I, 3J, Supplementary Figure 2). We also noted strong differences in antiviral signaling between $\mathrm{T}^{\mathrm{D}} \mathrm{D}^{\mathrm{PL}}$ and $\mathrm{T}^{\mathrm{T}} \mathrm{T}^{\mathrm{TD}}$ as described above. Put together, our findings suggest that with respect to direct oncolysis, an oncolytic reovirus vector should have these attributes. In future, mono-reassortants should be compared in vivo to determine which of the virus attributes contribute most to in vivo oncolysis; though we predict that the mono-reassortants will show intermediate phenotypes between $\mathrm{T} 3 \mathrm{D}^{\mathrm{PL}}$ and $\mathrm{T} 3 \mathrm{D}^{\mathrm{TD}}$ parental strains as they did for plaque size.

Our genetic analysis has uncovered three reovirus genes that prominently contribute to the enhanced oncolytic activity of T3D $\mathrm{D}^{\mathrm{PL}}$ in vitro: $\mathrm{M} 1$ (encoding $\mu 2$ ), L3 (encoding $\lambda 1$ ), and S4 (encoding $\sigma 3$ ). Functional studies then revealed several phenotypic properties controlled by these proteins that likely contribute to the enhanced potency of $\mathrm{T}^{2} \mathrm{D}^{\mathrm{PL}} \cdot \mu 2$ enhanced the transcriptional activity of viral cores and influenced viral factory morphology, $\lambda 1$ increased factory size, and $\sigma 3$ was required for induction of NF-kb-dependent, IFN-independent genes. A genotypic comparison was then used to identify reovirus genes that strongly associated with the high oncolytic activity of $\mathrm{T}_{3} \mathrm{D}^{\mathrm{PL}}$ relative to $\mathrm{T} 3 \mathrm{D}^{\mathrm{TD}}$. First, the $\mathrm{M} 1$-encoded $\mu 2$ protein of $\mathrm{T}^{\mathrm{P}} \mathrm{D}^{\mathrm{PL}}$ was demonstrated to increase virus transcription activity and promote a globular morphology of reovirus factories (Figure 4D, 4F-H). The $\mu 2$ protein serves at least two distinct functions; a structural protein within virus cores that functions as a transcription co-factor, and a tubulin-associated protein during virus replication involved in accumulating virus proteins into localized sites of virus replication called factories (Coombs, 1998; Parker et al., 2002). This is the first time, to our knowledge, that a mutation in $\mu 2$ is shown to increase rates of transcription in infected cells, and supports previous suggestions that $\mu 2$ is a polymerase co-factor (Kim et al., 2004; Noble and Nibert, 1997b). Previous studies also proposed that $\mu$ has NTPase activity and amino acids in positions 399-421 and 446-449 affect nucleotide binding and NTPase activities (Eichwald et al., 2017; Kim et al., 2004; Noble and Nibert, 1997b). We found that the S208P mutation is most-important for increased replication of $\mathrm{T}^{\mathrm{D}} \mathrm{D}^{\mathrm{PL}}$, but that the other mutations (R342Q and A528S) provide especially when combined with the S208P mutation (Figure 7B). None of these variations lie in the so-far identified NTP binding and NTPase activity domains, suggesting that either the mutations affect these activities in the folded $\mu 2$ structure, or that additional domains impact the transcriptional co-factor role of $\mu 2$. Future crystal structure determination of $\mu 2$ would help decipher between these possibilities. With respect to our finding that all reassortants containing $\mathrm{T}^{\mathrm{PL}} \mathrm{D}^{\mathrm{PL}} 2$ exhibited globular factory morphology, this phenotype was already previously described to be associated with polymorphisms at position 208 (Parker et al., 2002; Yin et al., 2004). Specifically, other laboratories noticed that a proline at position 208 of $\mu 2$ produced globular factory morphology for reovirus serotype 1 (T1L), while a serine at the same position produced fibrous factory morphology for reovirus serotype 3 (T3D). Since $\mathrm{T} 3 \mathrm{D}^{\mathrm{PL}}$ has a proline at 208 and globular morphology, we predict that the T3D strain used in previous analyses was of $\mathrm{T} 3 \mathrm{D}^{\mathrm{TD}}$ origin. Altogether, our findings suggest that strong transcription activity and globular factory morphology associate with high oncolytic potency. While it is clear how enhanced transcription would permit rapid onset of virus infection and therefore oncolysis, additional 
studies are needed to understand how globular-versus-fibrous factory morphology could promote reovirus oncolytic potency.

A second gene prominently attributed to stronger oncolytic activity of $\mathrm{T} 3 \mathrm{D}^{\mathrm{PL}}$ was $\lambda 1$. The inner capsid of reovirus cores is composed of dimers of $\lambda 1$ and $\sigma 2$ (Supplemental Figure 6). T3D $\mathrm{D}^{\mathrm{PL}}$ and $\mathrm{T} 3 \mathrm{D}^{\mathrm{TD}}$ have two amino acid differences in $\lambda 1$ (I500S and Q852H), but only the I500S polymorphism corresponded with increased reovirus replication in tumor cells (Figure 7C). The $\lambda 1$ gene of $\mathrm{T} 3 \mathrm{D}^{\mathrm{PL}}$ was also associated with strikingly larger virus factories, without affecting the morphology of the virus factory which depended on $\mu 2$ as discussed above. Based on crystal structures of reovirus cores (Reinisch et al., 2000), amino acid 500 is located on the surface of $\lambda 1$ that associated with $\sigma 2$. The most-likely hypothesis is therefore that I500S promotes $\lambda 1-\sigma 2$ interactions and thereby co-association of these core proteins to factories and assembly of new cores, which would serve to amplify reovirus replication by synthesizing more RNAs. Alternative possibilities are that $\lambda 1$ I500S mutation contributes to virus protein trafficking to factories or factory construction.

The third reovirus gene that correlated with superior oncolysis by $\mathrm{T}^{\mathrm{P}} \mathrm{D}^{\mathrm{PL}}$ was $\sigma 3$. Analysis of the specific polymorphisms of $\sigma 3$ between $\mathrm{T} 3 \mathrm{D}^{\mathrm{TD}}$ and $\mathrm{T} 3 \mathrm{D}^{\mathrm{PL}}$ led to a surprising result; while $\mathrm{T} 3 \mathrm{D}^{\mathrm{PL}}$ has one polymorphism that drastically promotes reovirus replication (W133R), the other two polymorphisms (G198K and E229D) are unfavorable and reduce reovirus replication relative to the W133R polymorphism alone (Figure 7A). As discussed above, this finding proposes that the optimal reovirus base vector might consist of a T3DPL/TD hybrid, whereby all sequences are of $\mathrm{T} 3 \mathrm{D}^{\mathrm{PL}}$ origin except $\sigma 3$ which would contain a glycine at 198 and glutamic acid at 229 derived from $\mathrm{T}_{3} \mathrm{D}^{\mathrm{TD}}$. The $\sigma 3$ protein has two well-characterized roles: it is the outer-most capsid protein that maintains reovirus stability and must be removed during virus entry, and it binds dsRNA during virus replication to quench cellular dsRNA binding proteins such as RNA-dependent protein kinase (PKR) and subdues antiviral mechanisms (Beattie et al., 1995; Chandran et al., 1999; Jane-Valbuena et al., 2002; Olland et al., 2001; Yue and Shatkin, 1997). Interestingly, all three polymorphisms lie in similar proximity in the $\sigma 3$ structure (Supplementary Figure 6). The polymorphisms are next to the hypercleavable sequence needed for degradation of $\sigma 3$ during virus entry (Liemann et al., 2002; Mendez et al., 2003), but also among the charged surface of $\sigma 3$ involved in dsRNA binding (Denzler and Jacobs, 1994; Mabrouk et al., 1995; Mabrouk and Lemay, 1994; Miller and Samuel, 1992; Olland et al., 2001; Schiff et al., 1988; Wang et al., 1996). In our studies, minimal differences were noted in $\sigma 3$

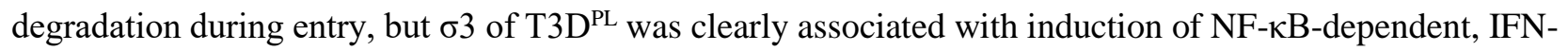
independent IMGs (Figure 6A, 6D). We therefore propose that the polymorphisms likely affect reovirus replication by modulating dsRNA-specific but IFN-independent cellular processes. For example, PKR was previously suggested to promote reovirus replication by terminating host translation outside of viral factories, leaving ribosomes to freely translate reovirus mRNAs at virus factories where host anti-viral factors were excluded (Desmet et al., 2014; Smith et al., 2006; Stanifer et al., 2017; Yue and Shatkin, 1997). We propose a model whereby $\mathrm{T}^{\mathrm{T}}{ }^{\mathrm{TD}}$ predominantly stimulates RIG-I and IRF3 signalling, with minimal NF- $\mathrm{B}$ activation, leading primarily to expression of IFNs and IFN-dependent genes (Figure 7E). Conversely, T3D ${ }^{\mathrm{PL}}$ activates 
another pathway such as PKR that stimulates strong NF-אB activity, but overcomes IRF3 activation through rapid

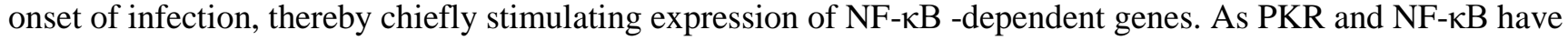
been previously associated with promotion of reovirus, for example by stimulating host protein shut-off, virus replication and apoptosis of infected cells (Hansberger et al., 2007; Knowlton et al., 2012; Pan et al., 2013; Pan et al., 2011; Smith et al., 2006; Yue and Shatkin, 1997), this model would favor T3D ${ }^{\mathrm{PL}}$. Future assessment of $\sigma 3$ dsRNA binding efficiencies and activities of additional signalling molecules such upstream of NF-kB, as PKR, will help resolve precisely how the three polymorphisms of $\sigma 3$ contribute to enhanced IFN-independent gene expression and replication of $\mathrm{T} 3 \mathrm{D}^{\mathrm{PL}}$.

Altogether this study provides the first comprehensive analysis of how strains of an oncolytic virus can affect oncolytic activity. We show that single amino acid changes drastically affect virus replication and therefore direct viral oncolysis. Increased virus replication and dissemination could also increase opportunities for the virus to stimulate anti-tumor immune responses. Moreover, we show that single amino acid changes also change the profile of immunomodulatory host genes expressed by infected cells, which could also affect recruitment of immune cells important for anti-tumor response. The data supports that strong attention should be paid to the genome and phenotypic characteristics of specific oncolytic virus strains, if to achieve best therapeutic value of oncolytic viruses.

\section{MATERIALS AND METHODS}

\section{Cell lines}

All cell lines were grown at $37^{\circ} \mathrm{C}$ at $5 \% \mathrm{CO} 2$ and all media was supplemented with $1 \mathrm{x}$ antibiotic antimycotics (A5955, Millipore Sigma). Except for NIH/3T3 media that was supplemented with 10\% NCS (N4637, Millipore Sigma), all other media was supplemented with 10\% FBS (F1051, Millipore Sigma). L929, NIH/3T3, H1299, ID8, HCT 116 and B16-F10 cell lines (Dr. Patrick Lee, Dalhousie University), Huh7.5 (Dr. Michael Houghton, University of Alberta), WT MEFs, RIG-I/MDA5 -/- MEFs (Dr. Michael Gale Jr, University of Washington) and BHK-21-BSR T7/5 (Dr. Ursula Buchholz, NIAID) were generous gifts. L929 cell line was cultured in MEM (M4655, Millipore Sigma) supplemented with 1× non-essential amino acids (M7145, Millipore Sigma) and 1mM sodium pyruvate (S8636, Millipore Sigma). L929 cell line in suspension were cultured in Joklik's modified MEM (pH 7.2) (M0518, Millipore Sigma) supplemented with 2g/L sodium bicarbonate (BP328, Fisher Scientific), 1.2g/L HEPES (BP310, Fisher Scientific), 1× non-essential amino acids (M7145, Millipore Sigma) and 1mM sodium pyruvate (S8636, Millipore Sigma). H1299, ID8 and T-47D cell lines were cultured in RPMI (R8758, Millipore Sigma). NIH/3T3, B16-F10, Huh7.5, WT MEFs, RIG-I/MDA5 -/- MEFs and BHK-21BSR T7/5 cell lines were cultured in DMEM (D5796, Millipore Sigma) supplemented with 1mM sodium pyruvate (S8636, Millipore Sigma). BHK-21-BSR T7/5 cell line was selected in media containing 1mg/ml G418 
(A1720, Millipore Sigma) every second passage. All cell lines were routinely assessed for mycoplasma

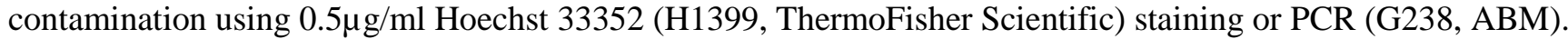

\section{Reovirus stocks}

Seed stock lysates of T1L, T2J, T3D-PL (Dr. Patrick Lee, Dalhousie University), T3D-KC (Dr. Kevin Coombs, University of Manitoba) and T3D-TD (Dr. Terence Dermody, University of Pittsburgh) were gifts in kind. T3D-ATCC (ATCC® VR-824) was purchased from American Type Culture Collection. Reovirus lysates were plaque purified and second or third passage L929 cell lysates were used as spinner culture inoculums.

\section{Plaque Purification}

Media was removed from confluent L929 cell monolayers in 6 well plates. Reovirus lysates were diluted in MEM (no additives) and 200 $\mu$ l of the dilution was added to each well. Virus inoculum was incubated for $1 \mathrm{hr}$ at $37^{\circ} \mathrm{C}$, while rocking gently every 5-10min. Virus inoculum was removed prior to addition of $3 \mathrm{ml}$ agar overlay which constituted an equal ratio of 2\% Agar and 2X MEM (Temin's modification, no phenol red, 11935046, ThermoFisher Scientific) supplemented with 20\% FBS, 2× non-essential amino acids (M7145, Millipore Sigma), 2mM sodium pyruvate (S8636, Millipore Sigma) and 2x antibiotic antimycotics (A5955, Millipore Sigma). The agar overlays were allowed to solidify for 30 minutes at room temperature and incubated at $37^{\circ} \mathrm{C}$ until plaques were clearly visible. Isolated plaques were selected and marked on the plate base using a sharpie. Using sterile cotton plugged glass pasteur pipets and rubber bulbs, agar plugs over selected plaques were carefully extracted, dispensed into $1.5 \mathrm{ml}$ microcentrifuge tubes with $200 \mu \mathrm{l}$ of MEM (no additives) and incubated overnight at $4^{\circ} \mathrm{C}$.

\section{Reovirus Passaging}

Following overnight incubation, plaque isolated agar plug in MEM was diluted in 1:1 in 100 $\mu 1$ MEM (no additives). Media was removed from 60-80\% confluent L929 cell monolayers in 6 well plates and $200 \mu$ l of diluted plaque isolated agar plug was added to the well. Following incubation for $1 \mathrm{hr}$ at $37^{\circ} \mathrm{C}$ (rocking gently every $5-10 \mathrm{~min}$ ), $2 \mathrm{ml}$ cell culture media was added to each well. Cell death was monitored microscopically every 12-24hrs. When more than $80 \%$ cell death was attained, each well was scraped using a sterile plastic cell lifter (08100240, Fisher Scientific) and transferred to $2 \mathrm{ml}$ microcentrifuge tube. This was referred to as passage 1 . Following 3 freeze/vortex/thaw cycles, virus concentration in passage 1 lysate was determined using plaque assay.

Lysate from passage 1 was serially diluted in MEM (no additives) such that a final dilution of MOI 1-3 (assuming $1.1 \times 107$ cells) in $1 \mathrm{ml}$ was attained. Media was removed from $60-80 \%$ confluent $(1.1 \times 107$ cells at $80 \%)$ L929 cells in a $55 \mathrm{~cm} 2$ dish and $1 \mathrm{ml}$ passage 1 lysate dilution was added. Following incubation for $1 \mathrm{hr}$ at $37^{\circ} \mathrm{C}$, while rocking gently every $5-10 \mathrm{~min}, 9 \mathrm{ml}$ cell culture media was added. Cell death was monitored microscopically every $12-24 \mathrm{hrs}$. When more than $80 \%$ cell death was attained, dish was scraped using a sterile plastic cell lifter (08100240, Fisher Scientific) and transferred to a $15 \mathrm{ml}$ conical centrifuge tube. This was referred to as passage 2. 
T3D-PL, T3D-KC and T3D-TD lysates from passage 2 or PL-RG, TD-RG, TD+PL-S4, TD+PL-M1, TD+PL-L3, PL+TD-S4, PL+TD-M1 and PL+TD-L3 lysates from passage 1, were serially diluted in MEM (no additives) such that a final dilution of MOI 1-3 (assuming $3 \times 107$ cells) in $6 \mathrm{ml}$ was attained. Media was removed from $2150 \mathrm{~cm} 2$ dishes with 60-80\% confluent (3×107 cells at 80\%) L929 cells and 3ml passage 2 lysate dilution was added to each dish. Following incubation for $1 \mathrm{hr}$ at $37^{\circ} \mathrm{C}$, while rocking gently every $5-10 \mathrm{~min}, 15 \mathrm{ml}$ cell culture media was added to each dish. Cell death was monitored microscopically every 12-24hrs. When more than $80 \%$ cell death was attained, both dishes were scraped using a sterile plastic cell lifter (08100240, Fisher Scientific), pooled and transferred to a $50 \mathrm{ml}$ conical centrifuge tube. Following 3 freeze/vortex/thaw cycles, virus concentration was determined using plaque assay. This passage was used as the inoculum for large scale spinner culture amplification.

\section{Large Scale Reovirus Amplification}

Four $150 \mathrm{~cm} 2$ dishes with $100 \%$ confluent L929 cell monolayers were detached using trypsin, were resuspended in 500ml JMEM culture media and added to sterile 2L flat bottom flask (10-035G, Fisher Scientific) with stir bar and aluminum foil cover. Flask containing cells was incubated at $37^{\circ} \mathrm{C}$ with low speed stirring in either a large chamber incubator or a water bath, neither of which had CO2 regulation. Cell density was monitored every $24 \mathrm{hrs}$ by removing a $1 \mathrm{ml}$ aliquot and performing a trypan blue cell count using either a haemocytometer or Biorad TC-20 cell counter. When cell density reached approximately $1 \times 106$ cells $/ \mathrm{ml}, 700 \mathrm{ml}$ JMEM culture media was added to the flask. Cell density was monitored every $12-24 \mathrm{hrs}$ and at approximately $1 \times 106 \mathrm{cells} / \mathrm{ml}(1.2 \times 109$ cells/1200ml/flask), virus lysates were diluted in MEM (no additives) and added to the flask at an MOI 1-3. Cell density and death was monitored every $12-24 \mathrm{hrs}$. At 50-70\% cell death, cells were collected by centrifugation at $1000 \mathrm{~g}$ for $15 \mathrm{~min}$ at $4^{\circ} \mathrm{C}$. The cell pellet from each flask was resuspended in $15 \mathrm{ml}$ homogenization buffer $(10 \mathrm{mM}$ Tris $\mathrm{pH} 7.4,250 \mathrm{mM} \mathrm{NaCl}, 10 \mathrm{mM} \beta$-mercaptoethanol, $1 \times$ protease inhibitor cocktail), transferred to a $50 \mathrm{ml}$ conical centrifuge tube and frozen at $-80^{\circ} \mathrm{C}$. Frozen cell pellets were thawed at $4^{\circ} \mathrm{C}$ and vortexed for $5 \mathrm{~min}$ on maximum speed. Per cell pellet, 10ml vertel XF (Dymar Chemicals Limited, ON, Canada) was added, vortexed for $5 \mathrm{~min}$ on maximum speed and probe sonicated for $30 \mathrm{sec}$ on maximum amplitude ensuring a homogenous emulsification. Following centrifugation at $4000 \mathrm{rpm}$ for $10 \mathrm{~min}$ at $4^{\circ} \mathrm{C}$, the top (reddish-pink color) layer was separated into a new 50ml conical centrifuge tube. Ten $\mathrm{ml}$ of vertel XF (Dymar Chemicals Limited, ON, Canada) was added to the top layer, vortexed for $5 \mathrm{~min}$ on maximum speed and probe sonicated for $30 \mathrm{sec}$ on maximum amplitude ensuring a homogenous emulsification. Following centrifugation at $4000 \mathrm{rpm}$ for $10 \mathrm{~min}$ at $4^{\circ} \mathrm{C}$, the top (reddish-pink color) layer was separated into a new $50 \mathrm{ml}$ conical centrifuge tube and layered on a $\mathrm{CsCl}$ gradient $(9 \mathrm{ml} 1.4 \mathrm{~g} / \mathrm{cc}, 9 \mathrm{ml} 1.2 \mathrm{~g} / \mathrm{cc})$ in SW28 ultra clear tubes. Tubes were topped up with PBS, weight balanced on a digital scale and centrifuged at $100,000 \mathrm{~g}$ at $4^{\circ} \mathrm{C}$ for $6-12 \mathrm{hrs}$. Reovirus separates into two white bands signifying top component empty virions and bottom layer full virions. The bottom band was extracted using a needle (19$22 \mathrm{Ga}$ ) and syringe (5-10ml) and loaded into dialysis tubing (10-20KDa). Extracted virus was dialyzed in dialysis buffer (150mM NaCl, $10 \mathrm{mM} \mathrm{MgCl} 2,10 \mathrm{mM}$ Tris pH 7.4) with 3 buffer changes, the first after 1-3hrs, the second 
after 3-6hrs and third after 6-12hrs. The dialyzed virus was transferred into a $15 \mathrm{ml}$ conical centrifuge tube and allowed any precipitate to settle at $4^{\circ} \mathrm{C}$ for $12 \mathrm{hrs}$. The supernatant was aliquoted into $1.5 \mathrm{ml}$ microcentrifuge tubes and stored at $4^{\circ} \mathrm{C}$. Virus concentration was determined using plaque assay

\section{Reovirus plaque assays}

Reovirus dilutions were added to $100 \%$ confluent L929 cells for $1 \mathrm{hr}$ at $37^{\circ} \mathrm{C}$ with gentle rocking every 10 minutes, followed by addition of agar overlay (1:1 ratio of $2 \%$ agar $2 \times$ JMEM media). Overlays were allowed to solidify for 30 minutes at room temperature and incubated at $37^{\circ} \mathrm{C}$. When plaques became visible (3-7 days post infection), 4\% formaldehyde solution (33314, Alfa Aesar) was added to the overlay for 30 minutes. Formaldehyde was discarded, agar overlays were carefully scooped out and cells were further fixed with methanol for $5 \mathrm{~min}$. Methanol was discarded, and cells were stained with crystal violet solution (1\% crystal violet (C581, Fisher Scientific) in 50\% ethanol and 50\% water) for 10min and rinsed with water. For cell lines other than L929, after methanol staining, plaques were stained using immunocytochemistry with rabbit anti-reovirus pAb. Plaques were scanned on the ImageQuant LAS4010 imager (GE Healthcare Life Sciences), and plaque area was measured using ImageQuant TL software (GE Healthcare Life Sciences).

\section{Virus Infections}

Reovirus (purified stock, cell lysate, plaque isolated agar plug) was diluted in MEM (no additives). Cell culture media was aspirated from 90-100\% confluent cell monolayers. Virus inoculum was added to each well and incubated for $1 \mathrm{hr}$ with gentle rocking every 5-10min to allow for virus adsorption. The virus inoculum was aspirated and the monolayer was washed once with MEM (no additives). Cell culture media was added and the incubated at $37^{\circ} \mathrm{C}$. Note that a "wash" in the above protocol constitutes addition of reagent, gently rocking back and forth twice and aspiration of reagent.

When samples were assessed and or standardized for virus binding, cells (90-100\% confluent cell monolayers) were pre-incubated at $4^{\circ} \mathrm{C}$ for $30 \mathrm{~min}$. Cell culture media was aspirated, virus inoculum was added to each well and incubated at $4{ }^{\circ} \mathrm{C}$ for $1 \mathrm{hr}$ with gentle rocking every $5-10 \mathrm{~min}$ to allow for virus adsorption. The virus inoculum was aspirated and the monolayer was washed twice with ice-cold MEM (no additives). Cell culture media was added and the incubated at $37^{\circ} \mathrm{C}$. During virus adsorption, the cell plates, virus inoculum and MEM (no additives) were always kept on ice or the $4^{\circ} \mathrm{C}$ fridge. Note that a "wash" in the above protocol constitutes addition of reagent, gently rocking back and forth twice and aspiration of reagent.

\section{Immunocytochemistry}

Colorimetric infectivity assay: Following reovirus infection (Virus infection or Reovirus plaque assay protocols), cell culture media was aspirated, or agar overlays were removed, and cell monolayers were washed once with PBS. Cells were fixed with methanol or $4 \%$ paraformaldehyde, washed twice with PBS, and incubated with blocking buffer (3\% BSA/PBS/0.1\% Triton X-100) for 1 hour at room temperature. Blocking buffer was 
981 aspirated and primary antibody (rabbit anti-reovirus $\mathrm{pAb}$ ) diluted in blocking buffer for a final concentration of $9821: 10,000$ was added and incubated overnight at $4{ }^{\circ} \mathrm{C}$. Samples were washed $3 \times 5$ minutes with PBS/0.1\% Triton

983 X-100. Secondary antibody diluted in blocking buffer (goat anti-rabbit AP) was added and incubated for 1-3hrs at 984 room temperature. Samples were washed $3 \times 5$ minutes with PBS/0.1\% Triton X-100. NBT/BCIP substrate diluted 985 in AP buffer $(100 \mathrm{mM}$ Tris $\mathrm{pH} 9.5,100 \mathrm{mM} \mathrm{NaCl}, 5 \mathrm{mM} \mathrm{MgCl} 2)$ was added and infected cells were monitored for 986 black/purple staining using microscopy. 100× NBT/BCIP substrate stocks were diluted as follows in 987 dimethylformamide (DMF) (D4551, Millipore Sigma): NBT (30mg/1ml) (B8503, Millipore Sigma), BCIP 988 (15mg/1ml) (N6639, Millipore Sigma). When infected cells had stained a dark purple color, substrate was 989 removed and reactions were stopped by adding PBS/5mM EDTA. Note that a "wash" in the above protocol 990 constitutes addition of reagent, gently rocking back and forth twice and aspiration of reagent.

\section{Fluorescence infectivity assay}

Following reovirus infection (Virus infection protocol), cell culture media was aspirated, and cell monolayers were washed once with PBS. Cells were fixed with $4 \%$ paraformaldehyde, washed twice with PBS, and incubated with blocking buffer (3\% BSA/PBS/0.1\% Triton X-100) for 1 hour at room temperature. Blocking buffer was aspirated and primary antibody (rabbit anti-reovirus pAb) diluted in blocking buffer for a final concentration of 1:10,000 was added and incubated overnight at $4^{\circ} \mathrm{C}$. Samples were washed $3 \times 5$ minutes with PBS/0.1\% Triton X-100. Secondary antibody diluted in blocking buffer (goat anti-rabbit Alexa Fluor 488) was added and incubated for 1-3hrs at room temperature. Samples were washed $3 \times 5$ minutes with PBS/0.1\% Triton X-100. Nuclei were stained with $0.5 \mu \mathrm{g} / \mathrm{ml}$ Hoechst 33352 (H1399, ThermoFisher Scientific) for 15min and stained samples were visualized and imaged using EVOS FL Auto Cell Imaging System (ThermoFisher Scientific). Note that a "wash" in the above protocol constitutes addition of reagent, gently rocking back and forth twice and aspiration of reagent.

\section{Immunofluorescence}

Cells were seeded on \#1.5 thickness coverslips. Following reovirus infection (Virus infection protocol), cell culture media was aspirated, and cell monolayers were washed once with PBS. Cells were fixed with $4 \%$ paraformaldehyde, washed twice with PBS, and incubated with blocking buffer (3\% BSA/PBS/0.1\% Triton X100) for 1 hour at room temperature. Blocking buffer was aspirated and primary antibody (mouse anti- $\sigma \mathrm{NS} 3 \mathrm{E} 10$ conjugated to Alexa Fluor 568, mouse-anti- $\sigma 3$ 10G10 conjugated to Alexa Fluor 647, rabbit anti- $\mu 2 \mathrm{pAb}$ ) diluted in blocking buffer was added and incubated overnight at $4^{\circ} \mathrm{C}$. Primary mAbs mouse anti- $\sigma \mathrm{NS}$ and mouse-anti- $\sigma 3$ 10G10 were conjugated to Alexa Fluor 568 and Alexa Fluor 647, respectively, using APEX antibody labeling kits as per manufacturer's protocol (ThermoFisher Scientific). Samples were washed $3 \times 5$ minutes with PBS/0.1\% Triton X-100. Secondary antibody diluted in blocking buffer (goat anti-rabbit Alexa Fluor 488) was added and incubated for $1-3 \mathrm{hrs}$ at room temperature. Samples were washed $3 \times 5$ minutes with PBS/0.1\% Triton X-100.

1014 Nuclei were stained with $0.5 \mu \mathrm{g} / \mathrm{ml}$ Hoechst 33352 (H1399, ThermoFisher Scientific) for 15min. Coverslips were 
1015 mounted on microscope slides using 10 $\mu 1$ SlowFade Diamond (S36967, ThermoFisher Scientific) and visualized 1016 using an Olympus IX-81 spinning disk confocal microscope (Quorum Technologies). Note that a "wash" in the 1017 above protocol constitutes addition of reagent, gently rocking back and forth twice and aspiration of reagent.

\section{Flow cytometry}

Cell culture media was aspirated and cell monolayers were rinsed with PBS (1ml/12well). PBS was discarded and trypsin $(200 \mu 1 / 12$ well $)$ was added and incubated until cells detached. Tryspin in detached cells was quenched with cell culture media ( $1 \mathrm{ml} / 12 \mathrm{well})$. Volumes of PBS, trypsin and cell culture media were scaled up/down according to well size. Detached cells were centrifuged and washed with $1 \mathrm{ml}$ PBS. Refer to Table 1.1 for reagent volumes. PBS was aspirated, cell pellet was gently resuspended in $4 \%$ paraformaldehyde and incubated at $4^{\circ} \mathrm{C}$ for $30 \mathrm{~min}$. Samples were centrifuged and washed with $1 \mathrm{ml} \mathrm{PBS} / 0.1 \%$ Triton X-100 (wash buffer). Wash buffer was aspirated, cell pellet was gently resuspended in 3\% BSA/wash buffer (blocking buffer) and incubated at 1 hour at room temperature for 30min. Samples were spiked with primary antibody (rabbit antireovirus pAb) diluted in blocking buffer for a final concentration of 1:10,000 and incubated overnight at $4^{\circ} \mathrm{C}$. Samples were centrifuged and washed twice with $1 \mathrm{ml}$ wash buffer. Wash buffer was aspirated, and cell pellet was gently resuspended in secondary antibody diluted in blocking buffer (goat anti-rabbit Alexa Fluor 647 at 1:1:2,000 dilution) and incubated for 1-3hrs at room temperature. Samples were centrifuged and washed twice with $1 \mathrm{ml}$

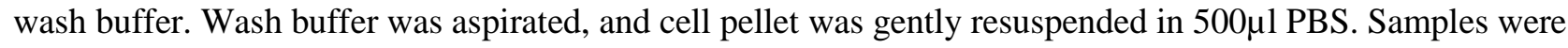
processed using a FACSCanto (BD Biosciences) and data was analyzed using FSC Express 5 (De Novo Software). Total cells were gated using FSC-A and SSC-A, while single cells were gated using FSC-A and FSCH. A minimum of 10,000 total cells were collected for each sample. Note that a "wash" in the above protocol constitutes aspiration of supernatant, resuspension of pellet and centrifugation. Prior to fixation, cells were centrifuged at $500 \mathrm{~g}$ for $5 \mathrm{~min}$ at $4{ }^{\circ} \mathrm{C}$. After fixation, cells were centrifuged at $1,000 \mathrm{~g}$ for $5 \mathrm{~min}$ at $4{ }^{\circ} \mathrm{C}$.

\section{RNA extraction and RT-PCR}

Cells were lysed in TRI Reagent ${ }^{\circledR}$ (T9424, Millipore Sigma) and the aqueous phase was separated following chloroform extraction as per TRI Reagent ${ }^{\circledR}$ protocol. Ethanol was mixed with the aqueous phase and RNA isolation protocol was continued as per GenElute Mammalian Total RNA Miniprep kit (RTN350, Millipore Sigma) protocol. RNA was eluted using RNAse free water and total RNA was quantified using Biodrop DUO (Biodrop). Using $1 \mu \mathrm{g}$ RNA per $20 \mu 1$ reaction, cDNA synthesis was performed with random primers (48190011, 1043 ThermoFisher Scientific) and M-MLV reverse transcriptase (28025013, ThermoFisher Scientific) as per M-MLV 1044 reverse transcriptase protocol. Following a 1/8 cDNA dilution, RT-PCR reactions were executed as per SsoFast 1045 EvaGreen Supermix (1725204, Bio-Rad) protocol using a CFX96 system (Bio-Rad).

\section{Western blot analysis}



CA-630 (NP-40), 0.5\% sodium deoxycholate) supplemented with protease inhibitor cocktail (11873580001, Roche) and phosphatase inhibitors (1 $\mathrm{mM}$ sodium orthovanadate, $10 \mathrm{mM} \beta$-glycerophosphate, $50 \mathrm{mM}$ sodium 1050 fluoride). For each 12 well, $100 \mu 1$ lysis buffer was used and volume was scaled up/down according to well size. 1051 Following addition of $5 \times$ protein sample buffer (250mM Tris pH 6.8, 5\% SDS, 45\% glycerol, 9\% $\beta$ 1052 mercaptoethanol, $0.01 \%$ bromophenol blue) for a final $1 \times$ protein sample buffer, samples were heated for $5 \mathrm{~min}$ at $1053100^{\circ} \mathrm{C}$ and loaded onto SDS-acrylamide gels. After SDS-PAGE, separated proteins were transferred onto 1054 nitrocellulose membranes using the Trans-Blot ${ }^{\circledR}$ Turbo ${ }^{\text {TM }}$ Transfer System (Bio-Rad). Membranes were blocked 1055 with 3\% BSA/TBS-T (blocking buffer) and incubated with primary and secondary antibodies (5ml blocking 1056 buffer, primary and secondary antibody per mini $(7 \times 8.5 \mathrm{~cm})$ membrane). Membranes were washed $3 \times 5 \mathrm{~min}$ with 1057 TBS-T after primary and secondary antibodies. (10ml wash buffer per mini $(7 \times 8.5 \mathrm{~cm})$ membrane). Membranes 1058 with HRP-conjugated antibodies were exposed to ECL Plus Western Blotting Substrate (32132, ThermoFisher 1059 Scientific) $(2 \mathrm{ml}$ substrate per mini $(7 \times 8.5 \mathrm{~cm})$ membrane) for $2 \mathrm{~min}$ at room temperature. Prior to visualization, 1060 membranes were rinsed with TBT. Membranes were visualized using ImageQuant LAS4010 imager (GE 1061 Healthcare Life Sciences), and densitometric analysis was performed by using ImageQuant TL software (GE 1062 Healthcare Life Sciences). Note that a "wash" in the above protocol constitutes addition of reagent, gently rocking 1063 back and forth twice and removal of reagent.

\section{Double-stranded genomic reovirus RNA visualization}

RNA was extracted from $\mathrm{CsCl}$ purified reovius preparations $(\sim 1 \times 1010$ virus particles $)$ using TRI Reagent LS (T3934, Millipore Sigma) as per manufacturer's protocol. Purified RNA was diluted in 4× Laemmli sample buffer (1610747, Bio-Rad), and separated on an 8\% SDS-acrylamide gel for 22 hours at $6 \mathrm{~mA}$ (per gel) at $4^{\circ} \mathrm{C}$. RNA was stained using ethidium bromide $(0.5 \mu \mathrm{g} / \mathrm{mL})$ for $1 \mathrm{hr}$ at room temperature, gels were destained with TAE (40mM Tris, $5 \mathrm{mM}$ sodium acetate, $1 \mathrm{mM}$ EDTA [pH 7.5]) for $2 \mathrm{hrs}$ at room temperature and gels were imaged on ImageQuant LAS4010 imager (GE Healthcare Life Sciences).

\section{Flow cytometry binding assay}

L929 cells were detached with CellStripper (Corning), diluted and aliquoted $\left(5 \times 10^{10}\right.$ cells $\left./ \mathrm{sample} / \mathrm{ml}\right)$, pre-chilled at $4^{\circ} \mathrm{C}$ for $30 \mathrm{~min}$ and bound with normalized virions at $4^{\circ} \mathrm{C}$ for 1 hour. Unbound virus was washed off and cell-bound virus was quantified using flow cytometry following sequential binding with rabbit anti-reovirus pAb and goat anti-rabbit Alexa Fluor 488. After secondary antibody staining, samples were fixed with 4\% paraformaldehyde for 30 minutes at $4^{\circ} \mathrm{C}$. Following a wash with PBS to remove $4 \%$ paraformaldehyde, cell pellet was gently resuspended in 500 $\mu 1$ PBS. Samples were processed using a FACSCanto (BD Biosciences) and data was analyzed using FSC Express 5 (De Novo Software). Total cells were gated using FSC-A and SSC-A, while single cells were gated using FSC-A and FSC-H. A minimum of 10,000 total cells were collected for each sample. 
1081 the diluent and wash buffer. Prior to fixation, cells were centrifuged at $500 \mathrm{~g}$ for $5 \mathrm{~min}$ at $4^{\circ} \mathrm{C}$. After fixation, cells 1082 were centrifuged at $1,000 \mathrm{~g}$ for $5 \mathrm{~min}$ at $4{ }^{\circ} \mathrm{C}$. Two wash steps were performed following virus binding and primary 1083 and secondary antibody incubation. Note that a "wash" in the above protocol constitutes centrifugation, aspiration 1084 of supernatant, resuspension of pellet in wash buffer, centrifugation and aspiration of wash buffer.

\section{Flow cytometry cell death assay}

Early apoptosis and cell death were measured by Annexin V and 7-AAD staining precisely as previously described (Shmulevitz and Lee, 2012), prior to processing with FACSCanto (BD Biosciences) and analysis with FSC Express 5 (De Novo Software). Identical gates were applied to all samples of a given experiment, and were applied based on discrimination of the live (Annexin V and 7-AAD negative) population.

Agarose gel separation of reovirus

Purified virions $\left(5 \times 10^{10}\right.$ virus particles) diluted in 5\% Ficoll and $0.05 \%$ bromophenol blue were run on a $0.7 \%$ agarose gel in TAE buffer (40mM Tris, $5 \mathrm{mM}$ sodium acetate, $1 \mathrm{mM}$ EDTA [pH 7.5]) for 12 hours at room temperature, stained with Imperial total protein stain for $2 \mathrm{hrs}$ at room temperature, destained overnight in TAE buffer and visualized on the ImageQuant LAS4010 imager (GE Healthcare Life Sciences)

\section{In-vitro reovirus core transcription assay}

Reovirus cores were generated by incubating purified virions with chymotrypsin (CHT) (C3142, Millipore Sigma) at $14 \mu \mathrm{g} / \mathrm{ml}$ for 2 hours at 37C. CHT digest reactions were halted by adding protease inhibitor cocktail (11873580001, Roche) and incubating at $4^{\circ} \mathrm{C}$. Reovirus cores were pelleted by centrifugation at $100,000 \mathrm{~g}$ for 2 hours at $4^{\circ} \mathrm{C}$, and reconstituted in $100 \mathrm{mM}$ Tris $\mathrm{pH} 8$. Transcription reactions were assembled on ice to include 100mM Tris $\mathrm{pH} 8,10 \mathrm{mM} \mathrm{MgCl} 2,100 \mu \mathrm{g} / \mathrm{ml}$ pyruvate kinase (P7768, Millipore Sigma), 3.3mM phosphoenol pyruvate (P0564, Millipore Sigma), 0.32 units/ $\mu 1$ RNaseOUT (10777019, ThermoFisher Scientific), $0.2 \mathrm{mM}$ rATP, $0.2 \mathrm{mM}$ rCTP, $0.2 \mathrm{mM}$ rGTP, $0.2 \mathrm{mM}$ rUTP and $1 \times 1011$ virus cores per $150 \mu 1$ reaction. Negative control samples were set up without rATP. Reactions were allowed to proceed at $40^{\circ} \mathrm{C}$ and at indicated timepoints, $40 \mu 1$ transcription aliquots were added to 400ul TRI Reagent LS (T3934, Millipore Sigma) containing 3ng of mouse GAPDH RNA (in-vitro transcribed using T7 RiboMAX (Promega), as per manufacturer's protocol). Using 10 $\mathrm{gg}$ glycogen (R0551, ThermoFisher Scientific) as a carrier according to manufacturer's instructions, RNA was purified, converted to cDNA (28025013, ThermoFisher Scientific) using random primers (48190011, ThermoFisher Scientific) and RT-PCR (1725204, Bio-Rad) performed to quantify reovirus S4, reovirus M2 and mouse GAPDH. Values were standardized to GAPDH and plotted relative to 0 hours post transcription. For high throughput transcription assays, reactions were set up similar, aliquoted into RT-PCR 96well tubes and spiked with 10× final SYBR Green II (S7564, ThermoFisher Scientific). Relative fluorescence was measured at 5-minute intervals for 2 hours in a CFX96 system (Bio-Rad).

\section{In-vivo oncolysis experiments}


Fifteen six-week-old female C57BL/6 mice (Charles River Laboratory, Montreal, Canada) were injected subcutaneously in the hind flank with $1 \times 10^{5}$ B16-F10 cells per 100ul per mouse. When tumors become palpable (14 days post B16-F10 cell injection), a total of 3 equivalent doses $\left(5 \times 10^{8} \mathrm{pfu} / 100 \mathrm{ul}\right)$ were inoculated intratumorally at 2-day intervals. The negative control group was inoculated with PBS. Tumor volumes were measured in 3 dimensions using digital calipers every 2 days. Mice were sacrificed when either tumors became too large (200mm3), and/or tumors had visible signs of necrosis and ulceration. All experiments were done in accordance with guidelines on humane handling of experimental animals as established by the Canadian Council on Animal Care.

\section{T3D-PL and T3D-TD reverse genetics system}

L929 cells in 6well plates were infected with T3D-PL or T3D-TD at an MOI of 3 and cell lysates were collected at 24hpi in TRI Reagent ${ }^{\circledR}$ (T9424, Millipore Sigma). Total RNA was purified using as per TRI Reagent ${ }^{\circledR}$ protocol. Using $1 \mu \mathrm{g}$ RNA per $20 \mu 1$ reaction, cDNA synthesis was performed with pooled forward and reverse gene specific primers for all 10 genes, and M-MLV reverse transcriptase (28025013, ThermoFisher Scientific) as per M-MLV reverse transcriptase protocol. Using cDNA $(2 \mu \mathrm{l})$ as a template, each gene segment was PCR amplified (100 $\mu$ l total reaction) using a gene specific primer set with iProof High Fidelity PCR kit (BioRad), as per manufacturer's protocol. PCR products were purified using QIAquick PCR Purification Kit (28106, Qiagen). S1, M1, M2, M3, L1, L2 and L3 gene segments were gel extracted using PureLink ${ }^{\mathrm{TM}}$ Quick Gel Extraction Kit (K210012, Fisher Scientific). All purified PCR products were double digested with CpoI (FD0744, ThermoFisher Scientific) and NotI (FD0594, ThermoFisher Scientific) and purified using QIAquick PCR Purification Kit (28106, Qiagen).

Vector pBacT7-S1T3D (addgene plasmid \#33282) was double digested with CpoI (FD0744, ThermoFisher Scientific) and NotI (FD0594, ThermoFisher Scientific), and vector backbone (5716bp fragment) was gel extracted using PureLink ${ }^{\mathrm{TM}}$ Quick Gel Extraction Kit (K210012, Fisher Scientific). Gel extracted vector 1137 backbone was treated using alkaline phosphatase (EF0654, ThermoFisher Scientific) as per manufacturer's 1138 protocol, and purified using QIAquick PCR Purification Kit (28106, Qiagen). ThermoFisher Scientific) in a 20ul reaction as per manufacturer's protocol. Ligation reactions were transformed into Stbl3 chemically competent bacteria and transformants were selected on LB/agar/carbnecillin $(100 \mu \mathrm{g} / \mathrm{ml})$

1142 plates. For each gene, 8 bacteria colonies were selected for colony PCR validation. Positive bacteria clones were 1143 inoculated into $50 \mathrm{ml} \mathrm{LB} /$ carbnecillin $(100 \mu \mathrm{g} / \mathrm{ml})$ culture for amplification and midiprep plasmid purification 1144 using GenElute ${ }^{\mathrm{TM}}$ HP Plasmid Midiprep Kit (NA0200, Millipore Sigma). All plasmids except T3D-L1 were 1145 amplified at $37^{\circ} \mathrm{C}$ for $14-16 \mathrm{hrs}$. T3D-L1 plasmids were amplified at $30^{\circ} \mathrm{C}$ for $24-28 \mathrm{hrs}$. All plasmids were sequenced to validate inserted gene sequences. 


\section{Reassortant reovirus generation}

BHK-21-BSR T7/5 cells were seeded in 12 well plates and transfected when cells reached 80-90\% confluency. Volumes below are for a single 12 well reaction: $0.35 \mu \mathrm{g}$ of each of 10 reovirus genes and $0.8 \mu \mathrm{g}$ C3P 3 (T7 RNA Polymerase linked with (G4S)4 to NP8686 African Swine Fever Virus capping enzyme) were diluted in 50 $\mu 1$ Opti-MEM (31985070, ThermoFisher Scientific). 11 $\mu 1$ TransIT®-LT1 (MIR2300, Mirus Bio) was diluted in $50 \mu 1$ Opti-MEM and incubated for 10 minutes at room temperature. LT1 and plasmid dilutions were combined and incubated for 20 minutes at room temperature. Cell media was replaced with $500 \mu l$ fresh media and transfection mixture was added dropwise to each well. Following a $16-18$ hour incubation at $37^{\circ} \mathrm{C}$, media was replaced with $750 \mu \mathrm{l}$ fresh media and incubated for an additional 3-5days. Lysates were scraped, collected and plaqued on L929 cells following three freeze/thaw cycles.

Lentivirus production and generation of stable cell lines expressing shRIG-I, shEMPTY or shSCR for microarray and qRT-PCR experiments in supplemental figures.

Lentivirus was generated as per MISSION® Lentiviral Packaging Mix protocol (SHP001, Millipore Sigma) using 6 well plates. Lentivirus containing supernatants were collected every $12 \mathrm{hrs}$ for $72 \mathrm{hrs}$. Pooled lentivirus collections were centrifuged at $600 \mathrm{~g}$ for $10 \mathrm{~min}$ at $4^{\circ} \mathrm{C}$, and the supernatant was $0.45 \mu \mathrm{m}$ filter sterilized, aliquoted and stored at $-80^{\circ} \mathrm{C}$.

Lentivirus stock was diluted in cell culture media supplemented with sequabrene (S2667, Millipore Sigma) at $8 \mu \mathrm{g} / \mathrm{ml}$ final. Dilutions ranged from $1 / 3$ to $1 / 36$. Media was aspirated from 12 well plates with cells at $50-60 \%$ cell confluency, $500 \mu 1$ lentivirus dilution was added to each well and allowed to incubate at $37^{\circ} \mathrm{C}$ for 12hrs. Lentivirus was aspirated and replaced with cell culture media for an additional 12-24hrs until cells became confluent. At $100 \%$ confluency, cells were trypsinized, transferred to a 6 well plate and incubated at $37^{\circ} \mathrm{C}$ for and cell death was monitored by microscopy. Cells not treated with lentivirus but exposed to puromycin supplemented media were used to determine when untransduced cells were killed. When lentivirus transduced cells reached $90-100 \%$ confluency, cells, were trypsinized and transferred to $55 \mathrm{~cm} 2$ flask with media supplemented with puromycin. Lowest lentivirus dilution with minimal (0-10\%) cell death was selected for further assessment. Puromycin selection was performed every second passage.

\section{Microarray Analysis}

NIH/3T3 cells transduced with lentivirus generated from either empty plko.1 vector (shEMPTY) or plko. 1 containing shRNA targeting mouse RIG-I (shRIG-I) were selected with $2 \mu \mathrm{g} / \mathrm{ml}$ puromycin for seven days, followed by $\mathrm{T} 3 \mathrm{D}^{\mathrm{PL}}$ infection at the dose empirically determined to cause $70 \%$ reovirus-antigen-positive cells on

1179 NIH/3T3 shEMPTY cells by immunofluorescence with anti-reovirus polyclonal antibodies. At 12 hpi, RNA was 1180 extracted from reovirus infected and mock infected samples and sent for microarray processing at MOgene LC 1181 (1005 North Warson Road, Suite 403, St. Louis, MO 63132 USA) using the Agilent Mouse SurePrint G3 GE, 
1182 8x60k - 028005 array type. Raw microarray image files were extracted with Agilent's Gene Expression

1183 Microarray Software, GeneSpring GX and is accessible from NCBI GEO DataSet \# GSE35521. Data sets for 1184 untreated and LPS treated, WT, cRel-/- p65-/- and IFNAR-/- MEFs were obtained from NCBI GEO DataSet \# 1185 GSE35521 (Cheng C.S. et al, 2011). For each data set, the normalized microarray data along with gene and 1186 sample information was input into the pheatmap package in R. Hierarchical clustering of data was performed with 1187 "Euclidean distance" as the measure of dissimilarity. Heatmaps were generated using pheatmap and the associated 1188 dendrogram clusters were extracted for further analysis.

\section{ACKNOWLEDGEMENTS}

This work was funded by a Canadian Institutes of Health Research (CIHR) project grant MS, a project grant from the Li Ka Shing Institute of Virology to MS, a salary award to MS from the Canada Research Chairs (CRC) and infrastructure support from Canada Foundation for Innovation (CFI). AM received scholarships from the Alberta Cancer Foundation (ACF) and the Faculty of Medicine and Dentistry. We would like to thank Kevin Coombs at the University of Manitoba and Terrence Dermody at University of Pittsburgh for generously sharing their laboratory reovirus T3D virus lysates, Aja Reiger at the Faculty of Medicine and Dentistry flow cytometry facility, Rob Maranchuk at the Li Ka Shing Institute of Virology RNAi screening facility and Stephen Ogg at the Faculty of Medicine \& Dentistry cell imaging centre, for valuable technical advice, training and support. These core facilities at the University of Alberta receive financial support from the Faculty of Medicine and Dentistry

\section{AUTHOR CONTRIBUTIONS}

1204 Conceptualization, A.M. and M.S.; Methodology, A.M and M.S.; Investigation, A.M., D.R.C., P.K. and M.S.; 1205 Writing - Original Draft, A.M. and M.S.; Writing -Review \& Editing, A.M., J.R.S. and M.S.; Funding 1206 Acquisition, M.S.; Resources, M.E.V and C.K.B.; Supervision, M.S., J.R.S., S.A.G.

1209 MS filed a provisional patent for the modified reovirus as an improved oncolytic vector (Serial No. 62/642,881). 


\section{REFERENCES}

1213 Acs, G., Klett, H., Schonberg, M., Christman, J., Levin, D.H., and Silverstein, S.C. (1971). Mechanism of reovirus 1214 double-stranded ribonucleic acid synthesis in vivo and in vitro. J Virol 8, 684-689.

1215 Adler, A.J., Mittal, P., Ryan, J.M., Zhou, B., Wasser, J.S., and Vella, A.T. (2017). Cytokines and metabolic factors 1216 regulate tumoricidal T-cell function during cancer immunotherapy. Immunotherapy 9, 71-82.

1217 Alain, T., Hirasawa, K., Pon, K.J., Nishikawa, S.G., Urbanski, S.J., Auer, Y., Luider, J., Martin, A., Johnston, R.N., 1218 Janowska-Wieczorek, A., et al. (2002). Reovirus therapy of lymphoid malignancies. Blood 100, 4146-4153.

1219 Amgen Inc (2018). KEYNOTE-034. In Clinical Trials.

1220 Barton, E.S., Forrest, J.C., Connolly, J.L., Chappell, J.D., Liu, Y., Schnell, F.J., Nusrat, A., Parkos, C.A., and Dermody, 1221 T.S. (2001). Junction adhesion molecule is a receptor for reovirus. Cell 104, 441-451.

1222 Beattie, E., Denzler, K.L., Tartaglia, J., Perkus, M.E., Paoletti, E., and Jacobs, B.L. (1995). Reversal of the 1223 interferon-sensitive phenotype of a vaccinia virus lacking E3L by expression of the reovirus S4 gene. J Virol 69, 1224 499-505.

1225

1226

1227

1228

1229

1230

1231

1232

1233

1234

1235

1236

1237

1238

1239

1240

1241

1242

1243

1244

1245

1246

1247

1248

1249

1250

1251

1252
Becker, M.M., Peters, T.R., and Dermody, T.S. (2003). Reovirus sigma NS and mu NS proteins form cytoplasmic inclusion structures in the absence of viral infection. J Virol 77, 5948-5963.

Bergeron, J., Mabrouk, T., Garzon, S., and Lemay, G. (1998). Characterization of the thermosensitive ts453 reovirus mutant: increased dsRNA binding of sigma 3 protein correlates with interferon resistance. Virology 246, 199-210.

Bisaillon, M., Bergeron, J., and Lemay, G. (1997). Characterization of the nucleoside triphosphate phosphohydrolase and helicase activities of the reovirus lambda1 protein. J Biol Chem 272, 18298-18303.

Bokiej, M., Ogden, K.M., Ikizler, M., Reiter, D.M., Stehle, T., and Dermody, T.S. (2012). Optimum length and flexibility of reovirus attachment protein sigma1 are required for efficient viral infection. J Virol 86, 1027010280.

Bonjardim, C.A. (2017). Viral exploitation of the MEK/ERK pathway - A tale of vaccinia virus and other viruses. Virology 507, 267-275.

Broering, T.J., Arnold, M.M., Miller, C.L., Hurt, J.A., Joyce, P.L., and Nibert, M.L. (2005). Carboxyl-proximal regions of reovirus nonstructural protein muNS necessary and sufficient for forming factory-like inclusions. J Virol 79, 6194-6206.

Broering, T.J., Kim, J., Miller, C.L., Piggott, C.D., Dinoso, J.B., Nibert, M.L., and Parker, J.S. (2004). Reovirus nonstructural protein mu NS recruits viral core surface proteins and entering core particles to factory-like inclusions. J Virol 78, 1882-1892.

Broering, T.J., McCutcheon, A.M., Centonze, V.E., and Nibert, M.L. (2000a). Reovirus nonstructural protein muNS binds to core particles but does not inhibit their transcription and capping activities. J Virol 74, 5516-5524.

Broering, T.J., McCutcheon, A.M., Centonze, V.E., and Nibert, M.L. (2000b). Reovirus nonstructural protein muNS binds to core particles but does not inhibit their transcription and capping activities. J Virol 74, 5516-5524.

Broering, T.J., Parker, J.S., Joyce, P.L., Kim, J., and Nibert, M.L. (2002). Mammalian reovirus nonstructural protein microNS forms large inclusions and colocalizes with reovirus microtubule-associated protein micro 2 in transfected cells. J Virol 76, 8285-8297.

Campbell, J.A., Schelling, P., Wetzel, J.D., Johnson, E.M., Forrest, J.C., Wilson, G.A., Aurrand-Lions, M., Imhof, B.A., Stehle, T., and Dermody, T.S. (2005). Junctional adhesion molecule a serves as a receptor for prototype and field-isolate strains of mammalian reovirus. J Virol 79, 7967-7978. 
Carlson, L.E., Bultz, B.D., and Morris, D.G. (2005). Individualized quality of life, standardized quality of life, and distress in patients undergoing a phase I trial of the novel therapeutic Reolysin (reovirus). Health Qual Life Outcomes 3, 7.

Chakrabarty, R., Tran, H., Fortin, Y., Yu, Z., Shen, S.H., Kolman, J., Onions, D., Voyer, R., Hagerman, A., Serl, S., et al. (2014). Evaluation of homogeneity and genetic stability of REOLYSIN (pelareorep) by complete genome sequencing of reovirus after large scale production. Appl Microbiol Biotechnol 98, 1763-1770.

Chandran, K., Walker, S.B., Chen, Y., Contreras, C.M., Schiff, L.A., Baker, T.S., and Nibert, M.L. (1999). In vitro recoating of reovirus cores with baculovirus-expressed outer-capsid proteins mu1 and sigma3. J Virol 73, 39413950.

Chang, C.T., and Zweerink, H.J. (1971). Fate of parental reovirus in infected cell. Virology 46, 544-555.

Cheng, C.S., Behar, M.S., Suryawanshi, G.W., Feldman, K.E., Spreafico, R., and Hoffmann, A. (2017). Iterative Modeling Reveals Evidence of Sequential Transcriptional Control Mechanisms. Cell Syst 4, 330-343 e335.

Clements, D.R., Sterea, A.M., Kim, Y., Helson, E., Dean, C.A., Nunokawa, A., Coyle, K.M., Sharif, T., Marcato, P., Gujar, S.A., et al. (2015). Newly recruited CD11b+, GR-1+, Ly6C(high) myeloid cells augment tumor-associated immunosuppression immediately following the therapeutic administration of oncolytic reovirus. J Immunol 194, 4397-4412.

Coffey, M.C., Strong, J.E., Forsyth, P.A., and Lee, P.W. (1998). Reovirus therapy of tumors with activated Ras pathway. Science 282, 1332-1334.

Coombs, K.M. (1998). Stoichiometry of reovirus structural proteins in virus, ISVP, and core particles. Virology $243,218-228$.

Coombs, K.M. (2011). Reoviruses. In eLS (John Wiley \& Sons, Ltd).

Cross, R.K., and Fields, B.N. (1972). Temperature-sensitive mutants of reovirus type 3: studies on the synthesis of viral RNA. Virology 50, 799-809.

Danthi, P., Kobayashi, T., Holm, G.H., Hansberger, M.W., Abel, T.W., and Dermody, T.S. (2008). Reovirus apoptosis and virulence are regulated by host cell membrane penetration efficiency. J Virol 82, 161-172.

Denzler, K.L., and Jacobs, B.L. (1994). Site-directed mutagenic analysis of reovirus sigma 3 protein binding to dsRNA. Virology 204, 190-199.

Desmet, E.A., Anguish, L.J., and Parker, J.S. (2014). Virus-mediated compartmentalization of the host translational machinery. MBio 5, e01463-01414.

Doyle, J.D., Danthi, P., Kendall, E.A., Ooms, L.S., Wetzel, J.D., and Dermody, T.S. (2012). Molecular determinants of proteolytic disassembly of the reovirus outer capsid. J Biol Chem 287, 8029-8038.

Ebert, D.H., Deussing, J., Peters, C., and Dermody, T.S. (2002). Cathepsin L and cathepsin B mediate reovirus disassembly in murine fibroblast cells. J Biol Chem 277, 24609-24617.

Ebihara, H., Takada, A., Kobasa, D., Jones, S., Neumann, G., Theriault, S., Bray, M., Feldmann, H., and Kawaoka, Y. (2006). Molecular determinants of Ebola virus virulence in mice. PLoS Pathog 2, e73.

Eichwald, C., Kim, J., and Nibert, M.L. (2017). Dissection of mammalian orthoreovirus micro2 reveals a selfassociative domain required for binding to microtubules but not to factory matrix protein microNS. PLoS One 12, e0184356.

Errett, J.S., Suthar, M.S., McMillan, A., Diamond, M.S., and Gale, M., Jr. (2013). The essential, nonredundant roles of RIG-I and MDA5 in detecting and controlling West Nile virus infection. J Virol 87, 11416-11425.

Fields, B.N. (1971). Temperature-sensitive mutants of reovirus type 3 features of genetic recombination. Virology 46, 142-148. 
Goubau, D., Schlee, M., Deddouche, S., Pruijssers, A.J., Zillinger, T., Goldeck, M., Schuberth, C., Van der Veen, A.G., Fujimura, T., Rehwinkel, J., et al. (2014). Antiviral immunity via RIG-I-mediated recognition of RNA bearing 5'-diphosphates. Nature 514, 372-375.

Gujar, S., Dielschneider, R., Clements, D., Helson, E., Shmulevitz, M., Marcato, P., Pan, D., Pan, L.Z., Ahn, D.G., Alawadhi, A., et al. (2013). Multifaceted therapeutic targeting of ovarian peritoneal carcinomatosis through virus-induced immunomodulation. Mol Ther 21, 338-347.

Gujar, S.A., Clements, D., Dielschneider, R., Helson, E., Marcato, P., and Lee, P.W. (2014). Gemcitabine enhances the efficacy of reovirus-based oncotherapy through anti-tumour immunological mechanisms. Br J Cancer 110, 83-93.

Gujar, S.A., and Lee, P.W. (2014). Oncolytic virus-mediated reversal of impaired tumor antigen presentation. Front Oncol 4, 77.

Gujar, S.A., Pan, D., Marcato, P., Garant, K.A., and Lee, P.W. (2011). Oncolytic Virus-initiated Protective Immunity Against Prostate Cancer. Mol Ther 19, 797-804.

Hansberger, M.W., Campbell, J.A., Danthi, P., Arrate, P., Pennington, K.N., Marcu, K.B., Ballard, D.W., and Dermody, T.S. (2007). IkappaB kinase subunits alpha and gamma are required for activation of NF-kappaB and induction of apoptosis by mammalian reovirus. J Virol 81, 1360-1371.

Hata, Y., Etoh, T., Inomata, M., Shiraishi, N., Nishizono, A., and Kitano, S. (2008). Efficacy of oncolytic reovirus against human breast cancer cells. Oncol Rep 19, 1395-1398.

Henderson, D.R., and Joklik, W.K. (1978). The mechanism of interferon induction by UV-irradiated reovirus. Virology 91, 389-406.

Hirasawa, K., Nishikawa, S.G., Norman, K.L., Alain, T., Kossakowska, A., and Lee, P.W. (2002). Oncolytic reovirus against ovarian and colon cancer. Cancer Res 62, 1696-1701.

Hrdy, D.B., Rosen, L., and Fields, B.N. (1979). Polymorphism of the migration of double-stranded RNA genome segments of reovirus isolates from humans, cattle, and mice. J Virol 31, 104-111.

Huismans, H., and Joklik, W.K. (1976). Reovirus-coded polypeptides in infected cells: isolation of two native monomeric polypeptides with affinity for single-stranded and double-stranded RNA, respectively. Virology 70 , 411-424.

Imani, F., and Jacobs, B.L. (1988). Inhibitory activity for the interferon-induced protein kinase is associated with the reovirus serotype 1 sigma 3 protein. Proc Natl Acad Sci U S A 85, 7887-7891.

Izzi, V., Buler, M., Masuelli, L., Giganti, M.G., Modesti, A., and Bei, R. (2014). Poxvirus-based vaccines for cancer immunotherapy: new insights from combined cytokines/co-stimulatory molecules delivery and "uncommon" strains. Anticancer Agents Med Chem 14, 183-189.

Jane-Valbuena, J., Breun, L.A., Schiff, L.A., and Nibert, M.L. (2002). Sites and determinants of early cleavages in the proteolytic processing pathway of reovirus surface protein sigma3. J Virol 76, 5184-5197.

Johnson, E.M., Doyle, J.D., Wetzel, J.D., McClung, R.P., Katunuma, N., Chappell, J.D., Washington, M.K., and Dermody, T.S. (2009). Genetic and pharmacologic alteration of cathepsin expression influences reovirus pathogenesis. J Virol 83, 9630-9640.

Kim, J., Parker, J.S., Murray, K.E., and Nibert, M.L. (2004). Nucleoside and RNA triphosphatase activities of orthoreovirus transcriptase cofactor mu2. J Biol Chem 279, 4394-4403.

Kim, M., Garant, K.A., zur Nieden, N.I., Alain, T., Loken, S.D., Urbanski, S.J., Forsyth, P.A., Rancourt, D.E., Lee, P.W., and Johnston, R.N. (2011). Attenuated reovirus displays oncolysis with reduced host toxicity. Br J Cancer 104, 290-299. 
Knowlton, J.J., Dermody, T.S., and Holm, G.H. (2012). Apoptosis induced by mammalian reovirus is beta interferon (IFN) independent and enhanced by IFN regulatory factor 3- and NF-kappaB-dependent expression of Noxa. J Virol 86, 1650-1660.

Kobayashi, T., Ooms, L.S., Chappell, J.D., and Dermody, T.S. (2009). Identification of functional domains in reovirus replication proteins muNS and mu2. J Virol 83, 2892-2906.

Lanoie, D., and Lemay, G. (2018). Multiple proteins differing between laboratory stocks of mammalian orthoreoviruses affect both virus sensitivity to interferon and induction of interferon production during infection. Virus Res 247, 40-46.

Larson, S.M., Antczak, J.B., and Joklik, W.K. (1994). Reovirus exists in the form of 13 particle species that differ in their content of protein sigma 1. Virology 201, 303-311.

Lee, P.W., Hayes, E.C., and Joklik, W.K. (1981). Protein sigma 1 is the reovirus cell attachment protein. Virology $108,156-163$.

Lemay, G., and Danis, C. (1994). Reovirus lambda 1 protein: affinity for double-stranded nucleic acids by a small amino-terminal region of the protein independent from the zinc finger motif. J Gen Virol 75 (Pt 11), 3261-3266.

Liemann, S., Chandran, K., Baker, T.S., Nibert, M.L., and Harrison, S.C. (2002). Structure of the reovirus membrane-penetration protein, Mu1, in a complex with is protector protein, Sigma3. Cell 108, 283-295.

Lim, Y.X., Ng, Y.L., Tam, J.P., and Liu, D.X. (2016). Human Coronaviruses: A Review of Virus-Host Interactions. Diseases 4.

Liu, M., Guo, S., and Stiles, J.K. (2011). The emerging role of CXCL10 in cancer (Review). Oncol Lett 2, 583-589.

Lloyd, R.M., and Shatkin, A.J. (1992). Translational stimulation by reovirus polypeptide sigma 3: substitution for VAI RNA and inhibition of phosphorylation of the alpha subunit of eukaryotic initiation factor 2 . J Virol 66,6878 6884.

Loken, S.D., Norman, K., Hirasawa, K., Nodwell, M., Lester, W.M., and Demetrick, D.J. (2004). Morbidity in immunosuppressed (SCID/NOD) mice treated with reovirus (dearing 3 ) as an anti-cancer biotherapeutic. Cancer Biol Ther 3, 734-738.

Loo, Y.M., Fornek, J., Crochet, N., Bajwa, G., Perwitasari, O., Martinez-Sobrido, L., Akira, S., Gill, M.A., GarciaSastre, A., Katze, M.G., et al. (2008). Distinct RIG-I and MDA5 signaling by RNA viruses in innate immunity. J Virol $82,335-345$.

Lopez, C.B. (2014). Defective viral genomes: critical danger signals of viral infections. J Virol 88, 8720-8723.

Lopez, C.B. (2019). Unexpected lessons from the neglected: How defective viral genomes became important again. PLoS Pathog 15, e1007450.

Mabrouk, T., Danis, C., and Lemay, G. (1995). Two basic motifs of reovirus sigma 3 protein are involved in double-stranded RNA binding. Biochem Cell Biol 73, 137-145.

Mabrouk, T., and Lemay, G. (1994). Mutations in a CCHC zinc-binding motif of the reovirus sigma 3 protein decrease its intracellular stability. J Virol 68, 5287-5290.

Marcato, P., Shmulevitz, M., Pan, D., Stoltz, D., and Lee, P.W. (2007). Ras transformation mediates reovirus oncolysis by enhancing virus uncoating, particle infectivity, and apoptosis-dependent release. Mol Ther 15, 1522-1530.

Mendez, II, She, Y.M., Ens, W., and Coombs, K.M. (2003). Digestion pattern of reovirus outer capsid protein sigma3 determined by mass spectrometry. Virology 311, 289-304.

Miller, C.L., Arnold, M.M., Broering, T.J., Eichwald, C., Kim, J., Dinoso, J.B., and Nibert, M.L. (2007). Virus-derived platforms for visualizing protein associations inside cells. Mol Cell Proteomics 6, 1027-1038. 
Miller, C.L., Arnold, M.M., Broering, T.J., Hastings, C.E., and Nibert, M.L. (2010). Localization of mammalian orthoreovirus proteins to cytoplasmic factory-like structures via nonoverlapping regions of microNS. J Virol 84, 867-882.

Miller, C.L., Broering, T.J., Parker, J.S., Arnold, M.M., and Nibert, M.L. (2003). Reovirus sigma NS protein localizes to inclusions through an association requiring the mu NS amino terminus. J Virol 77, 4566-4576.

Miller, J.E., and Samuel, C.E. (1992). Proteolytic cleavage of the reovirus sigma 3 protein results in enhanced double-stranded RNA-binding activity: identification of a repeated basic amino acid motif within the C-terminal binding region. J Virol 66, 5347-5356.

Mohamed, A., Teicher, C., Haefliger, S., and Shmulevitz, M. (2015). Reduction of virion-associated sigma1 fibers on oncolytic reovirus variants promotes adaptation toward tumorigenic cells. J Virol 89, 4319-4334.

Mohamed, M.R., and McFadden, G. (2009). NFkB inhibitors: strategies from poxviruses. Cell Cycle 8, 3125-3132.

Noble, S., and Nibert, M.L. (1997a). Characterization of an ATPase activity in reovirus cores and its genetic association with core-shell protein lambda1. J Virol 71, 2182-2191.

Noble, S., and Nibert, M.L. (1997b). Core protein mu2 is a second determinant of nucleoside triphosphatase activities by reovirus cores. J Virol 71, 7728-7735.

Norman, K.L., Coffey, M.C., Hirasawa, K., Demetrick, D.J., Nishikawa, S.G., DiFrancesco, L.M., Strong, J.E., and Lee, P.W. (2002a). Reovirus oncolysis of human breast cancer. Hum Gene Ther 13, 641-652.

Norman, K.L., Coffey, M.C., Hirasawa, K., Demetrick, D.J., Nishikawa, S.G., DiFrancesco, L.M., Strong, J.E., and Lee, P.W. (2002b). Reovirus oncolysis of human breast cancer. Hum Gene Ther 13, 641-652.

Norman, K.L., Hirasawa, K., Yang, A.D., Shields, M.A., and Lee, P.W. (2004). Reovirus oncolysis: the Ras/RalGEF/p38 pathway dictates host cell permissiveness to reovirus infection. Proc Natl Acad Sci U SA 101, 11099-11104.

Nygaard, R.M., Lahti, L., Boehme, K.W., Ikizler, M., Doyle, J.D., Dermody, T.S., and Schiff, L.A. (2013). Genetic determinants of reovirus pathogenesis in a murine model of respiratory infection. J Virol 87, 9279-9289.

Odegard, A.L., Chandran, K., Zhang, X., Parker, J.S., Baker, T.S., and Nibert, M.L. (2004). Putative autocleavage of outer capsid protein micro1, allowing release of myristoylated peptide micro1 $\mathrm{N}$ during particle uncoating, is critical for cell entry by reovirus. J Virol 78, 8732-8745.

Olland, A.M., Jane-Valbuena, J., Schiff, L.A., Nibert, M.L., and Harrison, S.C. (2001). Structure of the reovirus outer capsid and dsRNA-binding protein sigma3 at 1.8 A resolution. EMBO J 20, 979-989.

Oncolytics Biotech Inc (2018). REOLYSIN - Innately Adaptive. In Corporate Presentation.

Pan, D., Marcato, P., Ahn, D.G., Gujar, S., Pan, L.Z., Shmulevitz, M., and Lee, P.W. (2013). Activation of p53 by chemotherapeutic agents enhances reovirus oncolysis. PLoS One 8, e54006.

Pan, D., Pan, L.Z., Hill, R., Marcato, P., Shmulevitz, M., Vassilev, L.T., and Lee, P.W. (2011). Stabilisation of p53 enhances reovirus-induced apoptosis and virus spread through p53-dependent NF-kappaB activation. $\mathrm{Br} \mathrm{J}$ Cancer 105, 1012-1022.

Parker, J.S., Broering, T.J., Kim, J., Higgins, D.E., and Nibert, M.L. (2002). Reovirus core protein mu2 determines the filamentous morphology of viral inclusion bodies by interacting with and stabilizing microtubules. J Virol 76, 4483-4496.

Pol, J., Kroemer, G., and Galluzzi, L. (2016). First oncolytic virus approved for melanoma immunotherapy. Oncoimmunology 5, e1115641. 
1419

1420

1421

1422

1423

1424

1425

1426

1427

1428

1429

1430

1431

1432

1433

1434

1435

1436

1437

1438

1439

1440

1441

1442

1443

1444

1445

1446

1447

1448

1449

1450

1451

1452

1453

1454

1455

1456

1457

1458

1459

1460

Potts, K.G., Irwin, C.R., Favis, N.A., Pink, D.B., Vincent, K.M., Lewis, J.D., Moore, R.B., Hitt, M.M., and Evans, D.H. (2017). Deletion of F4L (ribonucleotide reductase) in vaccinia virus produces a selective oncolytic virus and promotes anti-tumor immunity with superior safety in bladder cancer models. EMBO Mol Med 9, 638-654.

Prestwich, R.J., Ilett, E.J., Errington, F., Diaz, R.M., Steele, L.P., Kottke, T., Thompson, J., Galivo, F., Harrington, K.J., Pandha, H.S., et al. (2009). Immune-mediated antitumor activity of reovirus is required for therapy and is independent of direct viral oncolysis and replication. Clin Cancer Res 15, 4374-4381.

Rajani, K., Parrish, C., Kottke, T., Thompson, J., Zaidi, S., Ilett, L., Shim, K.G., Diaz, R.M., Pandha, H., Harrington, K., et al. (2016). Combination Therapy With Reovirus and Anti-PD-1 Blockade Controls Tumor Growth Through Innate and Adaptive Immune Responses. Mol Ther 24, 166-174.

Reinisch, K.M., Nibert, M.L., and Harrison, S.C. (2000). Structure of the reovirus core at 3.6 A resolution. Nature 404, 960-967.

Romee, R., Leong, J.W., and Fehniger, T.A. (2014). Utilizing cytokines to function-enable human NK cells for the immunotherapy of cancer. Scientifica (Cairo) 2014, 205796.

Russell, L., and Peng, K.W. (2018). The emerging role of oncolytic virus therapy against cancer. Chin Clin Oncol 7, 16.

Sandekian, V., and Lemay, G. (2015). A single amino acid substitution in the mRNA capping enzyme lambda2 of a mammalian orthoreovirus mutant increases interferon sensitivity. Virology 483, 229-235.

Schiff, L.A., Nibert, M.L., Co, M.S., Brown, E.G., and Fields, B.N. (1988). Distinct binding sites for zinc and doublestranded RNA in the reovirus outer capsid protein sigma 3. Mol Cell Biol 8, 273-283.

Schmitz, M.L., Kracht, M., and Saul, V.V. (2014). The intricate interplay between RNA viruses and NF-kappaB. Biochim Biophys Acta 1843, 2754-2764.

Sei, S., Mussio, J.K., Yang, Q.E., Nagashima, K., Parchment, R.E., Coffey, M.C., Shoemaker, R.H., and Tomaszewski, J.E. (2009). Synergistic antitumor activity of oncolytic reovirus and chemotherapeutic agents in non-small cell lung cancer cells. Mol Cancer 8, 47.

Shah, P.N.M., Stanifer, M.L., Hohn, K., Engel, U., Haselmann, U., Bartenschlager, R., Krausslich, H.G., KrijnseLocker, J., and Boulant, S. (2017). Genome packaging of reovirus is mediated by the scaffolding property of the microtubule network. Cell Microbiol 19.

Shatkin, A.J., Sipe, J.D., and Loh, P. (1968). Separation of ten reovirus genome segments by polyacrylamide gel electrophoresis. J Virol 2, 986-991.

Sherry, B. (2009). Rotavirus and reovirus modulation of the interferon response. J Interferon Cytokine Res 29, 559-567.

Sherry, B., Torres, J., and Blum, M.A. (1998). Reovirus induction of and sensitivity to beta interferon in cardiac myocyte cultures correlate with induction of myocarditis and are determined by viral core proteins. J Virol 72, 1314-1323.

Shmulevitz, M., Gujar, S.A., Ahn, D.G., Mohamed, A., and Lee, P.W. (2012). Reovirus variants with mutations in genome segments S1 and L2 exhibit enhanced virion infectivity and superior oncolysis. J Virol 86, 7403-7413.

Shmulevitz, M., and Lee, P.W. (2012). Exploring host factors that impact reovirus replication, dissemination, and reovirus-induced cell death in cancer versus normal cells in culture. Methods Mol Biol 797, 163-176.

Shmulevitz, M., Marcato, P., and Lee, P.W. (2005). Unshackling the links between reovirus oncolysis, Ras signaling, translational control and cancer. Oncogene 24, 7720-7728.

Shmulevitz, M., Marcato, P., and Lee, P.W. (2010a). Activated Ras signaling significantly enhances reovirus replication and spread. Cancer Gene Ther 17, 69-70. 
Shmulevitz, M., Pan, L.Z., Garant, K., Pan, D., and Lee, P.W. (2010b). Oncogenic Ras promotes reovirus spread by suppressing IFN-beta production through negative regulation of RIG-I signaling. Cancer Res 70, 4912-4921.

Showalter, A., Limaye, A., Oyer, J.L., Igarashi, R., Kittipatarin, C., Copik, A.J., and Khaled, A.R. (2017). Cytokines in immunogenic cell death: Applications for cancer immunotherapy. Cytokine 97, 123-132.

SillaJen Inc (2018). PHOCUS Trial. In Development Pipeline.

Skehel, J.J., and Joklik, W.K. (1969). Studies on the in vitro transcription of reovirus RNA catalyzed by reovirus cores. Virology 39, 822-831.

Smith, J.A., Schmechel, S.C., Raghavan, A., Abelson, M., Reilly, C., Katze, M.G., Kaufman, R.J., Bohjanen, P.R., and Schiff, L.A. (2006). Reovirus induces and benefits from an integrated cellular stress response. J Virol 80, 20192033.

Sobol, P.T., Boudreau, J.E., Stephenson, K., Wan, Y., Lichty, B.D., and Mossman, K.L. (2011). Adaptive antiviral immunity is a determinant of the therapeutic success of oncolytic virotherapy. Mol Ther 19, 335-344.

Stanifer, M.L., Kischnick, C., Rippert, A., Albrecht, D., and Boulant, S. (2017). Reovirus inhibits interferon production by sequestering IRF3 into viral factories. Sci Rep 7, 10873.

Steele, L., Errington, F., Prestwich, R., llett, E., Harrington, K., Pandha, H., Coffey, M., Selby, P., Vile, R., and Melcher, A. (2011). Pro-inflammatory cytokine/chemokine production by reovirus treated melanoma cells is PKR/NF-kappaB mediated and supports innate and adaptive anti-tumour immune priming. Mol Cancer 10, 20.

Stoeckel, J., and Hay, J.G. (2006). Drug evaluation: Reolysin--wild-type reovirus as a cancer therapeutic. Curr Opin Mol Ther 8, 249-260.

Stuart, J.D., Holm, G.H., and Boehme, K.W. (2018). Differential Delivery of Genomic Double-Stranded RNA Causes Reovirus Strain-Specific Differences in Interferon Regulatory Factor 3 Activation. J Virol 92.

Thirukkumaran, C., Shi, Z.Q., Thirukkumaran, P., Luider, J., Kopciuk, K., Spurrell, J., Elzinga, K., and Morris, D. (2017). PUMA and NF-kB Are Cell Signaling Predictors of Reovirus Oncolysis of Breast Cancer. PLoS One 12, e0168233.

Tripathi, S., Balasubramaniam, V.R., Brown, J.A., Mena, I., Grant, A., Bardina, S.V., Maringer, K., Schwarz, M.C., Maestre, A.M., Sourisseau, M., et al. (2017). A novel Zika virus mouse model reveals strain specific differences in virus pathogenesis and host inflammatory immune responses. PLoS Pathog 13, e1006258.

Waldmann, T.A. (2017). Cytokines in Cancer Immunotherapy. Cold Spring Harb Perspect Biol.

Wang, Q., Bergeron, J., Mabrouk, T., and Lemay, G. (1996). Site-directed mutagenesis of the double-stranded RNA binding domain of bacterially-expressed sigma 3 reovirus protein. Virus Res 41, 141-151.

Wetzel, J.D., Wilson, G.J., Baer, G.S., Dunnigan, L.R., Wright, J.P., Tang, D.S., and Dermody, T.S. (1997). Reovirus variants selected during persistent infections of $L$ cells contain mutations in the viral $S 1$ and $S 4$ genes and are altered in viral disassembly. J Virol 71, 1362-1369.

Wilcox, M.E., Yang, W., Senger, D., Rewcastle, N.B., Morris, D.G., Brasher, P.M., Shi, Z.Q., Johnston, R.N., Nishikawa, S., Lee, P.W., et al. (2001). Reovirus as an oncolytic agent against experimental human malignant gliomas. J Natl Cancer Inst 93, 903-912.

Wilson, G.J., Nason, E.L., Hardy, C.S., Ebert, D.H., Wetzel, J.D., Venkataram Prasad, B.V., and Dermody, T.S. (2002). A single mutation in the carboxy terminus of reovirus outer-capsid protein sigma 3 confers enhanced kinetics of sigma 3 proteolysis, resistance to inhibitors of viral disassembly, and alterations in sigma 3 structure. J Virol 76, 9832-9843. 
1501 Yang, W.Q., Senger, D.L., Lun, X.Q., Muzik, H., Shi, Z.Q., Dyck, R.H., Norman, K., Brasher, P.M., Rewcastle, N.B., 1502 George, D., et al. (2004). Reovirus as an experimental therapeutic for brain and leptomeningeal metastases from 1503 breast cancer. Gene Ther 11, 1579-1589.

1504 Yin, P., Keirstead, N.D., Broering, T.J., Arnold, M.M., Parker, J.S., Nibert, M.L., and Coombs, K.M. (2004).

1505 Comparisons of the M1 genome segments and encoded mu2 proteins of different reovirus isolates. Virol J 1, 6.

1506 Yue, Z., and Shatkin, A.J. (1997). Double-stranded RNA-dependent protein kinase (PKR) is regulated by reovirus 1507 structural proteins. Virology 234, 364-371.

1508 Zhang, L., Chandran, K., Nibert, M.L., and Harrison, S.C. (2006). Reovirus mu1 structural rearrangements that 1509 mediate membrane penetration. J Virol 80, 12367-12376.

1510 Zurney, J., Kobayashi, T., Holm, G.H., Dermody, T.S., and Sherry, B. (2009). Reovirus mu2 protein inhibits 1511 interferon signaling through a novel mechanism involving nuclear accumulation of interferon regulatory factor 9. 1512 J Virol 83, 2178-2187. 


\section{FIGURE LEGENDS}

1515 Figure 1. T3D ${ }^{\mathrm{PL}}$ Laboratory Clone has Enhanced Oncolytic Activity In Vitro and In Vivo.

1516 (A) Plaques generated by reovirus T3D strains (T3D ${ }^{\mathrm{PL}}, \mathrm{T}_{3} \mathrm{D}^{\mathrm{ATCC}}, \mathrm{T}^{\mathrm{T}} \mathrm{D}^{\mathrm{KC}}$ and $\mathrm{T} 3 \mathrm{D}^{\mathrm{TD}}$ ) on L929 cell line. Reovirus

1517 plaques were visualized by crystal violet staining (left) and plaque size quantified by ImageQuant colony counting 1518 software (right). Mean plaque size indicated above data points. (B) Plaques and foci generated by reovirus T3D 1519 strains (T3D ${ }^{\mathrm{PL}}, \mathrm{T}^{\mathrm{KC}}$ and $\mathrm{T}^{\mathrm{T}} \mathrm{D}^{\mathrm{TD}}$ ) on L929, ID8, Huh7.5 and H1299 cell lines. Reovirus plaques (L929) were 1520 visualized with crystal violet and reovirus foci (ID8, Huh7.5 and H1299) were stained with colorimetric 1521 immunocytochemistry using primary polyclonal reovirus antibody, alkaline phosphatase secondary antibody and 1522 BCIP/NBT substrate. (C) T3D ${ }^{\mathrm{PL}}$ and T3D ${ }^{\mathrm{TD}}$ foci formation on B16-F10 cells visualized by colorimetric 1523 immunocytochemistry as in (B). Inset displays a magnification of indicated well area. (D) Schematic timeline for 1524 comparing oncolytic potency of reovirus T3D strains in the B16-F10 mouse melanoma model. (E) Following the 1525 first intratumoral inoculation of PBS, $\mathrm{T} 3 \mathrm{D}^{\mathrm{PL}}$ or $\mathrm{T}^{\mathrm{D}} \mathrm{D}^{\mathrm{TD}}$, tumor volume was monitored using caliper measurements 1526 every 2-3 days. $\mathrm{n}=5$ mice per group. (F) Tumor volume comparison from 0-13 days post initial T3D $\mathrm{D}^{\mathrm{PL}}$ or T3D $\mathrm{D}^{\mathrm{TD}}$ 1527 dose. Data points obtained from (E). Statistical significance determined using unpaired t test, ${ }^{*} \mathrm{p}<0.05$. (G) 1528 Separation of reovirus dsRNA segments using SDS-PAGE and RNA staining using ethidium bromide. Genomic 1529 reovirus dsRNA was Trizol LS extracted from $\mathrm{CsCl}$ purified reovirus preparations. (H) Reovirus phylogenetic 1530 trees generated with concatenated complete reovirus amino acid sequences using the Geneious ${ }^{\circledR}$ tree builder add 1531 on. Assembly of phylogenetic trees was performed using the Jukes-Cantor genetic distance model and neighbour1532 joining tree build method. Outgroup set as T2J (top) or T3A (bottom). Concatenate sequences of 11 reovirus 1533 proteins, in order $\sigma 1, \sigma 1 \mathrm{~s}, \sigma 2, \sigma \mathrm{NS}, \sigma 3, \mu 1, \mu 2, \mu \mathrm{NS}, \lambda 1, \lambda 2$, $\lambda 3$. (I) Specific amino acid differences between

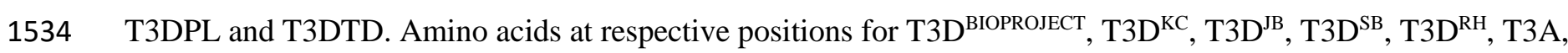
1535 T3D $\mathrm{D}^{\text {JOKLIK }}, \mathrm{T}^{\mathrm{C}} \mathrm{D}^{\text {CASHDOLLAR }}$ are included for source laboratory divergence. 


\section{Figure 2. PL-S4, PL-M1 and PL-L3 genes contribute towards enhanced T3D ${ }^{\mathrm{PL}}$ plaque size.}

1538 (A) L929 cells were coinfected T3D $\mathrm{D}^{\mathrm{PL}}$ and $\mathrm{T} 3 \mathrm{D}^{\mathrm{TD}}$ at high MOI (T3D ${ }^{\mathrm{PL}} \mathrm{MOI} 20$, T3D ${ }^{\mathrm{TD}} \mathrm{MOI} 200$ ). At 24hpi, cell 1539 lysate was collected and following 3 freeze/thaw cycles, plaque assays were performed on L929 cells. Using 1540 parental T3DPL and T3DTD plaques as a reference, twenty plaques similar in size to T3DPL were isolated, twice 1541 plaque purified on L929 cells and sequenced. (B) (Left) Foci size comparison of parental (PL and TD) and large 1542 plaque reassortants (B1-B12) following colorimetric immunocytochemical staining using primary polyclonal 1543 reovirus antibody, alkaline phosphatase secondary antibody and BCIP/NBT substrate. (Right) Summary of 1544 sequencing analysis of $\mathrm{T} 3 \mathrm{D}^{\mathrm{PL}} / \mathrm{T} 3 \mathrm{D}^{\mathrm{TD}}$ reassortants indicating parental gene $\left(+\mathrm{T} 3 \mathrm{D}^{\mathrm{PL}},-\mathrm{T}^{\mathrm{D}} \mathrm{D}^{\mathrm{TD}}\right)$ matched to plaque 1545 area quantification using ImageQuantTL colony counting add-on. The S3 gene was identical (=) between $\mathrm{T}^{\mathrm{PD}} \mathrm{PL}^{\mathrm{PL}}$ 1546 and T3D ${ }^{\mathrm{TD}}$. (C) BHK/T7-9 cells were transfected with a combination of plasmids encoding10 reovirus gene 1547 segments and C3P3. At 5 days post transfection, cell lysates were harvested, and recombinant reovirus plaque size 1548 was determined on L929 cells. C3P3 plasmid encodes T7 RNA polymerase and African swine fever virus 1549 NP868R capping enzyme separated by a linker sequence. (D) and (E) Using L929 cells, plaques of parental and 1550 recombinant reoviruses were visualized following crystal violet staining and quantified using ImageQuantTL 1551 colony counting add-on. (D) TD backbone with PL gene combinations (E) PL backbone with TD gene 1552 combinations. PL and TD are purified laboratory stocks of T3D ${ }^{\mathrm{PL}}$ and T3D ${ }^{\mathrm{TD}}$, respectively. PL-RG and TD-RG 1553 are reverse genetics generated virus lysates using complete set of parental $\mathrm{T} 3 \mathrm{D}^{\mathrm{PL}}$ and $\mathrm{T} 3 \mathrm{D}^{\mathrm{TD}}$ plasmids, 1554 respectively. Statistical significance determined using one-way ANOVA with Dunnett's multiple comparisons 1555 test, $* \mathrm{p}<0.05$, *** $\mathrm{p}<0.001$, **** $\mathrm{p}<0.0001$. Samples in (D) compared to TD-RG. Samples in (E) compared to 1556 PL-RG. ${ }^{1}$ Set of plaques were stopped when plaques in this well were visible 


\section{Figure 3. $\mathrm{T}^{\mathrm{PL}}{ }^{\mathrm{PL}}$ replicates more rapidly and to higher burst size in a single round of infection.}

1558

1559

1560

1561

1562

1563

1564

1565

1566

1567

1568

1569

1570

1571

1572

1573

1574

1575

1576

1577

1578

1579

1580

1581

1582

1583

1584

1585

1586

1587

1588

1589

1590

1591

(A) Diagrammatic representation of reovirus virion. Outer capsid proteins include $\sigma 1, \sigma 3$ and $\mu 1$. Inner capsid (core) proteins include $\lambda 2, \sigma 2, \lambda 1$. Within the viral core are $\lambda 3, \mu 2$ and 10 segments of dsRNA genome. (B) Levels of reovirus proteins were assessed using CsCl-purified virus preparations separated by SDS PAGE. Total protein was visualized by Coomassie dye staining whereas specific reovirus proteins were identified using Western blot analysis with reovirus protein specific antibodies, as indicated. (C) (Left) Densitometric band quantification from (B) of $\sigma 1$ relative to $\sigma 3 . n \geq 4$. Statistical significance determined using one-way ANOVA with Tukey's multiple comparisons test, $* * * \mathrm{p}<0.001, * * * * \mathrm{p}<0.0001$, ns $>0.05$. (Right) Agarose gel separation CsCl- purified virus preparations and based on $\sigma 1$ trimers per virion and stained with Coomassie dye. Table below indicates percentage of virions with specific $\sigma 1$ timers/virion calculated using densitometric band quantification. (D) $\mathrm{T} 3 \mathrm{D}^{\mathrm{PL}}, \mathrm{T} 3 \mathrm{D}^{\mathrm{KC}}$ and $\mathrm{T} 3 \mathrm{D}^{\mathrm{TD}}$ dilutions were bound at $4{ }^{\circ} \mathrm{C}$ to non-enzymatically detached $\mathrm{L} 929$ cells in suspension, and following extensive washing to remove unbound reovirus, cell-bound reovirus was stained using polyclonal reovirus antibodies and mean fluorescence intensity (MFI) quantified using flow cytometry. Following T3D ${ }^{\mathrm{PL}}$ standard curve generation linear regression analysis, relative cell binding of $\mathrm{T}^{\mathrm{K}} \mathrm{D}^{\mathrm{KC}}$ and $\mathrm{T} 3 \mathrm{D}^{\mathrm{TD}}$ was determined. $\mathrm{n}$ $\geq 5$. Statistical significance determined using one-way ANOVA with Tukey's multiple comparisons test, $* * \mathrm{p}<$ 0.01 , **** $\mathrm{p}<0.0001$. (E) L929 cells were infected with $\mathrm{T} 3 \mathrm{D}^{\mathrm{PL}}$ or T3D $\mathrm{D}^{\mathrm{TD}}$ at MOI 3 (left) or MOI 0.01 (right) and incubated at $37^{\circ} \mathrm{C}$. At each timepoint, total cell lysates were harvested, and virus titres performed in duplicate on L929 cells. (F) T3D ${ }^{\mathrm{PL}}$, T3D ${ }^{\mathrm{KC}}$ and T3D ${ }^{\mathrm{TD}}$ (MOI 1-3) were bound to L929 cell monolayers at $4{ }^{\circ} \mathrm{C}$ and following washing to remove unbound virions, cells were incubated at $37^{\circ} \mathrm{C}$ and cell lysates were collected at various timepoints post infection. (Top) Total proteins were separated using SDS PAGE and Western blot analysis with specific antibodies were used to identify reovirus proteins and $\beta$ actin (loading control). (Bottom) Densitometric band quantification of $\mu 1 \mathrm{C}$ and $\delta$ and $\%$ virus uncoating was calculated using the formula $[\delta /(\mu 1 \mathrm{C}+\delta)]^{*} 100 . \mathrm{n}=4$ $\pm \mathrm{SD}$ (MOI $1 \mathrm{n}=2$, MOI $3 \mathrm{n}=2$ ), linear regression analysis determined the slopes are not significantly different. (G) and (H) Similar experimental outline to (F) (MOI 3) except cell lysates were collected for RNA extraction (G) or total protein analysis $(\mathrm{H})$ at indicated timepoints. $(\mathrm{G})$ Total RNA was extracted, converted to cDNA and reovirus S4 and M2 RNA expression relative to housekeeping gene GAPDH was quantified using qRT-PCR. $\mathrm{n}=$ $3 \pm \mathrm{SD}, * * * \mathrm{p}<0.0001$, linear regression analysis determined that i) slope of $\mathrm{T}^{\mathrm{PL}}{ }^{\mathrm{PL}}$ differs from $\mathrm{T} 3 \mathrm{D}^{\mathrm{KC}}$ or $\mathrm{T} 3 \mathrm{D}^{\mathrm{TD}}$ and ii) slope of $\mathrm{T}^{3} \mathrm{D}^{\mathrm{KC}}$ does not differs from T3D ${ }^{\mathrm{TD}}$. (H) Total proteins were separated using SDS PAGE and Western blot analysis with specific antibodies were used to identify reovirus proteins and $\beta$ actin (loading control). (I) Following infection similar to (F), at 24 hpi, adherent and detached cells were collected and subjected to staining with 7-AAD and Annexin V, followed by flow cytometric analysis. (J) L929 cells were infected with $\mathrm{T}^{2} \mathrm{D}^{\mathrm{PL}}$ or $\mathrm{T} 3 \mathrm{D}^{\mathrm{TD}}$ (MOI 1) and incubated at $37^{\circ} \mathrm{C}$. Polyclonal reovirus antibody was added directly to the well media at 3hpi (3hpi $\alpha$ Reo Ab). Reovirus infected cells were visualized by fluorescence microscopy using polyclonal anti-reovirus antibodies (green) and HOECHST staining of cell nuclei (blue). (K) Standardized for equal infection (MOI 3), L929 cells were infected with parental T3D ${ }^{\mathrm{PL}}$ or T3D ${ }^{\mathrm{TD}}$, and $\mathrm{S} 4, \mathrm{M} 1$ and $\mathrm{L} 3$ gene 
1592 monoreassortant PL-RG or TD-RG viruses. At 12hpi, total RNA was extracted, converted to cDNA and reovirus 1593 S4 RNA expression relative to housekeeping gene GAPDH was quantified using qRT-PCR. $\mathrm{n} \geq 3$. All values 1594 were normalized to T3D ${ }^{\mathrm{TD}}$. Statistical significance determined using one-way ANOVA with Dunnett's multiple 1595 comparisons test, $* \mathrm{p}<0.05$, *** $\mathrm{p}<0.001$, **** $\mathrm{p}<0.0001$, ns $>0.05$. (L) Similar experimental outline to (K) 1596 except only the parental T3D ${ }^{\mathrm{PL}}$ or $\mathrm{T} 3 \mathrm{D}^{\mathrm{TD}}$, and $\mathrm{S} 4, \mathrm{M} 1$ and $\mathrm{L} 3$ gene monoreassortant TD-RG viruses were assessed 1597 at 12hpi. (Left) Total cell lysates were collected at 12hpi for Western blot analysis using specific antibodies to 1598 identify reovirus proteins. (Right) Densitometric band quantification of $\mu 1$ and $\sigma 3$, relative to non-specific 1599 background band. $\mathrm{n} \geq 3$. 
1601

Figure 4. M1-encoded $\mu 2$ of $\mathrm{T}^{\mathrm{PD}} \mathrm{D}^{\mathrm{PL}}$ confers accelerates core transcription and globular factory morphology while L3-encoded $\lambda 1$ confers increased factory size.

(A) $\mathrm{CsCl}$ purified preparations of $\mathrm{T}^{\mathrm{D}} \mathrm{D}^{\mathrm{PL}}, \mathrm{T} 3 \mathrm{D}^{\mathrm{KC}}$ and $\mathrm{T} 3 \mathrm{D}^{\mathrm{TD}}$ were each incubated with chymotrypsin at $37^{\circ} \mathrm{C}$ for $2 \mathrm{hrs}$. Viral cores were purified by ultra-centrifugation at $100,000 \mathrm{~g}$ for $90 \mathrm{~min}$ at $4 \mathrm{C}$. The pellet fraction containing viral cores was resuspended in 100mM Tris $\mathrm{pH} 8.0$ and assessed for purity followed by core transcription assays. (B) At every stage in viral core purification, aliquots were separated by SDS-PAGE and total protein was visualized with Coomassie dye, while reovirus $\sigma 1$ protein was identified using Western blot analysis with $\sigma 1$ specific antibody. (C) Purified viral cores from A) were added to transcription buffer (with or without ATP) and incubated at $40^{\circ} \mathrm{C}$. 1) Each timepoint sample was spiked with 3ng mouse GAPDH RNA. Following total RNA extraction using Trizol LS and cDNA synthesis, qRT-PCR was performed using gene-specific primers for reovirus S4, M2, L2 or GAPDH. 2) Transcription reactions were spiked with SYBR green II RNA dye and fluorescence was monitored at 5min intervals. (D) Following core transcription reaction as in C1), reovirus RNA (S4, M2, L2) values were standardized to respective GAPDH, and each group was normalized to the respective 0min (input) timepoint. $\mathrm{n}=3 \pm \mathrm{SD}$, ** $\mathrm{p}<0.001$, linear regression analysis determined that i) slope of $\mathrm{T} 3 \mathrm{D}^{\mathrm{PL}}$ differs from $\mathrm{T} 3 \mathrm{D}^{\mathrm{KC}}$ or $\mathrm{T} 3 \mathrm{D}^{\mathrm{TD}}$ and ii) slope of $\mathrm{T} 3 \mathrm{D}^{\mathrm{KC}}$ does not differs from $\mathrm{T} 3 \mathrm{D}^{\mathrm{TD}}$. (E) Viral cores were purified as described in (A) from parental $\mathrm{T}_{3} \mathrm{D}^{\mathrm{PL}}$ or $\mathrm{T} 3 \mathrm{D}^{\mathrm{TD}}$, and $\mathrm{S} 4, \mathrm{M} 1$ and $\mathrm{L} 3$ gene monoreassortant PL-RG or TD-RG viruses. Aliquots were separated by SDS-PAGE and total protein was visualized with Coomassie dye, prior to CHT incubation (Left) and viral core purification (Right). (F) Core transcription reaction were set-up as in C2), and fluorescence values was standardized to $0 \mathrm{~min}$ (input) timepoint. Parental T3D ${ }^{\mathrm{PL}}$ or T3D ${ }^{\mathrm{TD}}$, and S4, M1 and L3 gene monoreassortant PL-RG (Left) or TD-RG (Right) viruses. $\mathrm{n} \geq 4 \pm$ SEM. (G) Linear regression analysis performed on data from $(F) . n \geq 4$, Statistical significance determined using one-way ANOVA with Tukey's multiple comparisons test, with either parental $\mathrm{T}_{3} \mathrm{D}^{\mathrm{PL}}$ or $\mathrm{T} 3 \mathrm{D}^{\mathrm{TD}}$ as control dataset. $* \mathrm{p}<0.05$, *** $\mathrm{p}<0.001$, **** $\mathrm{p}<0.0001$, ns $>0.05$. (H) ID8 cells seeded on coverslips were infected (MOI 3) with parental T3D $\mathrm{D}^{\mathrm{PL}}$ or T3D ${ }^{\mathrm{TD}}$, and S4, M1 and L3 gene monoreassortants in a TD-RG backbone, for 20hpi. Cells were fixed and stained with reovirus protein specific antibodies $(\sigma \mathrm{NS}, \mu 2, \sigma 3)$. Nuclei were stained with HOESCHT 33342. Cells were imaged using confocal microscopy. Projection images from two fields of view for each condition are shown. (I) Using $\sigma \mathrm{NS}$ images from $(\mathrm{H})$, reovirus factory size was quantified using ImageQuant colony counting software and $\%$ of total factories was determined for indicated factory size range. Viral factories were analyzed for 4-5 fields of view, and total viral factories assessed were T3D ${ }^{\mathrm{TD}}$ 195, TD+PL-S4 193, TD+PL-L3 203. 
1630

1631

1632

1633

1634

1635

1636

1637

1638

1639

1640

1641

1642

1643

1644

1645

1646

1647

1648

1649

Figure 5. T3D ${ }^{\mathrm{TD}}$ activates interferon signaling more than $\mathrm{T}^{\mathrm{PL}} \mathrm{D}^{\mathrm{PL}}$, but IFN signaling does not impact the first round of reovirus infection.

(A) Overview of antiviral signaling induced during reovirus infection. (B-D) L929 cells were infected with T3D ${ }^{\mathrm{PL}}$ and/or $\mathrm{T} 3 \mathrm{D}^{\mathrm{TD}}$ at indicated MOI and incubated at $37^{\circ} \mathrm{C}$ for 12 hours. (B) and (D) Total proteins were separated using SDS PAGE and Western blot analysis with indicated antibodies. C) Total RNA was extracted, converted to cDNA and gene expression relative to housekeeping gene GAPDH was quantified using qRT-PCR. All values were normalized to T3D ${ }^{\mathrm{TD}}$ MOI 1. $\mathrm{n}=4$. (E) Standardized for equal infection (MOI 3), L929 cells were infected with parental $\mathrm{T}^{\mathrm{P}} \mathrm{PL}^{\mathrm{PL}}$ or T3D ${ }^{\mathrm{TD}}$, and S4, M1 and L3 gene monoreassortant PL-RG or TD-RG viruses. (Left) At 12hpi, total RNA was extracted, converted to cDNA and gene expression relative to housekeeping gene GAPDH was quantified using qRT-PCR. All values were normalized to T3D ${ }^{\mathrm{TD}} . \mathrm{n} \geq 3$. Statistical significance determined using one-way ANOVA with Dunnett's multiple comparisons test, * p $<0.05$, *** p $<0.001$, **** p $<0.0001$, ns $>0.05$. (Right) At 12hpi, total viral titres at $12 \mathrm{hpi}$ were plotted against Ifnbl gene expression, followed by linear regression analysis. (F-H) WT or RIG-I/MDA5 -/- double knockout (DKO) MEFs were infected with T3D ${ }^{\mathrm{PL}}$ or $\mathrm{T}^{2} \mathrm{D}^{\mathrm{TD}}$. (F) At indicated MOIs and timepoints, percent reovirus infected cells were identified using reovirus specific primary antibody and Alexa Fluor 488 conjugated secondary antibody and quantified using flow cytometry. $\mathrm{n}=1-3,(\mathrm{G})$ For MOI 6 at 12hpi, total RNA was extracted, converted to cDNA and gene expression relative to housekeeping gene GAPDH was quantified using qRT-PCR. All values were normalized to WT MEF T3D ${ }^{\mathrm{TD}}$. $\mathrm{n} \geq 1$-2, with experimental duplicates, $(\mathrm{H})$ At 3days post infection, reovirus infected cell foci were stained with colorimetric immunocytochemistry using primary polyclonal reovirus antibody, alkaline phosphatase secondary antibody and BCIP/NBT substrate. 


\section{Figure 6. T3D ${ }^{\mathrm{PL}}$ S4-encoded $\sigma 3$ stimulates expression of NFKB-dependent but IFN-independent cytokines.}

1651 (A) Standardized for equal infection (MOI 3), L929 cells were infected for $12 \mathrm{hrs}$ with parental T3D $\mathrm{D}^{\mathrm{PL}}$ or T3D $\mathrm{D}^{\mathrm{TD}}$, 1652 and S4, M1 and L3 gene monoreassortant TD-RG viruses. (Top) Total cell lysates were collected at 12hpi for 1653 Western blot analysis using indicated antibodies to identify reovirus proteins. (Bottom) Densitometric band 1654 quantification of phosphorylated relative to total protein. $\mathrm{n}=3$. (B) $\mathrm{L} 929$ cells were infected with $\mathrm{T} 3 \mathrm{D}^{\mathrm{PL}}$ and/or $1655 \mathrm{~T}^{\mathrm{TD}} \mathrm{D}^{\mathrm{TD}}$ at indicated MOI and incubated at $37^{\circ} \mathrm{C}$ for 12 hours. Total RNA was extracted, converted to cDNA and 1656 gene expression relative to housekeeping gene GAPDH was quantified using qRT-PCR. All values were 1657 normalized to T3D ${ }^{\text {TD }}$ MOI 1. $\mathrm{n}=4$. (C) NIH/3T3 cells stably transduced with scrambled (shSCR) or RIG-I 1658 (shRIG) lentivirus were infected with reovirus at indicated MOI (L929 cell line titres) and incubated at $37^{\circ} \mathrm{C}$. 1659 Samples were collected at 12hpi for RNA extraction, cDNA synthesis and qRT-PCR using gene-specific primers. 1660 Values were standardized to corresponding GAPDH and all samples were normalized to shSCR T3D ${ }^{\mathrm{PL}} \mathrm{MOI} 60 . \mathrm{n}$ $1661=2$. (D) Similar experimental outline to (A) except the parental T3D ${ }^{\mathrm{PL}}$ or T3D ${ }^{\mathrm{TD}}$, and S4, M1 and L3 gene 1662 monoreassortant for both PL-RG and TD-RG viruses were assessed. At 12hpi, total RNA was assessed for 1663 reovirus S4 RNA expression relative to housekeeping gene GAPDH. $n \geq 3$. Statistical significance determined 1664 using one-way ANOVA with Dunnett's multiple comparisons test, $* \mathrm{p}<0.05, * * * \mathrm{p}<0.001$, **** $\mathrm{p}<0.0001$, ns $1665>0.05$. 
1666 Figure 7. Specific polymorphisms in $\mathrm{S4}$, M1 and $\mathrm{L3}$ of $\mathrm{T}^{\mathrm{PL}} \mathrm{D}^{\mathrm{PL}}$ relative to $\mathrm{T3D} \mathrm{D}^{\mathrm{TD}}$ have positive or negative 1667 effects on replication; and a hybrid between T3D $^{\mathrm{PL}}$ and $\mathbf{T 3 D}^{\mathrm{TD}}$ has superior oncolytic activity over either 1668 T3D laboratory strain.

1669 (A-C) $\mathrm{T}^{\mathrm{PL}}{ }^{\mathrm{PL}}$ polymorphisms were inserted into $\mathrm{T} 3 \mathrm{D}^{\mathrm{TD}}$ backbone plasmids using site-directed mutagenesis, and 1670 modified plasmids were used to generate recombinant viruses in a TD-RG backbone using reverse genetics. Using 1671 L929 cells, plaques of parental and recombinant reoviruses were visualized following crystal violet staining and 1672 quantified using ImageQuantTL colony counting add-on. (A) S4 gene polymorphisms (B) M1 gene

1673 polymorphisms (C) L3 gene polymorphisms. (D) Similar experimental outline to (A-C) except specific 1674 recombinant viruses were generated in a $\mathrm{T}^{\mathrm{PL}} \mathrm{P}^{\mathrm{L}}$-reverse genetics $(\mathrm{RG})$ backbone. Statistical significance 1675 determined using one-way ANOVA with Dunnett's multiple comparisons test, * $\mathrm{p}<0.05$, ** $\mathrm{p}<0.01$, *** $\mathrm{p}<$ $16760.001, * * * * \mathrm{p}<0.0001$. In $(\mathrm{A}), \mathrm{T}^{\mathrm{P}} \mathrm{D}^{\mathrm{PL}}-\mathrm{RG}$ and $\mathrm{S} 4$ (+W133R) were compared to $\mathrm{T}^{\mathrm{D}} \mathrm{D}^{\mathrm{TD}}-\mathrm{RG}$, whereas remaining 1677 samples were independently compared to T3D ${ }^{\mathrm{RG}}$. Samples in (B) and (C) compared to T3D ${ }^{\mathrm{TD}}$-RG. (E) Summary 1678 model highlighting genetic and phenotypic differences between $\mathrm{T}^{\mathrm{P}} \mathrm{D}^{\mathrm{PL}}$ and $\mathrm{T} 3 \mathrm{D}^{\mathrm{TD}}$. 
bioRxiv preprint doi: https://doi.org/10.1101/569301; this version posted March 6, 2019. The copyright holder for this preprint (which was not certified by peer review) is the author/funder. All rights reserved. No reuse allowed without permission.

\section{SUPPLEMENTAL INFORMATION TITLES AND LEGENDS}

\section{0}

1681

1682

1683

1684

1685

1686
Figure S1: Virus-cell binding quantification using flow cytometry. (A) L929 cells were detached nonenzymatically using cell dissociation buffer (Sigma, C5914). T3D ${ }^{\mathrm{PL}}$ dilutions were bound $4^{\circ} \mathrm{C}$, and following extensive washing to remove unbound reovirus, cell-bound reovirus was stained using polyclonal reovirus antibodies and mean fluorescence intensity (MFI) quantified using flow cytometry (BD FACSCanto). Black histogram $=$ MOCK, Dark orange $=$ highest reovirus dilution, Light orange $=$ lowest reovirus dilution. $(\mathbf{B})$ Linear regression analysis of MFI determined from $(A)$, corrected for mock infected background $(n=2)$. 
1687 Figure S2: T3D ${ }^{\mathrm{PL}}$ establishes a productive infection earlier than T3D $^{\text {TD }}$. (A) L929 cells were mock infected or infected with $\mathrm{T} 3 \mathrm{D}^{\mathrm{PL}}$ or $\mathrm{T} 3 \mathrm{D}^{\mathrm{TD}}$ at the indicated MOI (based on titers established on L929 cells) and incubated at $37^{\circ} \mathrm{C}$ for 12,24 or 48 hours. Paraformaldehyde-fixed cells were then subjected to immunofluorescence staining with reovirus specific primary antibody and Alexa Fluor 488 conjugated secondary antibody as described in materials and methods of the main manuscript. Nuclei were stained with HOESCHT 33342. Immunofluorescence was imaged on the EVOS FL Auto Cell Imaging System. (B) Similar to (A) except at each time point, cells were subjected to immunofluorescence staining and flow cytometric analysis as described in materials and methods of the main manuscript. Gates were set based on Mock-infected cells. (C) Similar to (B) but on H1299, ID8, and B16-F10 cancer cell lines. 
1696 Figure S3: RIG-I signaling does not impact initial reovirus infection. NIH/3T3 cells stably transduced with 1697 scrambled (shSCR) or RIG-I (shRIG) lentivirus were mock-infected or infected with reovirus at MOIs of 20 and 169860 (relative to titers obtained on the more-susceptible L929 cells), and incubated at $37^{\circ} \mathrm{C}$. (A) At $12 \mathrm{hpi}$, RNA from cells infected at MOI of 20 was extracted and subjected to cDNA synthesis and qRT-PCR for mouse RIG-I (Rig-i) and mouse GAPDH. RIG-I mRNA levels were corrected for GAPDH and presented relative to shSCR $\mathrm{T} \mathrm{D}^{\mathrm{TD}}$ (set to 1.0). Two independent experiments are each represented by individual dots. (B) At 12hpi, samples were subjected to Western Blot analysis for RIG-I, reovirus $\mu 1$ and $\sigma 3$, or $\beta$ acting loading control. (C) At 12 and 24hpi, cells underwent immunofluorescence staining with reovirus specific primary antibody and Alexa Fluor 488 conjugated secondary antibody to detect reovirus infected cells (Green), and HOESCHT 33342 to detect nuclei (Blue). Green staining represents reovirus infected cells, and blue staining represents cell nuclei. (D) Similar to (A) but qRT-PCR was conducted for viral and cellular genes indicated above each plot, and following infection at MOIs of both 20 and 60 as indicated. 
1708 Figure S4: Characterization of RIG-I and NFkB dependent reovirus induced genes. A description of the microarray data used in this figure is provided in supplemental materials and methods. A list of candidate genes was selected based on the following criteria: (1) Genes induced ( $\geq 2$-fold) following T3D ${ }^{\mathrm{PL}}$ infection in shEMPTY NIH/3T3 cells, and (2) Genes inhibited ( $\geq 2$-fold) in cRel -/- p65-/- MEFs treated with LPS, relative to WT MEFs treated with LPS. (A) Hierarchical clustering heat maps depicting gene subsets dependent on RIG-I, IFNAR and/or NFkB as described below for each cluster. (B) Collection of graphs showing gene clusters from (A). Cluster 1: reovirus induced genes dependent on RIG-I signaling, based on $\geq 2$-fold change between shEMPTY versus shRIG-I. Cluster 2: reovirus induced genes independent of RIG-I signaling, based on , based on $<2$-fold change between shEMPTY versus shRIG-I. Cluster 3: reovirus induced genes dependent on RIG-I and NFkB signaling but independent of IFNAR signaling, based on genes in Cluster 1 that also change $\geq 2$-fold between WT versus $\mathrm{CREL}^{-/} \mathrm{p}^{-1-}$ but $<2$-fold change between WT and $\mathrm{IFNAR}^{-1-}$. Cluster 4: reovirus induced genes dependent on RIG-I, IFNAR and NFKB signaling, based on genes in Cluster 1 that also change $\geq 2$-fold between WT and both $\mathrm{cREL}^{--} \mathrm{p}^{-/-}$and IFNAR ${ }^{-/}$. Cluster 5: reovirus induced genes independent of RIG-I signaling but dependent on IFNAR and NFKB signaling, based on genes in Cluster 2 that also change $\geq 2$-fold between WT and both $\mathrm{cREL}^{-/-} \mathrm{p} 65^{-/-}$and IFNAR ${ }^{-/}$. Cluster 6: reovirus induced genes independent of RIG-I and IFNAR signaling but dependent on NFאB signaling, based on genes in Cluster 2 that also change $\geq 2$-fold between WT versus $\mathrm{cREL}^{-/-}$ p $65^{-1-}$ but $<2$-fold change between WT and IFNAR ${ }^{-/}$. 
Figure S5: Classification of IFN-dependent and IFN-independent genes and NFкB modulation effects on reovirus. (A) L929 cells were treated with $1 / 10$ dilutions (initial $1000 \mathrm{U} / \mathrm{ml} / 12$ well) of purified IFN $\alpha$ or IFN $\beta$ for 12 hours at $37^{\circ} \mathrm{C}$. Samples were collected for RNA extraction, cDNA synthesis and RT-PCR using gene-specific primers (corrected for GAPDH). Values were standardized to untreated sample, $n=3$. (B, Left) L929 cells were either mock infected or infected with $\mathrm{T}^{\mathrm{P}} \mathrm{D}^{\mathrm{PL}}$ or $\mathrm{T} 3 \mathrm{D}^{\mathrm{TD}}$ at an $\mathrm{MOI}$ of 3 and co-incubated throughout infection with either InSolution ${ }^{\mathrm{TM}} \mathrm{NF}-\kappa \mathrm{B}$ Activation Inhibitor (Calbiochem, 481407) at 10nM, 2nM or 0.4nM, mouse TNF (Sigma T7539) at 10ng/ml, 2ng/ml, or $0.4 \mathrm{ng} / \mathrm{ml}$, or left untreated (UT). At 24hpi, cells were stained for cell death using Annexin $\mathrm{V}$ and 7-AAD as described in materials and methods in the main manuscript. Cells were considered 'dying cells' if positive for either Annexin V and 7-AAD relative to untreated and mock infected cells. $\mathrm{N}=3$, 2way ANOVA with Dunnett's multiple comparisons test, $* * * \mathrm{p}<0.001$. (B, Right) Similar to (B, Left), however cells were either pre-treated for 3 hours with $10 \mathrm{nM}$ InSolution ${ }^{\mathrm{TM}} \mathrm{NF}-\kappa \mathrm{B}$ Activation Inhibitor prior to infection and co-infection treatments, or not treated prior to infection. Co-infection treatments included InSolution $^{\mathrm{TM}} \mathrm{NF}-\kappa \mathrm{B}$ Activation Inhibitor at $10 \mathrm{nM}, 2 \mathrm{nM}, 0.4 \mathrm{nM}$ or $0.08 \mathrm{nM}$, mouse TNF at $10 \mathrm{ng} / \mathrm{ml}, 2 \mathrm{ng} / \mathrm{ml}$, $0.4 \mathrm{ng} / \mathrm{ml}$, or $0.08 \mathrm{ng} / \mathrm{ml}$, or left untreated (UT) (C) Similar to (B, Right) except that samples were collected at 12hpi for Western Blot analysis to detect levels of reovirus proteins ( $\mu 1$ and $\sigma 3)$, IKK $\alpha$, NFkB-induced gene JunB, or $\beta$-Actin loading control, for InSolution ${ }^{\mathrm{TM}} \mathrm{NF}-\kappa \mathrm{B}$ Activation Inhibitor at $10 \mathrm{nM}, 2 \mathrm{nM}$, and $0.4 \mathrm{nM}$ or mouse TNF at $10 \mathrm{ng} / \mathrm{ml}$ and $2 \mathrm{ng} / \mathrm{ml}$. 
1742 Figure S6: Crystal structures highlighting T3D ${ }^{\mathrm{PL}}$ and $\mathrm{T}^{\mathrm{TD}} \mathrm{D}^{\mathrm{TD}}$ polymorphisms in $\mathrm{S4}$ and L3 genes. All

1743 structures were visualized and modified using the PyMOL molecular visualization program by Schrodinger. (A) $1744 \sigma 3$ dimer (1 fn9.pdb). Ribbons in shades of blue indicate 2 monomers of $\sigma 3$. Polymorphisms in $\sigma 3$ are represented 1745 by yellow spheres (W133R), red spheres (G198K), pink (E229D). Regions previously determined to bind dsRNA 1746 are indicated in cyan spheres. (B) $\sigma 33 \mu 13$ heterohexamer (1jmu.pdb). Ribbons in shades of blue indicate 3 1747 monomers of $\sigma 3$ and shades of green indicate 3 monomers of $\mu 1$. Polymorphisms in $\sigma 3$ are represented by yellow 1748 spheres (W133R), red spheres (G198K), pink (E229D) and orange spheres (Y354H). 


\section{Table S1: Key Resources Table}

1750 Table S2: Accession numbers for sequences analyzed in the manuscript

1751 Table S3: Oligonucleotide sequences for cloning reovirus genes into the reverse genetics backbone plasmid 1752 Table S4: Oligonucleotide sequences for primers used in qRT-PCR

1753 Table S5: Oligonucleotide sequences for primers used for site-directed mutagenesis

1754 Table S6: Lists for all genes in clusters 1-6 described in Figure S4 






